\title{
GUÍAS ESQUEMATIZADAS DE TRATAMIENTO DE LOS TRASTORNOS DE LA PERSONALIDAD PARA PROFESIONALES, DESDE EL MODELO DE THEODORE MILLON
}

\author{
SCHEMATIC-BRIEF FOR PROFESSIONALS TO TREAT PERSONALITY \\ DISORDERS, FROM THE MODEL OF THEODORE MILLON
}

\author{
Andrés Fernando López Pell \\ Universidad Católica de Santa Fe y FUNSALED, Argentina \\ Juan Manuel Rondón \\ Universidad Católica de Santa Fe, Argentina \\ Cecilia Cellerino \\ Universidad Católica de Santa Fe, Argentina \\ Silvina María Alfano \\ Universidad Católica de Santa Fe, Argentina
}

\begin{abstract}
Resumen: Los tratamientos psicológicos para los Trastornos de la personalidad todavía no alcanzan un grado de protocolización tan específico como para describir las intervenciones para cada sesión. Esto podría deberse a la heterogeneidad de los casos que dificultaría la posibilidad de diseñar un protocolo. Los tratamientos entonces se basan en conceptualizaciones de caso sustentadas teóricamente que después determinan los objetivos y las intervenciones a realizar. La dificultad para conceptualizar desde determinado modelo puede que sea una razón por la que a los psicoterapeutas les costaría realizar el tratamiento más adecuado. Para afrontar este problema hemos diseñado unas 'Guías esquematizadas para profesionales’ para mejorar la práctica de la psicoterapia para los trastornos y alteraciones de la personalidad. Estas guías son de una carilla para tenerlas a la vista durante las sesiones a fin conceptualizar los casos y guiar más fácilmente las intervenciones desde el modelo de Theodore Millon.
\end{abstract}

Palabras clave: Personalidad, Trastornos, Tratamiento, Integracionismo.

\begin{abstract}
Psychological treatments for personality disorders have not yet reached a level of protocol as specific as to describe interventions for each session. This could be due to the heterogeneity of cases that make it difficult to design a protocol. Treatments are then based on case conceptualizations supported by theories that determine the objectives and interventions performed. The difficulty to conceptualize, within a particular model, may be a reason that psychotherapists find problems to make the most appropriate treatment. Addressing this problem, we have designed (a set of?) 'Professional schematic(brief or scheme)-guides' to improve the practice of personality disorders psychotherapy. These one-page-guides were designed to be consulted during the sessions, and help to conceptualize cases and easily guide the interventions from the model of Theodore Millon.
\end{abstract}

Keywords: Personality, Disorders, Treatment, Integrationism.

\section{INTRODUCCIÓN}

Nada ha demostrado ser más eficaz que la aplicación de un protocolo psicoterapéutico científicamente validado. Sin embargo ¿qué hacer cuando el paciente tiene varios trastornos?, o ¿cuándo no hay un protocolo validado para tratar el trastorno que sufre? En tales cir- cunstancias, una opción es basar el tratamiento en una conceptualización de sus problemas guiada por un marco teórico. La dificultad para conceptualizar desde determinado modelo, puede que sea una la las tantas razones del por que a los psicoterapeutas les cueste más seguir las pautas descriptas para el abordaje de estas alteraciones. 
Otra cuestión de suma importancia es que son pacientes muy difíciles de mantener en tratamiento, por lo cual se requiere de mucha flexibilidad por parte del terapeuta. Esto, sumado a la heterogeneidad de los casos, dificulta la posibilidad de diseñar un protocolo de tratamiento de alta especificidad delineado para cada sesión como existe para otros trastornos (e.g., depresivo mayor, de angustia, ansiedad generalizada, etc.) ya que cada tratamiento, si bien es guiado por la misma base teórica, termina adquiriendo una forma particular.

En busca de enfrentar la problemática planteada, en un artículo anterior publicado en esta revista, López Pell, Rondón, Cellerino y Alfano (2010) propusieron el concepto de Guías esquematizadas para profesionales. En aquella ocasión, las guías se hicieron para el modelo de Beck, Freeman, Davis y otros (2005). En esta oportunidad, utilizando el mismo concepto, se realizarán para el modelo que vienen desarrollando -desde hace más de cincuenta años- Millon y sus distintos colaboradores.

Las Guías esquematizadas para profesionales están diseñadas para mejorar la práctica de la psicoterapia para los trastornos y alteraciones de la personalidad. Fueron realizadas en una carilla cada una, con la idea que los psicoterapeutas las tengan a la vista durante las sesiones y que de esta manera puedan conceptualizar sus casos y guiar más fácilmente sus intervenciones. Atento a estas cuestiones, en este artículo se presentan los conceptos centrales que deben guiar la praxis desde el modelo de Millon de una manera simple y comprensible a fin de facilitar la transferencia del conocimiento al set psicoterapéutico.

\section{TEORÍA DE LA PERSONALIDAD}

Theodore Millon es un psicólogo estadounidense la investigación sobre la personalidad. Dirige desde 2001 el Instituto para Estudios Avanzados sobre la Personalidad y la Psicopatología en Florida. Fue uno de los primeros en reclamar una psicoterapia personalizada para cada paciente de forma que esta se ajustase a sus intereses individuales y sociales. Se ha mostrado siempre crítico con el uso indiscriminado de los psicofármacos.
El modelo de la personalidad que proponen Millon y sus colaboradores es un tanto complejo y lleno de matices, por lo que resulta difícil resumirlo en unas pocas páginas. Este trabajo se propone ofrecer una visión lo más clara posible de algunos de los aspectos del modelo integrador sobre la personalidad y los trastornos de Theodore Millon. Debe tenerse en cuenta que la postura epistemológica del autor es integracionista. En efecto, su teoría incorpora información basada en evidencias de diferentes ciencias. Argumenta el autor que los teóricos de todas las perspectivas psicológicas intentan definir un grupo claro de atributos etiológicos pero se ven limitados debido a sus respectivas posturas filosóficas y metodológicas. Propone, entonces, una teoría multidimensional, focalizando tanto factores biológicos como psicógenos, tanto un análisis contemporáneo de las patologías como histórico, y recalca que no hay universalidad en los desarrollos de trastornos psicológicos, sino que éstos pueden deberse a múltiples causas. Teniendo en cuenta los conceptos enunciados es que llega a presentar un modelo terapéutico llamado psicoterapia personológica (Millon \& Davis, 1998), donde intenta adaptar la terapia a las diferentes posibilidades que puede presentar un paciente.

\section{Características generales de la Teoría de la Personalidad}

Se expondrán en primer lugar algunos puntos centrales de su teoría para concretar en los siguientes apartados sus aportaciones sobre los trastornos de personalidad, evaluación y tratamiento.

\section{La utilización de una perspectiva teórica integradora}

Según Cardenal, Sánchez y Tallo (2007) la integración es una de las características básicas del modelo de Millon. La integración, por ejemplo, entre la estructura y la dinámica de la personalidad ya que ambas cosas son imprescindibles para entender su funcionamiento, de la misma forma en que es necesaria la integración entre la perspectiva nomotética, que se interesa por la generalización, por descubrir cómo se relacionan entre sí las necesidades, los motivos, los mecanismos, los rasgos, los esquemas, las defensas, etc., y la perspectiva idiográfica que centra su atención en las diferencias 
individuales, enfatizando que la personalidad de un individuo es el resultado de una historia única de transacciones entre los factores biológicos y los contextuales. Precisamente, esta concepción integradora se plasma en la propuesta de una serie de estilos o prototipos, que son esencialmente nomotéticos, puesto que incorporan constructos desarrollados por la teoría de la evolución (e.g., las polaridades), a los que Millon añade un rango de subtipos de personalidad, fruto de un estudio más específico e idiográfico (Cardenal et al, 2007).

La integración se establece también entre diferentes modelos teóricos y distintas perspectivas de intervención. El sustento teórico de Millon consiste en diferentes enfoques que no se limitan sólo a la teoría sino que se orientan a la integración entre diferentes perspectivas de intervención para cada caso concreto. Sin embargo, no debe confundirse dicha integración con el eclecticismo. Si bien este último hace referencia al hecho de extraer de diferentes fuentes para producir un resultado compatible con diferentes enfoques teóricos y que sea aceptable para clínicos de orientación diversa; el enfoque integrador de Millon, en cambio, se caracteriza por la constante búsqueda de coherencia teórica a partir de principios universales comunes a todas las ciencias, lo que le permite no renunciar a lo valioso que posean las tradiciones teóricas anteriores (Cardenal et al, 2007).

Teniendo en cuenta los conceptos enunciados es que Millon y Davis (1998) llegan a presentar un modelo terapéutico llamado psicoterapia personológica, donde intentan adaptar la terapia a las distintas posibilidades que puede presentar un paciente. Para poder operacionalizar esto, proponen realizar un análisis causal e integrado de la patología, teniendo en cuenta la unidad temporal, donde se realice tanto un análisis contemporáneo (i.e., factores del ambiente de ese momento concreto que influyen en el comportamiento del individuo) como un análisis del desarrollo (i.e., secuencia histórica de experiencias pasadas que han provocado el comportamiento actual). Respecto al nivel conceptual, afirman que a la hora de realizar la diagnosis deben tenerse en cuenta tanto los factores biológicos como los psicógenos, que pueden actuar como precipitantes primarios de un trastorno pero que nunca son causas universales sino probables (Figura 1).

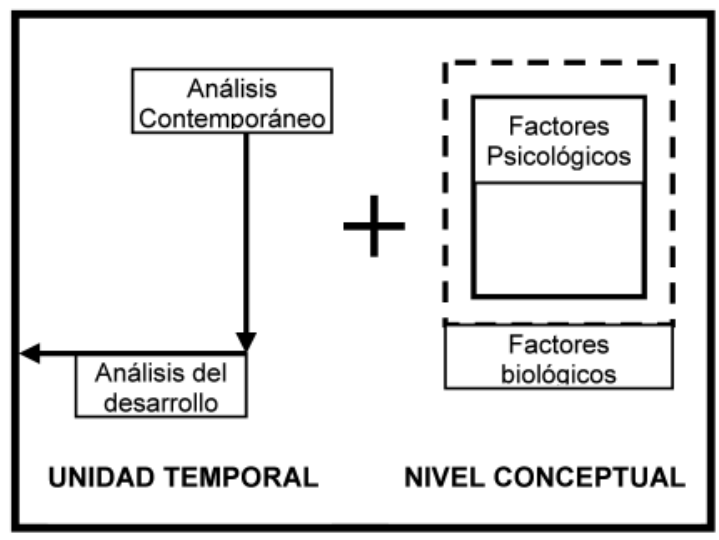

Figura 1. Análisis causal patógeno (Adaptado deMillon \& Davis, 1998)

\section{Su insistencia en el continuo 'normalidad/ patología'}

Por otra parte Millon (2002) entiende la 'normalidad'y la 'patología' donde no existe una línea divisoria tajante entre las dos. La personalidad normal y la patológica comparten los mismos principios y mecanismos de desarrollo. La diferencia fundamental es que las personalidades 'normales' son más flexibles cuando se adaptan a su entorno, mientras que las personalidades con trastornos muestran conductas mucho más rígidas y muy poco adaptativas. Así, se entiende por Personalidad normal los estilos distintivos de adaptación que resultan eficaces en entornos normales. En cambio, los Trastornos de Personalidad son estilos de funcionamiento inadaptados, que pueden atribuirse a deficiencias, desequilibrios o conflictos en la capacidad para relacionarse con el medio habitual. A su vez, estos últimos presentan ciertos criterios que los caracterizan, como ser: (a) una escasa flexibilidad adaptativa, que hace referencia a la utilización de estrategias rígidas e inflexibles en la relación con sí mismo y con el ambiente; (b) una tendencia a crear círculos viciosos, producto de esas estrategias rígidas e inflexibles, que hacen que el malestar de la persona persista y se intensifique; y (c) labilidad, que se manifiesta en la fragilidad y ausencia de elasticidad de la persona ante situaciones que provocan estrés.

Cabe destacar, dentro del continuum de normalidad-patología que expone Millon (2002), el concepto de Estilo y la importancia de los Prototipos a la hora de conceptualizar los trastornos de personalidad. 
Así, a lo largo de una dimensión se diferencian las reacciones y respuestas de la persona, los síndromes que presenta y sus rasgos de personalidad (Strak \& Millon, 2007).

\section{La incorporación a su modelo de los princi- pios de la Teoría de la Evolución}

Los principios que emplea Millon (2002) para explicar la estructura y la dinámica de los Estilos de Personalidad son esencialmente los mismos que empleaba Darwin para detallar sobre el origen de las especies. La Personalidad se concibe, entonces, como el estilo más o menos distintivo de funcionamiento adaptativo que un miembro de una especie presenta para relacionarse con su ambiente y, a su vez, está constituida por constructos bipolares que provienen de cuatro principios evolutivos básicos que se desarrollarán más adelante. Por tanto, la teoría de la evolución es la base que utiliza Millon para definir su modelo de la personalidad desde un nivel estructural y funcional, utilizando polaridades psíquicas (Millon \& Grossman, 2006).

\section{Factores influyentes en la personalidad nor- mal y patológica}

A continuación se exponen los diferentes factores que Millon incorpora en su teoría de la personalidad como influyentes sobre la misma. Debe tenerse presente que la distinción es cualitativa, ya que todos y cada uno forman a la personalidad.

\section{Factores biológicos patógenos}

El sistema nervioso de cada individuo selecciona, transforma y registra acontecimientos objetivos de acuerdo con sus diferentes características biológicas. Es por esto que el funcionamiento psicológico normal depende de la integridad de ciertas áreas clave de estructura biológica, y cualquier deterioro en ella puede llegar a provocar una alteración del pensamiento, la emoción y los comportamientos. Sin embargo debe señalarse claramente que, pese a que a los defectos biogénicos pueden producir la discontinuidad con la normalidad, son los determinantes psicológicos y sociales los que casi siempre configuran la forma de su expresión. En efecto, el hecho de aceptar el papel que desempeñan la influencias biógenas no excluye el papel de la experiencia social y del aprendizaje (Millon \& Davis, 1998). Los factores biológicos que pueden incidir en el desarrollo de un trastorno son:

- Herencia: El papel de la misma se deduce de las correlaciones de rasgo entre miembros de la misma especie. A partir de innumerables anomalías genéticas pueden aparecer defectos en el sistema nervioso central (Plomin, 1990). Resulta importante aclarar que la herencia no es una constante fija sino una disposición que adopta diferentes formas dependiendo de las circunstancias de la educación de un individuo. Es por esto que Millon y Davis (1998) consideran que los factores hereditarios no son necesarios para el desarrollo de la patología de la personalidad, ni son suficientes para fomentar comportamientos patológicos; sino que son fundamento fisiológico para que una persona sea susceptible a la disfunción bajo estrés o para que tienda a aprender comportamientos socialmente inadecuados.

- Individualidad biofísica: se refiere a los patrones fisicoquímicos propios de cada individuo que no siguen una regla fija (Williams, 1973). Por ello es muy complicado correlacionar la psicopatología con estructuras neurológicas, ya que la organización del cerebro presenta notables diferencias individuales.

- Disposiciones temperamentales: las mismas aluden al patrón distinto de sensibilidad y de tendencias de respuesta con las que cada niño se incorpora al mundo (Michelsson, Rinne \& Paajanen, 1990). Estos patrones son, en apariencia, de origen biogenético ya que se manifiestan antes que la experiencia del aprendizaje postnatal pueda influir sobre los niños. Millon y Davis (1998) sostienen que en lugar de preguntarse qué efectos tiene el ambiente sobre el niño, debe preguntarse qué efecto tiene el niño sobre el medio y cuáles de estas consecuencias afectan su desarrollo. Cierto es que los patrones iniciales se modifican muy poco desde la infancia a la niñez, pero esa continuidad no debe atribuirse sólo a las dotaciones innatas. En efecto, las experiencias sucesivas refuerzan las características que aparecen al principio de la vida (Kagan, 1989) debido a que los patrones iniciales de los niños condicionan y transforman al entorno en cierta medida, de manera tal 
que los seres cercanos se acoplan a dichos patrones intensificando y acentuando los comportamientos iniciales.

La interacción entre las disposiciones biológicas y la experiencia con el entorno es un sistema retroactivo, compuesto por los siguientes procesos (Millon \& Davis, 1998).

a- Aprendizaje adaptativo: El temperamento del niño en desarrollo refuerza la probabilidad de que predominen ciertos rasgos (Bates, 1980, 1987; Thomas, Chess \& Korn, 1982) e influye en la expresión de variables psicológicas (e.g., apego).

b- El temperamento de los niños provoca contrarreacciones en los demás que confirman y acentúan las tendencias temperamentales iniciales (Papousek \& Papousek, 1975). Un determinante crucial de si un temperamento concreto conducirá a una personalidad patológica parece ser la aceptación de los padres de la individualidad del niño. Si aceptan el temperamento de su hijo y luego modifican sus hábitos de forma adecuada pueden detener lo que de otra forma seria patológico. Por otro parte, si los padres experimentan sentimientos cotidianos de fracaso, frustración, ira y culpa, sin relación con la disposición del niño, contribuirán seguramente a un progresivo empeoramiento de su adaptación.

\section{Historia experiencial patógena}

Millon y Davis (1998) plantean que la psicopatología se desarrolla como resultado de una interacción íntima de fuerzas intraorganísmicas y ambientales que comienzan en el momento de la concepción y continúan a lo largo de toda la vida. Esta interacción es bidireccional, puesto que los determinantes biológicos preceden siempre e influyen en el curso del aprendizaje $y$, a su vez, son influidos por la experiencia; el orden de efectos puede cambiarse, sobre todo en los estadios tempranos del desarrollo. Esto es importante ya que las experiencias tempranas constituyen un aspecto crucial del desarrollo de los diversos patrones patológicos de la personalidad: si el sustrato biológico inicial no es correspondido con experiencias ambientales favorables, puede alterarse e incluso detenerse. Sobre todo si el organismo es privado de estimu- lación durante los períodos críticos en los que se produce un crecimiento neuronal rápido.

Millon y Davis (1998) claramente citan que el sustrato biológico innato y las experiencias tempranas, condicionan a la personalidad durante todo el continuo vital:

"[...] no sólo defendemos que los acontecimientos de la infancia son más significativos en la formación de la personalidad que en los acontecimientos posteriores, sino que pensamos también que los comportamientos posteriores están determinados por la experiencia temprana. A pesar de la separación ocasional y dramática del desarrollo, existe una continuidad ordenada y secuencial, generada por mecanismos de autoperpetuación y refuerzo social, que vincula el pasado con el presente" (p. 97).

\section{Desarrollo de la personalidad}

Es importante destacar que la teoría evolutiva de Millon dista mucho de ser lineal. Bajo su óptica, la maduración se refiere a una secuencia del proceso del desarrollo ontogenético, en la que las primeras estructuras del cuerpo, difusas e incipientes, van desplegándose progresivamente en unidades funcionales específicas (Millon \& Davis, 1998). Cierto es que la maduración sigue una progresión ordenada, pero la secuencia del desarrollo y el nivel de la composición biológica del organismo dependen de una variedad de estímulos y complementos nutricionales que provienen del ambiente. Entonces, la maduración no avanza según un curso fijo que conduce a un nivel predeterminado, sino que está sujeta a numerosas variaciones que reflejan la influencia del entorno.

\section{Modelo evolutivo}

Este modelo consta de cuatro fases evolutivas: existencia, adaptación, replicación y abstracción, con características ontogenéticas, psicológicas y neurológicas que les son propias. A su vez cada etapa contiene períodos críticos de maduración. Es importante destacar que si no se estimulan de manera adecuada aspectos plásticos de cada etapa ni se realizan las tareas necesarias, la persona puede presentar luego secuelas patológicas (Millon \& Davis, 1998). 
Cada fase evolutiva se corresponde con una etapa neuropsicológica distinta. A su vez, cada una de estas etapas están constituidas por constructos bipolares que el sujeto debe ir resolviendo (i.e., logrando un equilibrio entre ambos polos) durante el transcurso de los períodos críticos correspondientes a las mismas. A continuación se exponen las características y consecuencias de posibles desequilibrios en la estimulación en las cuatro etapas del desarrollo neuropsicológico antes mencionadas:

\section{Etapas neuropsicológicas}

\section{- Etapa 1: Fijación sensorial}

Etapa evolutiva correspondiente: Existencia.

Polaridad: Potenciación de la vida (placer) Preservación de la vida (dolor).

Función básica: Elaborar la distinción de objetos que producen placer y dolor. El objetivo de esta etapa es universal y tiene que ver con la conservación de la vida.

Desarrollo de las capacidades sensoriales: Durante el período neonatal no hay diferenciación ya que el organismo posee una percepción burda y no focalizada de placer-dolor que se van refinando paulatinamente a través de los contactos orales y táctiles.

Desarrollo de los comportamientos de apego: El neonato no diferencia entre objetos y personas, sino que las experimenta como estímulos. Como se encuentra desvalido en todas las áreas, depende de los demás para evitar el dolor y satisfacer sus necesidades de placer. Los comportamientos de apego deben considerarse como un intento de restablecimiento de la pérdida de la vida intrauterina que permitía el mantenimiento y la protección de la vida (Bowlby, 1982; Spitz, 1965).

Consecuencias de la infraestimulación: Inferior orientación sensorial y escasa vinculación social, discriminaciones emocionales anómalas, empobrecimiento de todas las reacciones afectivas, típico del patrón esquizoide.

Consecuencias de la hiperestimulación: Comportamientos de búsqueda constante de placer en la adultez.

\section{- Etapa 2: Autonomía sensoriomotora.}

Etapa evolutiva correspondiente: Adaptación. Polaridad: Acomodación ecológica (pasiva) Modificación ecológica (activa).

Función básica: pasar de la existencia del Sí mismo a la existencia dentro del entorno, aprende un modo de adaptación, que puede ser una tendencia a adaptarse más activamente, explorando su entorno y modificándolo; o una tendencia pasiva, acomodándose a cualquier entorno.

Desarrollo de las capacidades sensoriomotoras: La base neuronal se encuentra más desarrollada, la actividad muscular más refinada y existen más habilidades sensoriales que permiten adquisiciones complejas y refinadas.

Desarrollo de comportamientos autónomos: Hay más competencia, los niños buscan más aventuras. Surgen conflictos relacionados al control de esfínteres, interacción paterno-filial, autoridad poder y autonomía. De todas maneras, a menos que las restricciones ambientales, las limitaciones biológicas o la inseguridad en la vinculación retrasen las capacidades sensoriomotoras de los niños en crecimiento, dichas capacidades les permiten desempeñar un papel más activo en el afrontamiento de su entorno. Consecuencias de la infraestimulación: Retraso de las funciones de la autonomía y la iniciativa (i.e., estado pasivo). Sujetos dependientes, tímidos y sumisos.

Consecuencias de la sobreestimulación: Sujetos irresponsables e indisciplinados, con dificultad para relacionarse con otros -Patrón egocéntrico y arrogancia social-.

\section{- Etapa 3: Identidad puberal genérica}

Etapa evolutiva correspondiente: Replicación. Polaridad prolongación de la especie (otros) propagación individual (Sí mismo).

Función básica: Instauración de características sexuales propias del género: impulsos sexuales, características anatómicas, cambio de voz e incorporación de aspectos similares a los adultos. Psíquicamente se observan irregularidades del estado del ánimo, cambios en la autoimagen y búsqueda de identidad.

Consecuencias de la infraestimulación: Sujetos 'dirigidos hacia los demás' que vacilan en cada momento y cambian irregularmente sus acciones (i.e., Trastorno límite de la personalidad).

Consecuencias de la sobreestimulación: Dependencia excesiva en los hábitos y valores de propio grupo sexual -por temor de ser rechazados o ridiculizados-. Aumento del narcisismo, adopción de postura de arrogancia, rebelión y desafío a las normas sociales.

\section{- Etapa 4: Integración intracortical}

Etapa evolutiva correspondiente: Abstracción. 
Polaridad razonamiento intelectual (pensamiento) -resonancia afectiva (sentimiento).

Función básica: Integración coherente de las estructuras de pensamiento y las de sentimiento. Su falta de integración puede llevar a un trastorno de personalidad grave (e.g. límite o esquizotípico).

Consecuencia de la infraestimulación: Pueden convertirse en víctimas de su propio crecimiento, incapaces de orientar sus impulsos mediante la expresión de deseo.

Consecuencia de la sobreestimulación: Poca posibilidad de diseñar su propio destino careciendo de espontaneidad, flexibilidad y creatividad.

Así, estas polaridades básicas se emplean para construir un sistema de clasificación de los trastornos de personalidad basada en la teoría, y se intenta comprender la estructura y los estilos de personalidad con referencia a modos de adaptación ecológica o de estrategia reproductiva deficientes, desequilibrados o conflictivos.

\section{Evolución y trastornos de la personalidad}

Se considera que los trastornos de personalidad son constructos evolutivos que se derivan de las tareas fundamentales a las que todos los organismos se enfrentan, es decir, la lucha por existir o sobrevivir -placer versus dolor-, el esfuerzo de adaptarse al medio o de adaptar el medio a uno mismo -pasivo versus activo-, y la estrategia del organismo para invertir de forma reproductiva en los parientes o descendientes frente a una inversión en su propia replicación personal -otros versus self/uno mismo-. (Millon \& Davis, 1998). Al hablar de 'constructo', se hace referencia a que el trastorno de personalidad no es más que un punto ideal o de referencia con el que se compara a las personas reales, es decir, no son enfermedades sino entidades objetivadas que sirven a propósitos conceptuales y que se realizan a varios grados y de distintas maneras en diferentes personas. Algunas personalidades exhiben un equilibrio razonable en uno $u$ otro de los pares de polaridad, pero no todos los individuos caen en el centro, por supuesto. Las diferencias individuales en los rasgos de personalidad y el estilo global reflejan las posiciones relativas y los puntos fuertes de cada componente de la polaridad. Así, las personalidades deficientes en placer carecen de la capacidad de experimentar o representar ciertos aspectos de las tres polaridades (e.g. la personalidad esquizoide tiene un substrato defectuoso tanto para el placer como para el dolor); las personalidades interpersonalmente desequilibradas tienden fuertemente a uno u otro extremo de una polaridad (e.g., la persona con rasgos dependientes se orienta casi exclusivamente hacia la recepción del apoyo y el cuidado de los otros); y Las personalidades con conflictos intrapsíquicos presentan ambivalencia y se debaten entre extremos opuestos de una bipolaridad (e.g., el estilo negativista vacila entre cumplir las expectativas de los demás y hacer lo que él o ella quisiera) (Millon \& Davis, 1998; Millon \& Grossman, 2005).

Finalmente, a título de resumen, la Figura 2 representa un ejemplo de perfil de personalidad según las tres primeras polaridades. Las personas inician la vida con una predisposición genética/constitucional que se sitúa en un punto determinado entre el límite superior y el inferior, en los que esta predisposición puede expresarse en las personas. El rectángulo de puntos, la banda externa para cada persona, indica el posible potencial constitucional de ese individuo. El rectángulo de líneas continuas indica el nivel real que este potencial alcanza a partir de las experiencias a lo largo de la vida. El rectángulo de color negro representa el efecto de las circunstancias vitales actuales que limitan además el intervalo en el que normalmente se manifiesta la disposición real. En terapia, sólo podemos interceder en aumentar o disminuir este último aspecto, a no ser que la persona esté transitando por un período crítico del desarrollo. En ese caso, se podría trabajar con el entorno para conseguir un nivel real -en formación- más amplio.

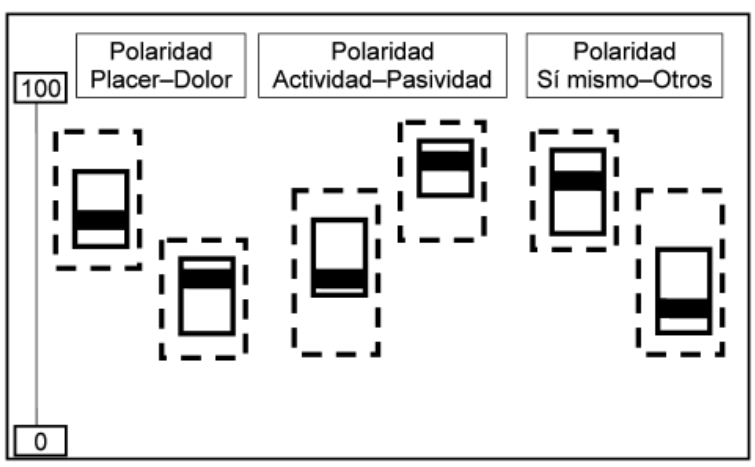

Figura 2. Polaridad de las disposiciones: constitucionales, adquiridas y presentes (Adaptado de Millon \& Davis, 1998) 


\section{EVALUACIÓN DE LA PERSONALIDAD}

Realizar una evaluación de la Personalidad mediante un análisis integrado de la patología, teniendo en cuenta la unidad temporal, donde se realice tanto un análisis contemporáneo como uno del desarrollo no es una tarea menor. Es por esto que se debe contar con información precisa y detallada sobre los diversos métodos y técnicas idóneos para tal fin. Atento a esto es que se presenta un apartado completo que brinda este detalle para guiar al clínico durante el proceso de evaluación de la Personalidad, lo que a posteriori sustentará la toma de decisiones clínicas respecto del tratamiento.

\section{La evaluación de la personalidad y sus ámbitos}

Privados de una base teórica sólida y oficialmente reconocida, los trastornos de la personalidad no pueden reducirse a una lista de indicadores definitivos a los que acudir sistemáticamente con fines diagnósticos. Aunque cada teoría es lógicamente coherente, hace diferentes presunciones sobre la naturaleza de la personalidad y explora su ámbito de forma distinta. Por ello hay tantas definiciones implícitas de las teorías como opiniones diferentes sobre cómo deben ser aplicadas metodológicamente y en el tratamiento de cada caso individual.

La evaluación es un procedimiento estandarizado en el que algunas cuestiones son explícitamente formuladas por una parte y respondidas de la misma forma por la otra. Es importante destacar que no es necesario que exista un trastorno de la personalidad para que su evaluación sea útil. Por consiguiente, una evaluación minuciosa de la personalidad es siempre un buen punto de partida para la terapia, tanto para un paciente ambulatorio como para una persona normal que desea mejorar su funcionamiento; motivo por el cual el diagnóstico no consiste -como en el modelo médico- en la determinación de la presencia o ausencia de un proceso de enfermedad y la especificación de su manifestación única en cada paciente. Por el contrario, consiste en determinar si el individuo representa un 'caso' y cómo está ligada su personalidad al significado de los problemas pasados y presentes. En otras palabras, el diagnóstico debe ser enfocado como una cuestión más pragmática que ontológica. "El problema de evaluación de la personalidad es que existe menos acuerdo sobre lo que está evaluando que sobre cómo hacerlo; de lo que se desprende que hay muy poco acuerdo sobre el ámbito que abarca" (Rorer, 1990, p. 693).

Una evaluación verdaderamente integral requiere evaluar la personalidad de forma sistemática a partir de múltiples esferas personológicas. A su vez, estas características diagnósticas son distinguibles según el nivel de los datos que representan: comportamental, fenomenológico, intrapsíquico y biofísico. Esta diferenciación refleja las cuatro orientaciones históricas que caracterizan el estudio de la psicopatología. Los ámbitos clínicos más específicos pueden ser organizados sistemáticamente de forma similar a las distinciones efectuadas en la esfera biológica, es decir, dividiéndolos en atributos estructurales y funcionales. La anatomía investiga estructuras internas y básicamente permanentes que sirven, por ejemplo, como sustrato para el estado de ánimo y la memoria. Su contrapartida funcional, la fisiología, se ocupa de los procesos que regulan las dinámicas internas y las transacciones externas. Las estructuras y las funciones configuran conjuntamente el organismo como una entidad coherente.

Al realizar una evaluación orientada al ámbito, los clínicos deben tener cuidado en no referirse a cada uno de ellos como si fuera una entidad concreta e independiente, ya que caerían en un operacionismo superficial y reduccionista. Cada ámbito es una parte legítima, aunque altamente contextualizada, de un todo integrado, tabla 1.

Tabla 1. Ámbitos funcionales y estructurales de la personalidad

\begin{tabular}{|c|c|}
\hline ÁMBITOS FUNCIONALES & ÁMBITOS ESTRUCTURALES \\
\hline $\begin{array}{c}\text { Nivel comportamental } \\
\text { Comportamiento observable } \\
\text { Comportamiento interper- } \\
\text { sonal }\end{array}$ & $\begin{array}{c}\text { Representaciones objetales } \\
\text { Autoimagen }\end{array}$ \\
\hline $\begin{array}{c}\text { Nivel fenomenológico } \\
\text { Estilo cognitivo }\end{array}$ & $\begin{array}{c}\text { Organización morfológica } \\
\text { Mecanismos de defensa }\end{array}$ \\
\hline Nivel biofísico & Estado de ánimo/tempera- \\
mento
\end{tabular}




\section{Ámbitos funcionales}

Dentro de cada nivel de datos se encuentran distintos ámbitos funcionales y estructurales. Los primeros representan 'formas de expresión de acciones reguladoras': comportamientos, conducta social, procesos cognitivos y mecanismos inconscientes que guían, ajustan, transforman, coordinan, equilibran, descargan y controlan el intercambio entre la vida interna y la externa. Los segundos, en cambio, representan un entramado profundo y relativamente estable de recuerdos, actitudes, necesidades, temores y conflictos, que dirigen la experiencia y transforman la naturaleza de los acontecimientos vitales, cerrando el organismo a nuevas interpretaciones del mundo para limitar así la posibilidad de expresión de las que son predominantes. A continuación se presentan los distintos ámbitos personológicos que corresponden a cada nivel:

\section{Nivel comportamental:}

En este nivel tenemos el comportamiento observable: (i.e., conducta manifiesta que se registra mediante la observación de qué hace y cómo actúa el paciente) y el comportamiento interpersonal (i.e., el estilo de relacionarse con los demás, las acciones del paciente que inciden en los demás, las actitudes que subyacen, los métodos que utiliza para relacionarse o la forma de afrontar las tensiones y los conflictos sociales).

\section{Nivel fenomenológico:}

Aquí tenemos el estilo cognitivo (i.e., la manera que tiene el paciente de centrar y distribuir su atención, codificar y procesar la información, organizar sus pensamientos, hacer atribuciones y comunicar reacciones e ideas a los demás), la autoimagen (i.e., percepción de sí mismo como objeto, es decir, como un distinto, omnipresente e identificable 'Yo sujeto' o 'Yo objeto') y las representaciones objetales (i.e., las experiencias recientes significativas con los demás dejan una huella interna, un residuo estructural, compuesto de recuerdos, actitudes y afectos).

\section{Nivel intrapsíquico:}

En este nivel nos encontramos con los tan conocidos mecanismos de defensa y con la organización morfológica (i.e., la arquitectura global que sirve de estructura para el interior psíquico del individuo, se refiere a la fuerza estructural, a la congruencia interior y a la eficacia funcional del sistema de personalidad).

\section{Nivel biofísico:}

Aquí tenemos el estado de ánimo o temperamento (i.e., carácter predominante del afecto de una persona y la intensidad y frecuencia con que se expresa).

Si bien todos los ámbitos son necesarios para el mantenimiento de la integridad funcionalestructural del organismo, los individuos se diferencian con respecto a los ámbitos que promueven con mayor frecuencia, no solo en cuanto al grado de aproximación a cada prototipo de personalidad, sino también en cuanto al grado en que cada imperativo de cada ámbito configura su comportamiento global. Por este motivo el objetivo de una evaluación es poner de manifiesto los imperativos que perpetúan la limitación, la rigidez y la consiguiente inflexibilidad adaptativa del sistema. Una vez identificados, el propósito de la terapia será flexibilizar estos imperativos, permitiendo que el sistema asuma una mayor variedad de estados o comportamientos adaptativos en distintas situaciones.

\section{Instrumentos de evaluación}

Se dividen en cuatro amplias categorías: cuestionarios autoinformados, entrevistas estructurados, lista de síntomas y técnicas proyectivas.

\section{Cuestionarios autoinformados}

Se dividen en dos subcategorías principales: 1.1. Los instrumentos diseñados específicamente para la identificación de los trastornos de la personalidad y que utilizan escalas específicas para todos o la mayoría de los trastornos de la personalidad: pueden basarse en una teoría, ser producto de datos empíricos -factoriales- o fundarse en la observación clínica. Cada uno de ellos posee escalas distintas e independientes para identificar la presencia y magnitud de cada uno de los trastornos del Eje II del DSM. Entre ellos se mencionan los siguientes:

- Cuestionario clínico multiaxial de Millon-III (MCMI-III): Se considera un instrumento psicodinámico objetivo, ya que está compuesto y se administra de forma estructurada y estandarizada, pero se interpreta a partir del examen de la interacción entre las puntuaciones de las escalas y de la extracción de relaciones clínicamente establecidas entre los procesos cognitivos, el comportamiento interpersonal y las fuerzas intrapsíquicas. El 
actual MCMI-III se compone de 24 escalas clínicas y 3 escalas 'de corrección' útiles para el análisis interpretativo. Estos tres índices correctores -Sinceridad, Deseabilidad y Falsedad o Encubrimiento- tienen como propósito identificar la tendencia a la distorsión que caracteriza a los pacientes y sus respuestas. Las dos primeras secciones clínicas incluyen las escalas de todos los trastornos de la personalidad del Eje II del DSM-III-R y del DSM-IV. Las siguientes dos secciones cubren varios de los síndromes del Eje I más prevalentes, desde los más moderados hasta los más graves. Dicha división entre escalas para trastornos de la personalidad y escalas para síndromes clínicos pretende que las interpretaciones del MCMI sean congruentes con la lógica multiaxial del DSM.

- Escalas de trastornos de la personalidad del MMPI: No es tanto un test estandarizado como un conjunto estandarizado de ítems que pertenece a la psicología misma. A lo largo de la historia del MMPI se han derivado cientos de escalas de personalidad. Morey, Waugh y Blashfield (1985) construyeron un grupo de escalas del MMPI con el fin de representar los 11 trastornos de la personalidad del DSM-III.

- Cuestionario diagnóstico de la personalidad-revisado (PDQ-R): A diferencia de otros cuestionarios autoinformados, el PDQ-R -Personality diagnostic questionnaire- es una traducción directa de los criterios diagnósticos del DSM-III-R para los trastornos de la personalidad en formato de respuesta verdadero-falso. El cuestionario actual consta de 152 preguntas y se completa en una media hora. Cabe destacar que este es una actualización del original PDQ derivado de los criterios del DSM-III, por lo que se espera que próximamente aparezca una versión relativa al DSM-IV.

- Otros cuestionarios autoinformados: Aunque hay otros cuestionarios ateóricos que parecen prometedores, hasta el momento carecen de apoyo empírico en la literatura. Un instrumento nuevo y bien diseñado es el Cuestionario para la evaluación dimensional de la patología de la personalidad Básica -DAPP-BQ-, elaborada por Livesley (1987) y colaboradores (Livesley, Jackson \& Schroeder, 1992; Livesley \& Schroeder, 1990; Schroeder, Wormworth \& Livesley, 1993). Tras una extensa revisión literaria,
Livesley recogió una lista inicial de descriptores para cada uno de los diagnósticos del DSM-III-R. Con el fin de identificar las características prototípicas de cada diagnóstico, se utilizaron juicios consensuados de clínicos de renombre. Fundamentándose en tales características se elaboraron categorías de rasgos y finalmente se definió cada trastorno mediante una agrupación de rasgos.Otro instrumento cuya validez ha sido estudiada por Coolidge y Mervin (1992), es el Cuestionario Coolidge para el Eje II -CATI-. EI CATI -Coolidge Axis II Inventory- se compone de 200 ítems puntuados desde 'claramente falso' hasta 'claramente cierto' en una escala de 4 puntos. Los 13 trastornos de la personalidad del DSM-III-R se reflejan en escalas que se componen desde 45 ítems para el Trastorno antisocial hasta 16 para los Trastornos por evitación, sádico y autodestructivo. También incluye una escala de validez de 3 ítems, una escala de deseabilidad social de 21 ítems y un índice de ajuste de 71 ítems que mide la psicopatología global, y tres escalas para el Eje I: ansiedad, depresión y disfunción cerebral.

- El Cuestionario para la evaluación de la personalidad (Morey, 1992) consiste en 34 ítems que conforman 2 escalas de validez, 11 escalas clínicas, 5 escalas de tratamiento y 2 escalas interpersonales. Sin embargo, sólo 3 escalas, Paranoia, características Límite y características Antisociales, evalúan directamente una patología de la personalidad.

1.2. Los instrumentos diseñados para identificar los principios o conceptos subyacentes que ayudan a caracterizar los factores, las dimensiones o las polaridades que son sustratos fundamentales para la aparición de los trastornos de la personalidad. Los cuestionarios siguientes no valoran directamente los trastornos de la personalidad o bien disponen de una serie de escalas secundarias, en las que dichos trastornos suelen puntuar. Una excepción es el complejo SNAP, que une métodos factoriales con un modelo temperamental, a la vez que contiene ítems que son adaptación de los criterios DSM.

Neuroticismo, extroversión, apertura a la experiencia-cuestionario de la personalidad-revisado (NEO-PI-R): Los 'cinco grandes' se basan originalmente en una orientación léxica que asume que la ma- 
yoría de las características de personalidad social e interpersonalmente relevantes están tipificadas en el lenguaje común (John, 1990). Esta concepción se deriva de una particular filosofía de la ciencia -empirismo-, una particular metodología -análisis factorial-, un particular modelo estructural -rasgos dimensionales y una particular tradición investigadora -la denominada hipótesis léxica-. Los defensores de este modelo postulan que cualquier tipo de personalidad, normal o anormal, puede ser conceptualizada a partir de cinco amplias dimensiones ortogonales. Evalúa lo que Costa y McCrae (1985) denominan Neuroticismo, Extroversión, Apertura a la experiencia, Afiliación y Responsabilidad. El cuestionario actual tiene sus orígenes en el cuestionario NEO del año 1978, que abarcaba tres de los cinco factores y 18 facetas. Costa y McCrae (1992) afrontan la cuestión alcance-fidelidad presentando seis facetas para cada uno de los cinco factores, lo que arroja un total de 30 escalas de faceta. Estas facetas fueron 'escogidas para representar constructos frecuentemente identificados en la literatura psicológica que matizan cada uno de los cinco ámbitos' (Costa \& McCrae, 1992, pág. 39).

Cuestionario de personalidad adaptativa y no adaptativa (SNAP): EI SNAP -Schule of Nonadaptative and Adaptative Personality- es un instrumento de 375 ítems verdadero-falso, diseñado según la más pura tradición inductiva. Sus dictados se basan fundamentalmente en el modelo teórico del temperamento formulado por Tellegan (1982, 1985). EI SNAP aporta información relevante sobre la personalidad a un nivel más fundamental que el de los diagnósticos del Eje II; sin embargo, el instrumento conlleva la formulación de derivados de los trastornos de la personalidad a partir de sus 15 escalas de rasgos.

- Cuestionario tridimensional de la personalidad (TPQ): Guiado por supuestos neurobiológicos, Cloninger (1987) ha especificado tres dimensiones comportamentales -Búsqueda de novedad, Evitación del daño y Dependencia de la recompensa- que subyacen en los estilos de aprendizaje e interacciones adaptativas de los rasgos y trastornos de la personalidad. Cada dimensión superordenada se compone de 30-34 ítems que, a su vez, se agrupan en cuatro dimensiones bipolares de orden inferior. Es importante destacar que la utilidad clínica del TPQ se verá más comprometida por la inaccesibilidad de la comunidad de profesionales de la salud al conocimiento neuroquímico y neuroanatómico, que por la productividad y coherencia de su esquema teórico. Los recientes cambios teóricos, en especial la adición de cuatro dimensiones más (Cloninger, Svracic \& Przybeck, 1993), obligarán a la realización de modificaciones sustanciales del instrumento original como medida del modelo conceptual.

- Cuestionario de trastornos de la personalidad de Wisconsin (WISPI): Una de las más innovadoras aproximaciones a la teoría interpersonal es el Análisis estructural del comportamiento social de Benjamin (1974, 1984). Este modelo conceptualiza el comportamiento interpersonal en función de dos dimensiones -filiación e interdependencia- a través de tres ámbitos -focalización en los otros, focalización en el Sí mismo, focalización intra-Sí mismo-, que describen respectivamente los comportamientos parentales, filiales e introyectados. Klein, Benjamin, Rosenfeld, Treece, Husted y Griest (1993) utilizaron este modelo para dirigir la elaboración del WIPSI -Wisconsin Personality Disorders Inventory- de $\mathbf{3 6 0}$ ítems. A través de varias etapas, se elaboraron descriptores interpersonales para cada uno de los criterios del Eje II del DSM-III y DSM-III-R. Una característica importante de estos ítems es su formulación en fases, que permiten que adopten un carácter funcional para la visión subjetiva del mundo de cada trastorno.

- Índice de estilos de personalidad de Millon (MIPS): Mientras el MCMI está diseñado para identificar más o menos directamente los trastornos de la personalidad, el MIPS -Millon Index of Personality Styles(Millon, Weiss, Millon \& Davis, 1994), igual que el NEO-PI y los instrumentos tridimensionales ya descritos, centra sus escalas en los constructos que subyacen a estos tipos de personalidad, es decir, en los elementos latentes que se combinan para conformarlos. Este inventario de 180 ítems, más útil para la valoración de estilos que para la detección de trastornos de la personalidad, agrupa sus escalas con el fin de corresponderse directamente con la teoría de Millon en que se basa (Millon, 1990). 


\section{Entrevistas estructuradas}

Debido a su aparente rigor científico se las ha empleado para seleccionar las muestras en las que deben ser evaluados los autoinformes y las escalas. No obstante, requieren un tiempo de administración prolongado y personal especializado, lo que no facilita el estudio de la validez convergente y discriminante de las distintas entrevistas.

\subsection{Cuestionarios multitrastorno y multirrasgo:} Los primeras se basan en la identificación directa de los trastornos de la personalidad. En cambio los segundos, intentan poner de manifiesto características y rasgos. Se describirán estas entrevistas estructuradas, empezando con las orientadas principalmente a los trastornos, avanzando hacia las que intentan valorar más un ámbito o un rasgo como base para la identificación de los trastornos.

- Entrevista clínica estructurada para el DSM (SCID): La SCID -Structural Clinical Interview for DSM- fue elaborada originalmente por Spitzer y Williams (1986) como una entrevista semiestructurada de 120 ítems que suele incluirse en el amplio cuestionario diseñado para evaluar la mayoría de los síndromes del Eje I. Formulada según el lenguaje utilizado en los criterios diagnósticos del DSM, los clínicos utilizan una escala de medición de 4 puntos para valorar el grado de presencia de las características examinadas. La entrevista empieza con un grupo introductorio de preguntas generales y continúa evaluando sucesivamente cada uno de los trastornos de la personalidad mediante 8 a 12 síntomas. Una de las ventajas del SCID es su rápida administración en comparación con la mayoría de las entrevistas estructuradas.

- Entrevista estructurada para trastornos de la personalidad del DSM-revisada (SIDP-R): La SIDP-R -Structured Interview for DSM Personality Disorders-Revised(Pfohl, Blum, Zimmerman \& Stangl, 1989) es una entrevista semiestructurada de unos 160 ítems adaptada a los criterios del DSM-III-R. Las preguntas se agrupan en 17 partes temáticas, no en función de los trastornos DSM de la personalidad. Se indica a los pacientes que respondan en función de 'su forma de ser habitual'.

- Cuestionario de evaluación de la personalidad (PAS): EI PAS -Personality Assessment Schedule- fue elaborado por Tyrer y Alexan- der (1979) antes de la aparición del DSM-III en 1980. Incluye 24 rasgos: pesimismo, inutilidad, optimismo, labilidad, ansiedad, suspicacia, introspección, timidez, reserva, sensibilidad, vulnerabilidad, irritabilidad, impulsividad, agresividad, insensibilidad, irresponsabilidad, infantilismo, carencia de recursos, dependencia, sumisión, responsabilidad, rigidez, excentricidad e hipocondría. Estos rasgos no se evalúan únicamente en base a su contenido, sino que se puntúan en una escala de 9 puntos -0 a 8- según el grado de dominancia del rasgo sobre la vida de la persona y su influencia disfuncional.

- Examen de los trastornos de la personalidad-revisado (PDE-R): El PDE-R -Personality Disorders Examination-Revisedfue elaborado durante varios años por Loranger, Susman, Oldham y Russakoff (1987) como medio para la exploración de la fenomenología y las experiencias vitales relevantes para el diagnóstico de los trastornos de la personalidad. Las puntuaciones dimensionales se obtienen en base a unos 328 ítems agrupados bajo seis encabezamientos: Trabajo, Sí mismo, Relaciones interpersonales, Afectos, Juicio de la realidad y Control de los impulsos. Una pregunta abierta introduce cada ámbito y el sujeto puede elaborar cuanto quiera la respuesta.

2.2. Entrevistas para un único trastorno: $A$ diferencia de los instrumentos de entrevista que comprendían todos los trastornos/rasgos de la personalidad, los siguientes se centran en un único trastorno.

Entrevista diagnóstica para el Trastorno límite.-revisada (DIB-R): La DIB -Diagnostic Interview for Borderlines-Revised- fue elaborada para conseguir fiabilidad diagnóstica en el caso específico de los pacientes límite (Gunderson, Kolb \& Austin, 1981) en base a la revisión de Gunderson y Singer (1975) de las características límite. Se evalúan cinco ámbitos de contenido relacionados con la concepción del Trastorno límite de la personalidad de estos autores: adaptación social, patrones de acción impulsivos, afectos, psicosis y relaciones interpersonales. Se obtienen puntuaciones de escala entre 0 y 2 para cada parte, que luego se suman para obtener una puntuación diagnóstica global que oscila entre 0 y 10 . Las 
puntuaciones iguales o superiores a 7 se consideran indicativas de la presencia de Trastorno límite de la personalidad. La entrevista entera requiere aproximadamente 1 hora de administración. Sin embargo, la DIB presenta el inconveniente de haber sido diseñada antes de la elaboración de la personalidad límite en el DSM-III y pretende confirmar la concepción que tienen los autores sobre el constructo, no la presentada en el DSM.

- Entrevista diagnóstica para el narcisismo (DIN): La DIN -Diagnostic Interview for Narcissism- es una entrevista diagnóstica semiestructurada elaborada por Gunderson, Ronningstam y Bodkin (1990), la segunda diseñada para la evaluación integral de un trastorno determinado. Todas las preguntas se puntúan en una escala de 2 a 0, y la administración de la entrevista requiere unos 45 minutos.

La DIN evalúa el narcisismo mediante cinco ámbitos de contenido: grandiosidad, relaciones interpersonales, reactividad, afectos y estados de ánimo y adaptación social y moral.

- Entrevista diagnóstica para la personalidad depresiva (DIDP): La DIDP -Diagnostic Interview for Depressive Personality- se ha mostrado profética, ya que es previa a la inclusión de la categoría personalidad depresiva en el DSM-IV (Phillips, Gunderson, Hirschfeld \& Smith, 1990). En estas entrevistas priman las características afectivas y las cognitivas. Entre las categorías principales se incluyen: tranquilo, tenso, infeliz, negativista y no asertivo. Las puntuaciones deben identificar 'rasgos habituales y duraderos característicos y presentes en la mayor parte de la vida adulta del paciente'. Esta distinción es fundamental para no confundir la personalidad depresiva con el Trastorno depresivo mayor.

\section{Lista de síntomas}

Se sitúan en la frontera entre las escalas de personalidad y los criterios diagnósticos. Puesto que estas listas pretenden ayudar a la decisión tipológica o diagnóstica, sus ítems suelen presentar un nivel de inferencia superior al de los cuestionarios autoinformados. Se expondrán tres listas de especial relevancia: la primera es una lista de adjetivos, la segunda evalúa varios de los ámbitos clínicos, y la tercera se centra en un único trastorno.
- Lista de adjetivos de la personalidad (PACL): El contenido inicial de la PACL -Personality Adjetive Checklist- era de 405 ítems y el formato utilizado era una lista de adjetivos. La estructura de la lista se diseñó para reflejar los ocho tipos clínicos básicos inicialmente formulados por la teoría de los trastornos de la personalidad de Millon $(1969,1981)$. Aunque originalmente se basaban en una concepción de la patología de la personalidad, los ítems de la PACL fueron seleccionados para ayudar a identificar los tipos de personalidad situados en la zona de la normalidad. No obstante, el instrumento también es también apropiado para poblaciones clínicas.

- Lista diagnóstica de la personalidad de Millon (MPDC): La MPDC -Millon Personality Diagnostic Checklist- agrupa varias categorías que ofrecen al diagnosticador la posibilidad de evaluar sistemáticamente a los pacientes en cinco de los ocho ámbitos clínicos en los que se expresan los trastornos: comportamiento observable, comportamiento interpersonal, estilo cognitivo, autoimagen y estado de ánimo/temperamento. Los otros tres ámbitos sin demasiado difíciles e inferenciales para que el clínico pueda utilizarlos con un mínimo de fiabilidad y comodidad. Los 14 trastornos de la personalidad están representados en los ítems que conforman la MPDC. La forma actual consiste en 160 frases de demostrado poder predictivo y discriminante en relación con los juicios clínicos de los diagnósticos de la personalidad del Eje II.

- Lista para la psicopatía-revisada (PCL-R): La PCL -Psychopathy Checklist- original fue publicada en 1980 por Hare como representación del constructo psicopatía concebido por Cleckley (1941). En la última revisión se eliminaron dos ítems con el fin de representar mejor la estructura bifactorial de orden superior del instrumento (Hare, 1985), lo que da lugar al PCL-R -Psychopathy Checklist-Revised-.

\section{Técnicas proyectivas}

Al igual que las entrevistas y los autoinformes, las técnicas proyectivas son necesarias pero no suficientes para una evaluación completa de la personalidad. Al igual que los restantes procedimientos de medición, las técnicas proyectivas tienen ventajas e inconvenientes. Una ventaja es la integración: pre- 
tenden acceder a aspectos más inferenciales e inconcientes de la personalidad. Una desventaja es la precisión: en la medida en que la interpretación psicológica del material proyectivo esté influido por factores inconcientes del clínico, el resultado final puede ser tan proyectivo como el material interpretado. La poca estructuración que hace que las técnicas proyectivas sean tan clínicamente ricas, provoca, en contrapartida, ambigüedades interpretativas que son inherentemente problemáticas. Los instrumentos de autoinformes no presentan estos inconvenientes, aunque tienen otras limitaciones. Los pacientes sólo pueden informar sobre lo que son concientes, o al menos sobre lo que creen conocer. Por consiguiente, las técnicas proyectivas desempeñan un papel importante y complementario por abarcar aquellos aspectos de la personalidad desconocidos para el Sí mismo y probablemente también para los demás.

Finalmente es importante destacar que, aunque existen guías para la valoración de ciertos aspectos de la personalidad mediante métodos proyectivos, no hay todavía un método sistemático e integrador de evaluación directa de los constructos de personalidad del DSM mediante técnicas proyectivas.

\section{TERAPIA DE LA PERSONALIDAD: PLANTEAMIENTO, MODALIDADES E INTE- GRACIÓN}

Millon y Davis (1998) plantean que en la actualidad el desarrollo de la psicoterapia está atravesado de manera intensa por el factor económico, lo que ha dado lugar y fundamenta el éxito de las terapias breves. Ese intento por parte de los terapeutas de hacer más con menos -más pacientes en menor tiempo implica, lamentablemente, dedicar menor tiempo a pensar en la dinámica de los problemas que presentan los mismos. Sin embargo, los trastornos de la personalidad parecen oponerse a la tendencia vigente de las terapias breves ya que al ser duraderos y profundos, se muestran impermeables al tratamiento, y esto se debe a que la personalidad se presenta como el sistema inmune de la psique resistiendo la influencia de fuerzas externas $y$, ante la presencia de un trastorno desarrollado y perpetuado a lo largo de los años, el terapeuta tiene que lidiar con una fuerza penetrante de la patología que absorbe sus recursos terapéuticos, llevándolo de manera casi inevitable al pesimismo y la deserción.
Como han referido anteriormente Millon y Davis (1998), el trastorno de personalidad no es más que un punto ideal o de referencia con el que se compara a las personas reales. No refiere a una enfermedad sino a entidades objetivadas que sirven a propósitos conceptuales y se realizan a varios grados y de distintas maneras en diferentes personas Por esta razón, el foco de atención de la terapia se centra en un individuo real en vez de hacerlo en un trastorno prototipo de la personalidad.

\section{Terapia ecléctica e integracionismo: una filosofía de tratamiento en crecimiento}

Millon y Davis (1998) parten de la tesis del desarrollo promulgada por Heinz Werner para establecer una comparación entre el desarrollo de los organismos y el de la psicoterapia. Werner (1940) planteaba que el desarrollo tiene lugar en tres etapas: desde la relativamente global, a la relativamente diferenciada, llegando a una totalidad integrada. Sin embargo en el desarrollo de la clínica no sucede lo mismo ya que, por un lado, el psicoanálisis demostró que solamente era una teoría parcial de la naturaleza humana rodeada de ambigüedades terminológicas y, por otro lado, surgieron otras filosofías de la naturaleza humana, como el conductismo y posteriormente la psicología cognitiva tan dominantes y excluyentes como el psicoanálisis. Estas corrientes han dado lugar a diversas escuelas de intervención y técnicas derivadas de la teoría, y su fuerte consistencia interna ha provocado que se desarrollen de manera aislada criticando y acarreando dudas sobre la solidez de las demás perspectivas. Esto provoca a su vez que estas corrientes caigan en un dogmatismo, cerrándose a las demás y considerándose a sí mismas como la verdad, sin buscar una base común fuera de cada perspectiva en la que se podría alcanzar cierto acercamiento.

El eclecticismo aparece, entonces, como una reacción a esta situación. A diferencia de las escuelas se considera ateórico, estimulando la investigación de todo tipo, dedicándose a lo que realmente ayuda a la gente. Millon y Davis (1998) sostienen que existen dos condiciones previas para el eclecticismo: la necesidad práctica, y una medida de ignorancia en cuanto a la naturaleza o el tema al alcance de la mano. Por este motivo no se lo considera un movimiento teórico sino que se constituye 
como un medio o un recurso para afrontar la complejidad hasta que aparezcan mejores esquemas y más integracionistas. El eclecticismo técnico enfatiza la eficacia de las técnicas, es decir, prescribe aquellas técnicas que han demostrado resultados positivos, independientemente de las teorías que las generaron, y sin necesidad de confirmarlas o validarlas (Beutler \& Clarkin, 1990; Lazarus, 1968, 1981). Al separar la técnica de la teoría se evita el problema de gran cantidad de teorías y terapias de la naturaleza humana. Sin embargo esta independencia representaría una ciencia clínica que no está integrada específicamente debido a que no habría una base científica sobre la que elegir una técnica concreta, excepto la base empírica.

Retomando la tesis de Werner (1940) sobre el desarrollo, si este parte de lo relativamente global a lo relativamente diferenciado, entonces puede ser posible buscar los puntos comunes entre las muchas escuelas diferenciadas para identificar las características nucleares que conducen a una psicoterapia satisfactoria. Sin embargo, el problema de este enfoque de factores comunes es que es insuficientemente teórico, constituye una base necesaria pero no suficiente para una psicoterapia científica. Establecen una especie de mínimo común denominador de las psicoterapias en el convirtiéndose en el mínimo de lo que debe ser una buena terapia, pero no el máximo de lo que debe lograr. Por este motivo, y a partir de las insuficiencias que presentan los modelos anteriormente mencionados, es que Millon y Davis (1998) consideran necesario y pertinente establecer una filosofía integracionista ya que es la única de la cual puede derivar una forma de terapia de la personalidad, que además sea teóricamente lógica y esto se debe a que las propiedades estructurales de la personalidad son integracionistas y se incluyen de manera específica en la definición del propio constructo. El integracionismo, a diferencia del eclecticismo, pone énfasis en considerar a la personalidad como una Gestalt, como un sistema sintetizado y esencial cuyos problemas representan la unión intrincadamente conectada de comportamientos, cogniciones, procesos intrapsíquicos que fluyen a través de bucles de feedback y encadenamientos desplegados en serie que emergen en diferentes momentos en configuraciones dinámicas y cambiantes. Cada área funcional y estructural está contextualizada y entrelazada con las demás, de manera que conforman un solo organismo. De igual manera, la psicoterapia integracionista se concebiría como una configuración de estrategias y tácticas, en las que cada técnica de intervención se selecciona no solo según su eficacia para resolver síntomas patológicos concretos, sino también por su contribución en la constelación global de procedimientos terapéuticos. Resulta importante aclarar que la integración natural está en la persona, no en las modalidades o tácticas. Proviene de las dinámicas y el carácter entrelazado de los rasgos y síntomas del paciente. Es por esto que la tarea del terapeuta no consiste en ver de qué manera puede combinar los modelos discordantes de las técnicas terapéuticas, sino unir el patrón integracionista que caracteriza a cada paciente y seleccionar los objetivos y las tácticas de tratamiento que representen de manera óptima dicho patrón. De esta manera los terapeutas integracionistas tendrán conocimiento de la persona desde el principio, de que las partes y los contextos adoptan diferentes significados, y que son necesarias diferentes intervenciones en términos de las personas que se producen (Millon \& Davis, 1998).

La personalidad es concebida como un todo integrado por áreas estructurales y funcionales. En cada individuo los elementos de cada una de estas áreas limitan lo que puede existir en otra parte de las áreas, configurando de esta manera la individualidad. Sin embargo, al considerarse a la personalidad como un sistema determinado por la configuración e interacción de sus componentes cuya función primaria es la hemostasia, la misma resulta de carácter opuesto a la finalidad de la terapia que es el cambio. Ante las intervenciones del terapeuta, el equilibrio interno de la persona puede verse amenazado, suscitando ansiedad en aquellas situaciones en que el funcionamiento de la personalidad está suprimido temporalmente, de manera que su repertorio de respuestas tiene más probabilidad de ampliarse. En este sentido, la psicoterapia personológica ha propuesto dos elementos conceptuales e interdependientes de la terapia para captar las características que definen los sistemas de personalidad y facilitar el cambio: las tácticas centradas en la sesión y las estrategias a largo plazo (Millon \& Davis, 1998). Las primeras hacen referencia a lo que ocurre en una sesión concreta con una intervención particular, es decir, cada sesión 
de terapia debe centrarse en un objetivo evitando que la terapia pase a ser difusa y genere una resistencia pasiva por parte del paciente. Las segundas refieren al plan general o diseño que guía el curso de toda la terapia. Uno utiliza tácticas de modalidad a corto plazo para cumplir con objetivos estratégicos a largo plazo.

Por otra parte, Millon y Davis (1998) establecen que si la terapia y la teoría han de formar parte de una única ciencia clínica integrada, los diagnósticos deben indicar ciertas formas de intervención, basadas en la teoría. Pero estos criterios diagnósticos deben permitir una comprensión esencial e integracionista del paciente a través de todas las áreas en las que se expresa la personalidad y que puedan existir como limitaciones del funcionamiento del sistema. Por este motivo es que los autores establecen que los criterios del DSM-IV no pueden cumplir esta función ya que dejan sin evaluar muchos sistemas que pueden operar de manera insidiosa en la perpetuación de la patología personal, y consideran como inadecuado a cualquier enfoque que vincule los criterios taxonómicos a la intervención sin una guía teórica que abarque la naturaleza funcional-estructural de la personalidad. En cambio, consideran que la teoría evolucionista que se propone sobre las polaridades dolor-placer, actividad-pasividad, sí mismo-otros y pensamiento-sentimiento, proporcionan un marco de trabajo y un punto de partida que resultan útiles para lograr una concepción terapéutica, un medio para comprender al paciente y una guía para planificar las estrategias y tácticas de tratamiento (Millon \& Davis, 1998). Partiendo de esta postulación, se establecen como principales estrategias a largo plazo u objetivos terapéuticos de la terapia personológica, los siguientes:

- Establecer un equilibrio de las polaridades, apuntando a lograr equilibrios orientados hacia la polaridad, teniendo en cuenta la polaridad patológica que se va a modificar y la secuencia de tratamiento integracionista. De esta manera, los objetivos de la terapia serán superar las dificultades para el placer en el caso de los evitadores, esquizoides y depresivos; restablecer las alteraciones de la polaridad con problemas interpersonales de los dependientes, histriónicos, narcisistas y antisociales; anular los conflictos intrapsíquicos de los sádicos, compulsivos, masoquistas y negativistas, y reconstruir los déficits estructurales en las personalidades esquizotípicas, límite y paranoide.

- Oposición a las tendencias de perpetuación, apuntando a prevenir la continúa intensificación de los hábitos y actitudes patológicas establecidas de los pacientes, ya que las experiencias del pasado no sólo definen el presente sino que perturban y transforman insidiosamente los consecuentes acontecimientos vitales.

Las tácticas, por su parte, se diferencian de las estrategias en que se eligen y se llevan a cabo de una manera más centrada en las áreas personológicas y no a nivel de polaridad. Millon y Davis (1998) presentan en base a cada área, los modos de tratamiento que funcionan para modificarlas:

- Intervenciones de la modalidad biofísica, consideran importante la utilización de sustancias farmacológicas debido a que los cambios neurohormonales, las alteraciones del equilibrio neurofisiológico y su significado psicológico inciden en el estado de ánimo, generando cambios de energía y temperamento que alteran las competencias de afrontamiento de los pacientes y los lleva a modificar su autoimagen.

- Intervenciones de la modalidad comportamental, son con respecto al comportamiento observable, pueden resultar útiles las terapias de acto expresivo, donde se implementen métodos como el contracondicionamiento, aprendizaje aversivo, abstinencia del refuerzo y refuerzo selectivo positivo. En cuanto al comportamiento interpersonal, pueden emplearse tanto la psicoterapia interpersonal, como la psicoterapia de grupo.

- Intervenciones de la modalidad fenomenológica, en cuanto a los estilos cognitivos, pueden utilizarse la terapia racional emotiva propuesta por Ellis $(1958,1962,1967)$ y la terapia de Beck, Wright, Newman y Liese (1993). Para el abordaje de la autoimagen, pueden emplearse el enfoque terapéutico centrado en el cliente (Rogers, 1959) y el enfoque existencial (Binswanger, 1942, 1947; Boss, 1957, 1963; Frankl, 1955, 1966; May, Ellenberger \& Angel, 1958; May \& Van Kaam, 1963). Finalmente, en lo referido a las representaciones objetales, resultan útiles aquellos enfoques que utilicen la 
transferencia como núcleo de los conflictos infantiles y las defensas del paciente para poder intentar quebrar las resistencias a través de la interpretación de su base racional e infantil.

- Intervenciones de la modalidad intrapsíquica, aquí las técnicas que pueden utilizarse son el análisis de la transferencia, análisis del sueño, asociación libre e hipnoterapia.

\section{Técnicas de la modalidad integracionista}

Como los trastornos de la personalidad son considerados como constructos multioperacionales y sistémicos y no exclusivamente comportamentales y cognitivos, su naturaleza intrínsecamente configuracional y el carácter interactivo de las áreas personológicas requiere un modelo integracionista que supera al eclecticismo.

En la terapia personológica, deberían integrarse las estrategias y las tácticas, eligiendo las tácticas que cumplieran con los objetivos del tratamiento y las estrategias sobre la base de lo que alcanzarían realmente las tácticas. Para lograrlos, Millon $(1988,1990)$ recomienda algunos procedimientos integradores que consisten en las llamadas parejas potenciadas que hacen referencia a la combinación simultánea de métodos de tratamiento para superar características problemáticas que pueden ser refractarias a las técnicas administradas por separado. Estas combinaciones ejercen presión y fuerza en busca del cambio de manera que la terapia se convierte en multioperacional como el propio trastorno. Otro de los procedimientos son las llamadas secuencias catalíticas cuyo objetivo es intentar planificar el orden en el que se llevan a cabo tratamientos coordinados. Comprenden medidas terapéuticas y series de tiempo que optimizan el impacto de los cambios, que serían menos eficaces si la combinación secuencial estuviera dispuesta de otra manera.

Si bien lo anteriormente expuesto hace referencia a los trastornos de personalidad en general, no debe pasarse por alto que cada trastorno se caracteriza por un perfil de interrelaciones en el que intervienen los conceptos anteriormente desarrollados. Por ello, Millon y Davis (1998) consideran que es posible dar un perfil distintivo de cada uno de los trastornos. Resulta de gran importancia tener en cuenta la tipología formulada por los autores sobre cada trastorno y, a su vez, realizar una adecuada conceptualización de cada caso en particular, identificando los componentes que hacen al perfil.

A la hora de planificar el curso de tratamiento, resultará fundamental tener en cuenta lo anteriormente expuesto. Por tal motivo también presentamos a continuación las guías esquematizadas para profesionales para cada uno de los trastornos de la personalidad, los objetivos terapéuticos más adecuados y aquellas técnicas más pertinentes en respuesta a los mismos, en vistas a un efectivo abordaje de cada trastorno. Están hechas en una carilla con la intención de facilitarle, en tiempo presente, al clínico la posibilidad de seguir un plan de tratamiento adecuado al caso en particular.

Finalmente, es importante destacar que, más allá de las diferencias que existan entre los distintos abordajes de cada trastorno, siempre existirá como objetivo común y primordial, la construcción de una relación terapéutica basada en la cooperación. Para ello, será necesario lograr un alto grado de acuerdo entre las expectativas del paciente y las del terapeuta acerca de las metas y objetivos terapéuticos.

\section{CONCLUSIÓN}

Si bien es un concepto nuevo, conocer, potenciar y utilizar las guías esquematizadas para profesionales puede que sea de suma utilidad para la práctica clínica. Los pacientes cada vez más, como consumidores desean que el tiempo en las sesiones sea aprovechado al máximo, saben lo que funciona y lo que no, lo que se les debe, ó no, aplicar, y qué es lo que tiene el mejor equilibrio costos y beneficios. Tienen, además, el derecho a saberlo. Es un tema de credibilidad que va a exigir en el futuro homogeneizar criterios y llevar a cabo los tratamientos de un modo más estandarizado y basados en la evidencia. Esto no significa que el clínico tenga que renunciar a sus habilidades terapéuticas para marcar ritmos, tiempos o tomar decisiones en función del individuo, adecuando la guía al individuo no el individuo a la guía. Es su trabajo y para eso tiene que estar capacitado sin olvidar nunca al paciente o cliente que se tiene delante. A él va dirigido este trabajo, experiencia y formación para poder ayudarle efectivamente. 


\section{REFERENCIAS}

Bates, J.E. (1980). The concept of difficult temperament. Merrill-Palmer Quarterly, 26,(4),299-319.

Bates, J.E. (1987). Temperament in infancy. En J.D. Osofsky (Ed), Handbook of infancy ( $2^{\circ}$ ed., pp. 1101-1149). New York: Wiley.

Beck, A.T., Freeman, A., Davis, D.D. y otros (2005). Terapia cognitiva de los trastornos de personalidad. Buenos Aires: Paidós Ibérica.

Beck, A.T., Wright, F.D., Newman, C.F. \& Liese, B.S. (1993). Cognitive Therapy of Substance Abuse. New York: Guilford Press.

Benjamin, L.S. (1974). Structural analysis of social behavior. Psychological Review, 81,(5),392-425.

Benjamin, L.S. (1984). Principles of prediction using structural analysis of social behavior (SASB). En R.A. Zucker, J. Aranoff \& A.J. Rubin (Eds), Personality and prediction of behavior (pp. 121-174). New York: Academic Press.

Beutler, L.E. \& Clarkin, J.F. (1990). Systematic treatment selection. New York: Brunner/Mazel.

Binswanger, L. (1942). Grundformen und erkenntnis menschlichen daseins. Zurich: Niehaus.

Binswanger, L. (1947). Ausgewählte vorträge und aufsätze. Berne: Francke.

Boss, M. (1957). Psychoanalyse und daseinsanalytik. Berne: Hans Huber.

Boss, M. (1963). Psychoanalysis and daseinanalysis. New York: Basic Books.

Bowlby, J. (1982). Attachment and loss. Vol. 1. Attachment. New York: Basic Books. (Original work publi-shed 1969).

Cardenal, V., Sánchez, M.P. \& Ortiz-Tallo, M. (2007). Adaptación y baremación al español del Inventario Clínico Multiaxial de Millon-III (MCMI-III). Madrid: TEA, Ediciones.

Cleckley, H. (1941). The mask of sanity. St. Louis: Mosby.

Cloninger, C.R. (1987). A systematic method for clinical description and classification of personality variants. Archives of General Psychiatry, 44,(6),573-588.

Cloninger, C.R., Svracic, D.M. \& Przybeck, T.R. (1993). A psychobiological model of temperament and cha-racter. Archives of General Psychiatry, 50,(12),975-990.

Coolidge, F.L. \& Merwin, M.M. (1992). Reliabilty and validity of the Coolidge Axis II Inventory: A new inventory for the assessment of personality disorders. Journal of Personality Assessment, 59,(2),223-238.

Costa, P.T. \& McCrae, R.R. (1985). The NEO Personality Inventory manual. Odessa, FL: Pyschological Assessment Resources.

Costa, P.T. \& McCrae, R.R. (1992). The five-factor model of personality and its relevance to personality disorders. Journal of Personality Disorders, 6,(4),343-359.

Ellis, A. (1958). Sex Without Guilt. NY: Hillman.

Ellis, A. (1962). Reason and emotion in psychotherapy. New York: Lyle Stuart.

Ellis, A. (1967). Goals of psychotherapy. En A.R. Mahrer (Ed), The goals of psychotherapy. New York: AppletonCentury- Crofts.

Frankl, V.E. (1955). The doctor and the soul: An introduction to logotherapy. New York: Knopf.

Frankl, V.E., (1966). Logotherapy and existential analysis: A review. American Journal of Psychotherapy, 20,(2),252-260.

Gunderson, J.G. \& Singer, M.T. (1975). Defining borderline patients: An overview. American Journal of Psychiatry, 132,(1),1-10.
Gunderson, J.G., Kolb, J.E. \& Austin, V. (1981). The diagnostic interview for borderline patients. American Journal of Psychiatry, 138,(7),896-903.

Gunderson, J.G., Ronningstam, E. \& Bodkin, A. (1990). The diagnostic interview for narcissistic patients. Archives of General Psychiatry, 47,(7),676-680.

Hare, R.D. (1985). The Psychopathy Checklist. Unpublished manuscript, University of British Columbia, Vancouver, Columbia.

John, O.P. (1990). The 'big five' factor taxonomy: Dimensions of personality in the natural language and in questionnaires. En L.A. Pervin (Ed), Handbook personality theory and research (pp. 66-100). New York: Guilford.

Kagan, J. (1989). Temperamental contribution to social behavior. American Psychologist, 44,(4),668-674.

Klein, M.H., Benjamin, L.S., Rosenfeld, R., Treece, C., Husted, J. \& Griest, J.H. (1993). The Wisconsin Personality Disorders Inventory: Development, reliability, and validity. Journal of Personality Disorders, 7,(4),285-303.

Lazarus, A.A. (1968). Learning theory and the treatment of depression. Behavior Research and Therapy, 6,(1),83-89.

Lazarus, A.A. (1981). The practice of multimodal therapy. New York: McGraw-Hill.

Livesley, W.J. \& Schroeder, M.L. (1990). Dimensions of personality disorder: The DSM-III Cluster-A diagnoses. Journal of Nervous \& Mental Disorders, 178,(10),627-635.

Livesley, W.J. (1987). Theoretical and empirical issues in the selection of criteria to diagnose personality disorders. Journal of Personality Disorders, 1,(1),88-94.

Livesley, W.J., Jackson, D.N. \& Schroeder, M.L. (1992). Factorial structure of traits delineating personality disorders in clinical and general population samples. Journal of Abnormal Psychology, 101,(3),432-440.

López Pell, A.F., Rondón, J.M., Cellerino, C. \& Alfano, S.M. (2010). Guías esquematizadas de tratamiento de los Trastornos de la personalidad para profesionales, desde el modelo de Beck, Freeman, Davis y otros (2005). Revista Ciencias Psicológicas, IV,(1),97-124.

Loranger, A.W., Susman, V.L., Oldham J.M. \& Russakoff, L.M. (1987). The Personality Disorder Examination: A preliminary report. Journal of Personality Disorders, 1,1-13.

May, R. \& Van Kaam, A. (1963). Existential theory and therapy. En J.H. Masserman (Ed), Current psychiatric (Vol. 3). New York: Grune \& Stratton.

May, R., Ellenberger, H.F. \& Angel, E. (1958). Existence: A new dimension in psychiatry and psychology. New York: Basic Books

Michelsson, K., Rinne, A. \& Paajanen, S. (1990). Crying, feeding and sleeping patterns in 1- to 12-month-old infants. Child Care, Health and Development, 16,(2),99-111.

Millon, T. \& Davis, R. (1998). Trastornos de la personalidad. Más allá del DSM-IV. Barcelona: Masson.

Millon, T. \& Grossman, S.D. (2005). Personology: A Theory based on evolutionary concepts. En M.F. Lenzenweger \& J.F. Clarkin (Eds), Major theories of personality disorder (pp. 332-390). Nueva York: Guilford Press.

Millon, T. \& Grossman, S.D. (2006). Goals of a theory of personality. En J.C. Thomas, D.L. Segal \& M. Hersen (Eds), Comprehensive handbook of personality and psychopathology, Vol. 1: Personality and everyday functioning (pp. 3-22). Hoboken, NJ, US: John Wiley \& Sons Inc.

Millon, T. (1969). Modern psychopathology: A biosocial approach to maladaptative learning and functioning. Philadelphia: Saunders.

Millon, T. (1981). Disorders of personality: DSM-III, Axis II. New York: Wiley. 
Millon, T. (1988). Personologic psychotherapy : Ten commandments for a posteclectic approach to integrative treatment. Psychotherapy, 25,(2),209-219.

Millon, T. (1990). Toward a new personlogy : An evolutionary model. New York: Wiley.

Millon, T. (2002). Assessment is not enough: The SPA should participate in constructing a comprehensive clinical science of personality. Journal of Personality Assessment. $78,(2), 209-218$.

Millon, T., Weiss, L., Millon, C. \& Davis, R. (1994). MIPS: Millon index of personality styles manual. San Antonio: The Psychological Corporation.

Morey, L.C. (1992). The Personality Assessment Inventory. Odessa, FL: Psychological Assessment Resources.

Morey, L.C., Waugh, M.H. \& Blashfield, R.B. (1985). MMPI scales for DSM-III personality disorders: Their derivation and correlates. Journal of Personality Assessment, $49,(3), 245-251$.

Norcross, J.C. \& Goldfried, M.R. (Eds). (1992). Handbook of psychotherapy integration. New York: Basic Books.

Papousek, H. \& Papousek, M. (1975). Cognitive aspects of preverbal social interaction between human infants and adults. En R. Porter \& M. O'Conner (Eds), Parent-infant interaction (pp. 241260). Amsterdam: Elsevier.

Pfohl, B., Blum, N., Zimmerman, M. \& Stangl, D. (1989). Structured interview for DSM-III-R personality (SIDP-R). lowa City: University of lowa, Department of Psychiatry.

Phillips, K.A., Gunderson, J.G., Hirschfeld, R.M. \& Smith, L.E. (1990). A review of the depressive personality. American Journal Of Psychiatry, 147,(7),830-837.

Plomin, R. (1990). The Role of inheritance in behavior. Science, 248,(4952),183-188.

Rogers, C.R. (1959). A theory of therapy, personality and interpersonal relationships as developed in the clientcentered framework. En S. Koch (Ed). Psychology: A study of a science. Vol. III. Formulations of the person and the social context. New York: McGraw Hill.

Rorer, L.G. (1990). Personality assessment: A conceptual survey. En L.A. Perwin (Ed), Handbook of Personality: Theory and Reserch (pp. 693-724). New York: Guilford.
Schroeder, M.L., Wormworth, J.A. \& Livesley, W.J. (1993). Dimensions of personality disorder and the five-factor model of personality. En P.T. Costa, Jr. \& T.A. Widiger (Eds), Personality disorders and the five-factor model of personality (pp. 117-127). Washington, DC: American Psychological Association.

Spitz, R.L. (1965). The first year of life. New York: International Universities Press.

Spitzer, R.L. \& Williams, J.B. (1986). Structures clinical interview for DSM-III-R. New York: New York Psychiatric Institute.

Strak, S. \& Millon, T. (2007). Contributions to the dimensional assessment of personality disorders using Millon's model and the Millon Clinical Multiaxial Inventory (MCMI-III). Journal of Personality Assessment. Special Issue: Dimensional versus categorical personality disorder diagnosis: Implications from and for psychological assessment, 89,(1),56-69.

Tellegen, A. (1982). Brief manual for the Multidimensional Personality Questionnaire. Unpublished manuscript, University of Minnesota, Department of Psychology, Minneapolis.

Tellegen, A. (1985). Structures of mood and personality and their relevance to assessing anxiety, with an emphasis on self-report. En A. H. Tuma \& J. Maser (Eds), Anxiety and the anxiety disorders (pp. 681-706). Hillsdale, NJ: Erlbaum.

Thomas, A., Chess, S. \& Korn, S.J. (1982). The reality of difficult temperament. Merrill-Palmer Quarterly, 28,(1),1-20.

Tyrer, P. \& Alexander, J. (1979). Classification of personality disorder. British Journal of Psychiatry, 135,(2),163167.

Werner, H. (1940). Comparative psychology of mental development. New York: Brunner/Mazel.

Williams, R.J. (1973). The biological approach to the study of personality. En T. Millon (Ed), Theories of psychopathology and personality (2da ed.). Philadelphia: Saunders. 
Trastorno Esquizoide de la Personalidad

\begin{tabular}{|c|c|c|c|}
\hline \multirow[t]{2}{*}{$\begin{array}{l}\text { Características } \\
\text { de la polaridad }\end{array}$} & Placer-Dolor & \multicolumn{2}{|r|}{$\begin{array}{l}\text { No solamente parecen carecer de la capacidad para experimentar } \\
\text { placer o dolor, sino que no obtienen ninguna gratificación de sí } \\
\text { mismos ni de los demás. }\end{array}$} \\
\hline & Actividad-Pasividad & \multicolumn{2}{|r|}{$\begin{array}{l}\text { La estrategia de afrontamiento para relacionarse con el entorno es } \\
\text { pasivamente desvinculada. }\end{array}$} \\
\hline \multicolumn{2}{|c|}{ Tendencias a la perpetuación } & \multicolumn{2}{|r|}{$\begin{array}{l}\text { El estilo que han desarrollado para afrontar los acontecimientos } \\
\text { cotidianos es, en gran medida, el resultado del déficit de sus } \\
\text { capacidades intrínsecas para experimentar emociones dolorosas y } \\
\text { placenteras. El impacto de los aprendizajes tempranos puede haber } \\
\text { debilitado aún más estas disposiciones a lo largo del tiempo, } \\
\text { perpetuando los patrones desadaptativos iniciales. }\end{array}$} \\
\hline \multicolumn{4}{|c|}{ Ámbitos personológicos } \\
\hline \multirow{2}{*}{$\begin{array}{l}\text { Nivel } \\
\text { comportamental }\end{array}$} & $\begin{array}{l}\text { Expresivamente } \\
\text { impasible }\end{array}$ & \multicolumn{2}{|r|}{$\begin{array}{l}\text { Estado emocional inerte, sin vida, carente de energía y vitalidad, } \\
\text { inmóvil, aburrido, inanimado, con déficit de activación y de } \\
\text { expresividad y espontaneidad motoras. }\end{array}$} \\
\hline & $\begin{array}{l}\text { Interpersonalmente } \\
\text { desvinculado }\end{array}$ & \multicolumn{2}{|r|}{$\begin{array}{l}\text { Indiferente, rara vez responde a las acciones y sentimientos de otros, } \\
\text { escoge actividades solitarias; está aislado y no se inmiscuye; no } \\
\text { desea ni disfruta de relaciones intimas, prefiere un segundo plano. }\end{array}$} \\
\hline & $\begin{array}{l}\text { Cognitivamente } \\
\text { empobrecido }\end{array}$ & \multicolumn{2}{|r|}{$\begin{array}{l}\text { Parece deficiente y muestra procesos de pensamiento vagos y } \\
\text { confusos, en especial en cuanto a temas sociales; comunicaciones } \\
\text { con los demás descentradas, sin propósito o intensión, irracionales. }\end{array}$} \\
\hline $\begin{array}{c}\text { Nivel } \\
\text { fenomenológico }\end{array}$ & $\begin{array}{l}\text { Autoimagen } \\
\text { autosuficiente }\end{array}$ & \multicolumn{2}{|r|}{$\begin{array}{l}\text { Muestra una mínima introspección y conciencia de Sí mismo; parece } \\
\text { impermeable a las implicaciones personales y emocionales de la vida } \\
\text { social cotidiana y se muestra indiferente al halago o a la crítica. }\end{array}$} \\
\hline & $\begin{array}{l}\text { Representaciones } \\
\text { objetales escasas }\end{array}$ & \multicolumn{2}{|r|}{$\begin{array}{l}\text { Las representaciones internalizadas son pocas y mal articuladas, } \\
\text { construidas a partir de percepciones y recuerdos de las pasadas } \\
\text { relaciones con los demás. Poca interacción entre impulsos y } \\
\text { conflictos. }\end{array}$} \\
\hline $\begin{array}{l}\text { Nivel } \\
\text { intrapsíquico }\end{array}$ & $\begin{array}{l}\text { Mecanismo de } \\
\text { intelectualización }\end{array}$ & \multicolumn{2}{|r|}{$\begin{array}{l}\text { Describe las experiencias interpersonales y afectivas ciñéndose a los } \\
\text { hechos, de forma abstracta, impersonal o mecánica; sólo presta } \\
\text { atención a los aspectos objetivos y formales de los acontecimientos } \\
\text { emocionales y sociales. }\end{array}$} \\
\hline & $\begin{array}{l}\text { Organización } \\
\text { indiferenciada }\end{array}$ & \multicolumn{2}{|r|}{$\begin{array}{l}\text { Presenta una barrera interna, escasa motivación para satisfacer sus } \\
\text { necesidades y una presión mínima para defenderse o resolver } \\
\text { conflictos internos, o afrontar las demandas externas. }\end{array}$} \\
\hline Nivel biofísico & $\begin{array}{l}\text { Estado de ánimo } \\
\text { apático }\end{array}$ & \multicolumn{2}{|r|}{$\begin{array}{l}\text { Emocionalmente inexcitable; intrínseca falta de sentimientos; es frío y } \\
\text { monótono, con débiles necesidades y deseos sexuales; incapaz de } \\
\text { sentir la mayoría de los afectos: placer, tristeza o ira. }\end{array}$} \\
\hline \multicolumn{4}{|c|}{ Curso del tratamiento } \\
\hline \multicolumn{3}{|c|}{ Objetivos } & Técnicas \\
\hline \multicolumn{3}{|c|}{ Establecer una relación terapéutica } & Ofrecer un entorno de apoyo y seguridad. \\
\hline \multirow{2}{*}{$\begin{array}{l}\text { Restablecimiento } \\
\text { del equilibrio entre } \\
\text { polaridades }\end{array}$} & \multicolumn{2}{|c|}{$\begin{array}{l}\text { Placer-Dolor: Promover } \\
\text { el extremo de placer. }\end{array}$} & $\begin{array}{l}\text { Intervención psicofarmacológica inicial si es necesario para } \\
\text { aumentar la activación y contrarrestar la incapacidad para } \\
\text { experimentar afecto o energía. Modificación cognitiva de las } \\
\text { quejas sobre su incapacidad para disfrutar de las actividades y } \\
\text { relaciones interpersonales. }\end{array}$ \\
\hline & \multicolumn{2}{|c|}{$\begin{array}{l}\text { Actividad-Pasividad: } \\
\text { Fortalecer el extremo } \\
\text { activo. }\end{array}$} & $\begin{array}{l}\text { Analizar pensamientos automáticos y la creencia de que están } \\
\text { mejor solos y que las relaciones no pueden ofrecerles nada. } \\
\text { Examinar aspectos funcionales y disfuncionales del aislamiento. }\end{array}$ \\
\hline \multirow{3}{*}{$\begin{array}{l}\text { Contrarrestar la } \\
\text { tendencia a la } \\
\text { perpetuación }\end{array}$} & \multicolumn{2}{|c|}{$\begin{array}{l}\text { Contrarrestar el } \\
\text { comportamiento } \\
\text { impasible. }\end{array}$} & $\begin{array}{l}\text { Analizar su repertorio comportamental e historia de refuerzos } \\
\text { para identificar los que están activados. } \\
\text { Proporcionarle oportunidades para la interacción social que } \\
\text { permitirán una mejora en las relaciones interpersonales. }\end{array}$ \\
\hline & \multicolumn{2}{|c|}{$\begin{array}{l}\text { Incrementar la } \\
\text { conciencia perceptiva. }\end{array}$} & $\begin{array}{l}\text { Registro de pensamientos disfuncionales para ayudarle a tomar } \\
\text { conciencia de sus emociones, sus variaciones de intensidad y } \\
\text { cómo estas afectan a sus interacciones con los demás. }\end{array}$ \\
\hline & \multicolumn{2}{|c|}{$\begin{array}{l}\text { Estimular la actividad } \\
\text { social. }\end{array}$} & $\begin{array}{l}\text { Mantenerlo en alguna actividad social que evite que quede } \\
\text { absorbido en sus fantasias y pierda el contacto con la realidad. }\end{array}$ \\
\hline \multirow{3}{*}{$\begin{array}{l}\text { Modificar las } \\
\text { principales } \\
\text { disfunciones }\end{array}$} & \multicolumn{2}{|c|}{$\begin{array}{l}\text { Activar el estado de } \\
\text { ánimo apático. }\end{array}$} & $\begin{array}{l}\text { Reorientar la inatención emocional que mantiene hacia los } \\
\text { demás para aumentar su afectividad y promover experiencias } \\
\text { sociales más variadas. }\end{array}$ \\
\hline & \multicolumn{2}{|l|}{$\begin{array}{l}\text { Desarrollar la } \\
\text { implicación } \\
\text { interpersonal. }\end{array}$} & $\begin{array}{l}\text { Entrenamiento en habilidades sociales para ampliar su } \\
\text { repertorio de comportamientos interpersonales. } \\
\text { Jerarquía de objetivos de interacción social que esté dispuesto a } \\
\text { alcanzar. Utilizar técnicas de imitación y la exposición in vivo. }\end{array}$ \\
\hline & \multicolumn{2}{|c|}{$\begin{array}{l}\text { Alterar las cogniciones } \\
\text { empobrecidas. }\end{array}$} & $\begin{array}{l}\text { Registro diario de creencias distorsionadas y tareas para casa } \\
\text { que permitan identificar los pensamientos automáticos y } \\
\text { contrarrestar la ambigüedad de sus vagas cogniciones. }\end{array}$ \\
\hline
\end{tabular}




\section{Trastorno de la Personalidad por Evitación}

\begin{tabular}{|c|c|}
\hline $\begin{array}{c}\text { Caracterís } \\
\text { ticas de } \\
\text { las } \\
\text { polaridade } \\
\mathbf{S}\end{array}$ & Placer-Dolor \\
\hline
\end{tabular}

Notable dificultad para experimentar placer. Evitan las experiencias humillantes, pero esto impide también las interacciones en las que podría encontrar afecto. El distanciamiento de las situaciones que temen potencia que casi nunca expresen sus deseos, incluso en relaciones que no son intimas.

Tendencia a la perpetuación

El distanciamiento social que emplean como mecanismo de defensa contra la experimentación de rechazo y crítica asegura que no experimenten ninguna interacción social que les ayude a poner en duda estas expectativas tan pesimistas.

Ámbitos personológicos

\begin{tabular}{|c|c|c|}
\hline \multirow{2}{*}{$\begin{array}{l}\text { Nivel } \\
\text { Comporta } \\
\text { mental }\end{array}$} & $\begin{array}{l}\text { Expresivamente } \\
\text { ansioso }\end{array}$ & $\begin{array}{l}\text { Estado de inquietud y desasosiego, temor, vacilación e impaciencia } \\
\text { reacciona exageradamente a acontecimientos inocuos y los juzga co } \\
\text { ansiedad como ridículo, crítica y desaprobación. }\end{array}$ \\
\hline & $\begin{array}{l}\text { Interpersonalmente } \\
\quad \text { aversivo }\end{array}$ & $\begin{array}{l}\text { Se distancian de actividades que implican relaciones personales íntima } \\
\text { Larga historia de panansiedad y desconfianza social. Busca aceptación, pe } \\
\text { no tiene voluntad de implicarse a menos que tenga certeza de que gustará. }\end{array}$ \\
\hline \multirow{3}{*}{$\begin{array}{l}\text { Nivel } \\
\text { Fenomeno } \\
\text { lógico }\end{array}$} & $\begin{array}{l}\text { Cognitivamente } \\
\text { distraído }\end{array}$ & $\begin{array}{l}\text { Rastrea constantemente el ambiente para identificar amenazas potenciales } \\
\text { está preocupado por pensamientos y observaciones irrelevantes e intrusos. }\end{array}$ \\
\hline & $\begin{array}{l}\text { Autoimagen } \\
\text { alienada }\end{array}$ & $\begin{array}{l}\text { Se ve a sí mismo socialmente inepto, inadecuado e inferior, lo que justifica } \\
\text { aislamiento y el rechazo de los demás. Se siente poco atractivo, devalúa s } \\
\text { logros y refiere una sensación persistente de soledad y vacío. }\end{array}$ \\
\hline & $\begin{array}{l}\text { Representaciones } \\
\text { objetales vejatorias }\end{array}$ & $\begin{array}{l}\text { Representaciones internalizadas compuestas por reacciones intensas } \\
\text { conflictivas de recuerdos sobre relaciones tempranas problemática } \\
\text { Limitaciones para experimentar o recordar gratificaciones, canalizar la } \\
\text { necesidades, controlar impulsos y resolver conflictos. }\end{array}$ \\
\hline \multirow{2}{*}{$\begin{array}{l}\text { Nivel } \\
\text { Intrapsíqui } \\
\text { co }\end{array}$} & $\begin{array}{l}\text { Mecanismo de la } \\
\text { Fantasía }\end{array}$ & $\begin{array}{l}\text { Depende de la imaginación para conseguir la satisfacción de las necesidade } \\
\text { el establecimiento de la confianza y la resolución de los conflictos. }\end{array}$ \\
\hline & Organización frágil & $\begin{array}{l}\text { Un complejo precario de emociones tortuosas que dependen cé } \\
\text { exclusivamente de una única modalidad para su resolución y liberacićc } \\
\text { evitación, escape y fantasía. }\end{array}$ \\
\hline $\begin{array}{l}\text { Nivel } \\
\text { Biofísico }\end{array}$ & $\begin{array}{l}\text { Estado de ánimo } \\
\text { angustiado }\end{array}$ & $\begin{array}{l}\text { Describe tensión, tristeza e ira constantes y confusas; vacila entre el des } \\
\text { afecto, el miedo a la burla el malestar y el embotamiento afectivo. }\end{array}$ \\
\hline
\end{tabular}

\section{Curso del tratamiento}

\begin{tabular}{|c|c|c|}
\hline \multicolumn{2}{|r|}{ Objetivos } & Técnicas \\
\hline $\begin{array}{l}\text { Establecimie } \\
\text { nto de una } \\
\text { relación } \\
\text { terapéutica. }\end{array}$ & Contrarrestar el temor al rechazo. & $\begin{array}{l}\text { Ofrecer empatía y apoyo. Brindar un ambiente terapéutico } \\
\text { protector que le permita expresarse de manera franca } \\
\text { abierta. }\end{array}$ \\
\hline $\begin{array}{l}\text { Restablecimi } \\
\text { ento del } \\
\text { equilibrio } \\
\text { entre las } \\
\text { polaridades }\end{array}$ & $\begin{array}{l}\text { Placer-Dolor: Centrarse de forma } \\
\text { activa en los estímulos } \\
\text { agradables. }\end{array}$ & $\begin{array}{l}\text { Organizar la secuencia de tareas para la casa, procurando } \\
\text { que vaya paso a paso. Esto permite tener una actitud más } \\
\text { activa y procurarse más gratificaciones. }\end{array}$ \\
\hline \multirow{4}{*}{$\begin{array}{l}\text { Contrarresta } \\
\text { r la } \\
\text { tendencia a } \\
\text { la } \\
\text { perpetuación }\end{array}$} & Invertir el aislamiento social. & $\begin{array}{l}\text { Autoobservación de conducta de aislamiento para aclarar su } \\
\text { inclinación a evitar a ciertas personas o situaciones. }\end{array}$ \\
\hline & $\begin{array}{l}\text { Disminuir la } \\
\text { suspicacia/comportamiento } \\
\text { temeroso. }\end{array}$ & $\begin{array}{l}\text { Jerarquía de las situaciones ansiógenas según el grado. } \\
\text { Exposición in vivo para ayudarlo a reaccionar con menos } \\
\text { temor ante situaciones percibidas como amenazadoras. }\end{array}$ \\
\hline & $\begin{array}{l}\text { Moderar la hipersensibilidad } \\
\text { perceptiva. }\end{array}$ & $\begin{array}{l}\text { Comprender su experiencia de humillación y malestar. } \\
\text { Confrontar situaciones temidas y explorar fantasías que } \\
\text { provocan ansiedad. Intervención psicofarmacológica si el } \\
\text { temor al rechazo es un riesgo de abandono del tratamiento. }\end{array}$ \\
\hline & $\begin{array}{l}\text { Desarmar la interferencia cognitiva } \\
\text { intencionada. }\end{array}$ & $\begin{array}{l}\text { Reestructuración cognitiva para descubrir los pensamientos } \\
\text { erróneos que inciden en sus conductas disfuncionales. }\end{array}$ \\
\hline \multirow{3}{*}{$\begin{array}{l}\text { Modificar las } \\
\text { principales } \\
\text { disfunciones } \\
\text { de ámbito }\end{array}$} & Ajustar la autoimagen alienada. & $\begin{array}{l}\text { Registro de creencias disfuncionales sobre sí mismo. } \\
\text { Experimentos conductuales para evaluar la validez de sus } \\
\text { esquemas cognitivos y desarrollar otros más adaptativos. }\end{array}$ \\
\hline & $\begin{array}{l}\text { Corregir el comportamiento } \\
\text { interpersonal aversivo. }\end{array}$ & $\begin{array}{l}\text { Entrenamiento en habilidades sociales para mejorar la } \\
\text { asertividad y la fluidez comportamental. Técnicas grupales } \\
\text { para exponerlo a personas desconocidas en un ambiente de } \\
\text { aceptación y pueda superar las situaciones sociales } \\
\text { embarazosas. }\end{array}$ \\
\hline & Sustituir los objetos humillantes. & $\begin{array}{l}\text { Analizar recuerdos de la infancia para clarificar las raíces } \\
\text { del trastorno. Técnicas cognitivo-conductuales para crear } \\
\text { esquemas mentales más realistas de las relaciones y } \\
\text { reemplazar representaciones objetales humillantes. }\end{array}$ \\
\hline
\end{tabular}




\section{Trastorno Depresivo de la Personalidad}

\begin{tabular}{|c|c|c|c|}
\hline \multirow{2}{*}{$\begin{array}{l}\text { Características de la } \\
\text { polaridad }\end{array}$} & Placer-Dolor & \multicolumn{2}{|r|}{$\begin{array}{l}\text { Aceptan el dolor como inevitable lo que justifica su inamovilidad y su } \\
\text { indefensión. Presentan un sentimiento de desesperanza sobre } \\
\text { cómo mejorar la calidad de vida. }\end{array}$} \\
\hline & $\begin{array}{l}\text { Actividad- } \\
\text { Pasividad }\end{array}$ & \multicolumn{2}{|r|}{$\begin{array}{l}\text { En lugar de actuar se resigna a soportar la carga de su suerte. } \\
\text { Responden con poco entusiasmo a las oportunidades de mejorar } \\
\text { su posición, afianzando su desesperanza y sus autorreproches. }\end{array}$} \\
\hline \multicolumn{2}{|c|}{ Tendencias a la perpetuación } & \multicolumn{2}{|r|}{$\begin{array}{l}\text { Como creen que carecen de capacidad para mejorar, manifiestan } \\
\text { un comportamiento interpersonal de indefensión y desvalimiento } \\
\text { por lo que se vuelvan a los demás con la esperanza de salvarse. }\end{array}$} \\
\hline \multicolumn{4}{|c|}{ Ámbitos personológicos } \\
\hline \multirow[b]{2}{*}{$\begin{array}{l}\text { Nivel } \\
\text { comportamental }\end{array}$} & $\begin{array}{l}\text { Expresivamente } \\
\text { abatido }\end{array}$ & \multirow{2}{*}{\multicolumn{2}{|c|}{$\begin{array}{l}\text { Su aspecto y estado transmiten un desamparo irremediable, } \\
\text { sombrío, desolado, abatido y decaído, desesperanza y desdicha. } \\
\text { Debido al sentimiento de vulnerabilidad y desprotección, suplicará a } \\
\text { los demás que le cuiden y protejan, temen el abandono y la } \\
\text { deserción: exiqirá afecto y dedicación. }\end{array}$}} \\
\hline & $\begin{array}{l}\text { Interpersonalmente } \\
\text { indefenso }\end{array}$ & & \\
\hline \multirow{3}{*}{$\begin{array}{c}\text { Nivel } \\
\text { fenomenológico }\end{array}$} & $\begin{array}{l}\text { Cognitivamente } \\
\text { pesimista }\end{array}$ & \multicolumn{2}{|r|}{$\begin{array}{l}\text { Actitudes derrotistas, espera siempre lo peor; se siente abrumado, } \\
\text { desanimado y triste, interpreta los acontecimientos de manera } \\
\text { desoladora. }\end{array}$} \\
\hline & Autoimagen inútil & \multicolumn{2}{|r|}{$\begin{array}{l}\text { Se juzga como insignificante, sin valor para él ni para los otros, inútil } \\
e \text { incapaz de aspiración alguna; improductivo, impotente y } \\
\text { censurable, despreciable, merecedor de críticas y descalificación. }\end{array}$} \\
\hline & $\begin{array}{l}\text { Representaciones } \\
\text { objetales } \\
\text { abandonadas }\end{array}$ & \multicolumn{2}{|r|}{$\begin{array}{l}\text { Parece desechar las representaciones internalizadas del pasado, } \\
\text { como si las experiencias tempranas de la vida se hubieran agotado } \\
\text { o debilitado, o estuvieran vacias de su riqueza y elementos } \\
\text { alegres, o ausentes de la memoria. }\end{array}$} \\
\hline \multirow[b]{2}{*}{ Nivel intrapsíquico } & $\begin{array}{l}\text { Mecanismo de } \\
\text { ascetismo }\end{array}$ & \multicolumn{2}{|r|}{$\begin{array}{l}\text { Comprometido en actos de autonegación, autocastigo y } \\
\text { autovejación, cree que debe hacer penitencia y privarse de } \\
\text { placeres; se autojuzga con posibles actos autodestructivos. }\end{array}$} \\
\hline & $\begin{array}{l}\text { Organización } \\
\text { disminuida }\end{array}$ & \multicolumn{2}{|r|}{$\begin{array}{l}\text { Un andamiaje para las estructuras morfológicas muy débil, con } \\
\text { afrontamientos endebles y estrategias defensivas precarias, vacias } \\
\text { y desprovistas de vigor y atención, que disminuyen la capacidad de } \\
\text { iniciar la acción y regular el afecto, el impulso y el conflicto. }\end{array}$} \\
\hline Nivel biofísico & $\begin{array}{l}\text { Estado de ánimo } \\
\text { melancólico }\end{array}$ & \multicolumn{2}{|r|}{$\begin{array}{l}\text { Típicamente apenado, desanimado, con llanto fácil, triste y arisco; } \\
\text { preocupado; el malhumor y el estado disfórico raras veces remiten. }\end{array}$} \\
\hline \multicolumn{4}{|c|}{ Curso del tratamiento } \\
\hline \multicolumn{3}{|c|}{ Objetivos } & Técnicas \\
\hline \multirow[t]{2}{*}{$\begin{array}{l}\text { Establecer una } \\
\text { relación terapéutica }\end{array}$} & \multicolumn{2}{|c|}{$\begin{array}{l}\text { Adoptar una actitud } \\
\text { empática y de apoyo. }\end{array}$} & $\begin{array}{l}\text { Impartir esperanza y optimismo en la posibilidad de mejorar el } \\
\text { funcionamiento y el estado de ánimo, dejando claro que el } \\
\text { paciente debe colaborar y asi llegar a soluciones positivas y } \\
\text { realistas. }\end{array}$ \\
\hline & $\begin{array}{r}\text { Promover el senti } \\
\text { autoeficacia }\end{array}$ & & $\begin{array}{l}\text { Transmitir confianza en la capacidad para cuidarse de sí } \\
\text { mismo y para resolver problemas. }\end{array}$ \\
\hline \multirow{2}{*}{$\begin{array}{l}\text { Restablecimiento } \\
\text { del equilibrio entre } \\
\text { polaridades }\end{array}$} & $\begin{array}{l}\text { Placer -Dolor: } \\
\text { incrementar el polc } \\
\text { placer. }\end{array}$ & & $\begin{array}{l}\text { Técnicas cognitivo-conductuales que lo estimulen a actuar de } \\
\text { manera más adaptativa con el entorno. }\end{array}$ \\
\hline & $\begin{array}{l}\text { Actividad-Pasivida } \\
\text { estimular una ma } \\
\text { actividad. }\end{array}$ & & $\begin{array}{l}\text { Disminuir el sentido de desamparo y reforzar la motivación } \\
\text { para que realice experiencias que resulten compensadoras, } \\
\text { fomentando estrategias de afrontamiento más activas. }\end{array}$ \\
\hline \multirow{3}{*}{$\begin{array}{l}\text { Contrarrestar la } \\
\text { tendencia a la } \\
\text { perpetuación }\end{array}$} & \multicolumn{2}{|c|}{$\begin{array}{l}\text { Anular las expectativas } \\
\text { pesimistas del paciente. }\end{array}$} & $\begin{array}{l}\text { Registro de pensamientos disfuncionales que subyacen al } \\
\text { pesimismo. Experimentos conductuales para probarlos. }\end{array}$ \\
\hline & \multicolumn{2}{|l|}{$\begin{array}{l}\text { Restablecer el } \\
\text { sentimiento de } \\
\text { autovalía. }\end{array}$} & $\begin{array}{l}\text { Entrenamiento en habilidades sociales y asertividad para } \\
\text { sustituir la conducta de abatimiento y el comportamiento } \\
\text { interpersonal de indefensión por alternativas más asertivas. } \\
\text { Dividir las tareas en pasos para exponerlo de manera } \\
\text { progresiva al éxito y reforzar sentimientos de autoeficacia y } \\
\text { su autoimagen. }\end{array}$ \\
\hline & \multicolumn{2}{|c|}{$\begin{array}{l}\text { Estimular el estado de } \\
\text { ánimo. }\end{array}$} & $\begin{array}{l}\text { Técnicas cognitivas para que busque el feedback objetivo en } \\
\text { su entorno, en lugar de mantenerse aislado en el } \\
\text { razonamiento emocional. Técnica de resolución de } \\
\text { problemas para generar planes alternativos en caso de } \\
\text { fracaso, previniendo que se hunda nuevamente en la } \\
\text { desesperanza y la apatía. }\end{array}$ \\
\hline \multirow[b]{2}{*}{$\begin{array}{l}\text { Modificar las } \\
\text { principales } \\
\text { disfunciones }\end{array}$} & \multicolumn{2}{|c|}{$\begin{array}{l}\text { Usar antidepresivos para } \\
\text { el estado de ánimo. }\end{array}$} & $\begin{array}{l}\text { Derivar a psiquiatra para suministrar antidepresivos que } \\
\text { proporcionan un aumento de energía y un indicio de } \\
\text { optimismo. }\end{array}$ \\
\hline & \multicolumn{2}{|c|}{$\begin{array}{l}\text { Promover cambios } \\
\text { cognitivos optimistas. }\end{array}$} & $\begin{array}{l}\text { Identificar pensamientos y creencias disfuncionales, plantear } \\
\text { experimentos conductuales para probar su validez y } \\
\text { modificarlos por creencias más adaptativas. Ensayo cognitivo } \\
\text { para que cumpla los objetivos, imaginando los pasos, } \\
\text { prediciendo obstáculos y conflictos y deduciendo maneras } \\
\text { de mejorarlos. }\end{array}$ \\
\hline
\end{tabular}




\begin{tabular}{|c|c|c|c|}
\hline \multicolumn{4}{|c|}{ Trastorno Dependiente de la Personalidad } \\
\hline \multirow{2}{*}{$\begin{array}{l}\text { Características de } \\
\text { la polaridad }\end{array}$} & Actividad-Pasividad & \multicolumn{2}{|c|}{$\begin{array}{l}\text { Para ganar apoyo y cuidado, han aprendido a esperar de forma pasiva que los } \\
\text { demás tomen las riendas. }\end{array}$} \\
\hline & Sí mismo-Otros & \multicolumn{2}{|c|}{ Se autodefine en términos de los demás y buscan el cuidado de ellos. } \\
\hline \multicolumn{2}{|c|}{ Tendencias a la perpetuación } & \multicolumn{2}{|c|}{$\begin{array}{l}\text { Los sentimientos de incompetencia contribuyen al fracaso para desarrollar una } \\
\text { vida más independiente. Otros factores perpetuadores reflejan estereotipos de } \\
\text { la infancia, en los que los demás aprendieron a percibir sólo las cualidades } \\
\text { dependientes, ignorando sus esfuerzos de independencia. }\end{array}$} \\
\hline \multicolumn{4}{|r|}{ Ámbitos personológicos } \\
\hline \multirow{2}{*}{$\begin{array}{l}\text { Nivel } \\
\text { comportamental }\end{array}$} & $\begin{array}{l}\text { Expresivamente } \\
\text { incompetente }\end{array}$ & \multirow{2}{*}{\multicolumn{2}{|c|}{$\begin{array}{l}\text { Evita responsabilidades adultas buscando ayuda en los demás; dócil y pasivo, } \\
\text { carece de competencias funcionales y evita la autoafirmación. } \\
\text { Necesita seguridad y consejos excesivos; se subordina a una figura más fuerte } \\
\text { que le proporcione cuidado; es incumplidor, conciliador y tranquilizador, y teme } \\
\text { tener que ocuparse de sí mismo. }\end{array}$}} \\
\hline & $\begin{array}{l}\text { Interpersonalmente } \\
\text { sumiso }\end{array}$ & & \\
\hline \multirow{3}{*}{$\begin{array}{c}\text { Nivel } \\
\text { fenomenológico }\end{array}$} & $\begin{array}{l}\text { Cognitivamente } \\
\text { ingenuo }\end{array}$ & \multicolumn{2}{|r|}{ Rara vez está en desacuerdo con los demás y se le convence con fácilmente. } \\
\hline & Autoimagen inepta & \multicolumn{2}{|c|}{$\begin{array}{l}\text { Se ve a sí mismo débil, frágil e inadecuado, y desprecia sus actitudes y } \\
\text { competencias. }\end{array}$} \\
\hline & $\begin{array}{l}\text { Representaciones } \\
\text { objetales inmaduras }\end{array}$ & \multicolumn{2}{|c|}{$\begin{array}{l}\text { Las representaciones internalizadas están compuestas por impresiones infantiles } \\
\text { de los demás, impulsos muy rudimentarios y competencias mínimas para } \\
\text { manejar y resolver situaciones estresantes. }\end{array}$} \\
\hline \multirow[t]{2}{*}{$\begin{array}{l}\text { Nivel } \\
\text { intrapsíquico }\end{array}$} & $\begin{array}{l}\text { Mecanismo de } \\
\text { introyección }\end{array}$ & \multicolumn{2}{|c|}{$\begin{array}{l}\text { Es devoto de los demás para fortalecer la creencia de que existe una unión } \\
\text { inseparable con ellos; subordina ideas de independencia en favor de las de los } \\
\text { otros para evitar amenazas a su relación. }\end{array}$} \\
\hline & $\begin{array}{l}\text { Organización } \\
\text { rudimentaria }\end{array}$ & \multicolumn{2}{|c|}{$\begin{array}{l}\text { Estructura morfológica deficiente y falta de diversidad en los controles internos, } \\
\text { que provocan una mezcla de habilidades adaptativas relativamente } \\
\text { subdesarrolladas e indiferenciadas y un sistema muy elemental para conducirse } \\
\text { independientemente }\end{array}$} \\
\hline Nivel biofísico & $\begin{array}{l}\text { Expresión afectiva } \\
\text { pacifica }\end{array}$ & \multicolumn{2}{|c|}{ Es cálido, tierno y no competitivo; evita la tensión social. } \\
\hline \multicolumn{4}{|c|}{ Curso del tratamiento } \\
\hline \multicolumn{3}{|c|}{ Objetivos } & Técnicas \\
\hline \multirow[b]{2}{*}{$\begin{array}{l}\text { Establecer una } \\
\text { relación terapéutica }\end{array}$} & \multicolumn{2}{|c|}{ Permitir cierta dependencia. } & $\begin{array}{l}\text { Proporcionar al principio una ayuda más directa, centrándose en la } \\
\text { resolución de problemas. }\end{array}$ \\
\hline & \multicolumn{2}{|c|}{$\begin{array}{l}\text { Ser menos directivo a } \\
\text { medida que se establece } \\
\text { mayor confianza. }\end{array}$} & $\begin{array}{l}\text { Refuerzo interpersonal para animar al paciente a experimentar } \\
\text { comportamientos cada vez más independientes. }\end{array}$ \\
\hline \multirow{2}{*}{$\begin{array}{l}\text { Restablecimiento del } \\
\text { equilibrio entre } \\
\text { polaridades }\end{array}$} & \multicolumn{2}{|c|}{$\begin{array}{l}\text { Si mismo- Otros: } \\
\text { contrarrestar creencia de } \\
\text { que su bienestar depende } \\
\text { de los demás y fomentar el } \\
\text { centrarse en el Yo. }\end{array}$} & $\begin{array}{l}\text { Entrenamiento en asertividad para expresarsentimientos negativos de } \\
\text { manera más constructiva y tratar la reticencia a hacer las cosas por sí } \\
\text { mismo. Entrenamiento de habilidades de comunicación e imitación para } \\
\text { practicar conductas asertivos. }\end{array}$ \\
\hline & \multicolumn{2}{|c|}{$\begin{array}{l}\text { Actividad-Pasividad: } \\
\text { incrementar implicación } \\
\text { activa en la satisfacción de } \\
\text { sus necesidades, sin } \\
\text { requerir un apoyo excesivo } \\
\text { de los otros. }\end{array}$} & $\begin{array}{l}\text { Registro de pensamientos erróneos sobre los problemas para probar su } \\
\text { validez. Sustituir las cogniciones pasivas por otras más activas. } \\
\text { Técnica de resolución de problemas para pensar soluciones } \\
\text { adaptativas. }\end{array}$ \\
\hline \multirow[b]{3}{*}{$\begin{array}{l}\text { Modificar las } \\
\text { principales } \\
\text { disfunciones }\end{array}$} & \multicolumn{2}{|c|}{$\begin{array}{l}\text { Corregir el comportamiento } \\
\text { interpersonal sumiso. }\end{array}$} & $\begin{array}{l}\text { Evaluar la validez de sus creencias sobre las consecuencias de un } \\
\text { comportamiento asertivo y autónomo, y animarlo a que realice pruebas } \\
\text { empiricas. }\end{array}$ \\
\hline & \multicolumn{2}{|c|}{$\begin{array}{l}\text { Potenciar una autoimagen } \\
\text { de eficacia. }\end{array}$} & $\begin{array}{l}\text { Identificar los pensamientos distorsionados con respecto a la imagen } \\
\text { que tiene de si mismo y someterlos a prueba. }\end{array}$ \\
\hline & \multicolumn{2}{|c|}{$\begin{array}{l}\text { Adquirir conductas } \\
\text { competentes. }\end{array}$} & $\begin{array}{l}\text { Reconocer patrones de dependencia, situaciones y cogniciones que } \\
\text { impulsan este comportamiento. Jerarquia de comportamientos } \\
\text { asertivos e independientes que producen ansiedad para ir } \\
\text { afrontándolos paulatinamente. Entrenamiento en respiración y y } \\
\text { relajación muscular para disminuir la ansiedad. La imitación y el } \\
\text { modelado que le brinden habilidades básicas para adquirir nuevos } \\
\text { comportamientos. }\end{array}$ \\
\hline \multirow{3}{*}{$\begin{array}{l}\text { Contrarrestar la } \\
\text { tendencia a la } \\
\text { perpetuación }\end{array}$} & \multicolumn{2}{|c|}{ Reducir la autodevaluación. } & $\begin{array}{l}\text { Continuum de dependencia-independencia para resolver el } \\
\text { pensamiento dicotómico que refuerza. }\end{array}$ \\
\hline & \multicolumn{2}{|c|}{$\begin{array}{l}\text { Potenciar las habilidades } \\
\text { adultas. }\end{array}$} & $\begin{array}{l}\text { Terapia familiar para facilitar el cambio conductual y poder exigir que } \\
\text { cumpla con sus responsabilidades de adulto. Explorar otros contextos } \\
\text { de relaciones para aumentar el crecimiento y minimizar la } \\
\text { dependencia continuada. }\end{array}$ \\
\hline & \multicolumn{2}{|c|}{$\begin{array}{l}\text { Disminuir los } \\
\text { comportamientos de } \\
\text { "enganche". }\end{array}$} & $\begin{array}{l}\text { Análisis conductual para aclarar áreas problemáticas de su vida } \\
\text { haciendo hincapié en la conducta de evitación. }\end{array}$ \\
\hline
\end{tabular}




\section{Trastorno Histriónico de la Personalidad}

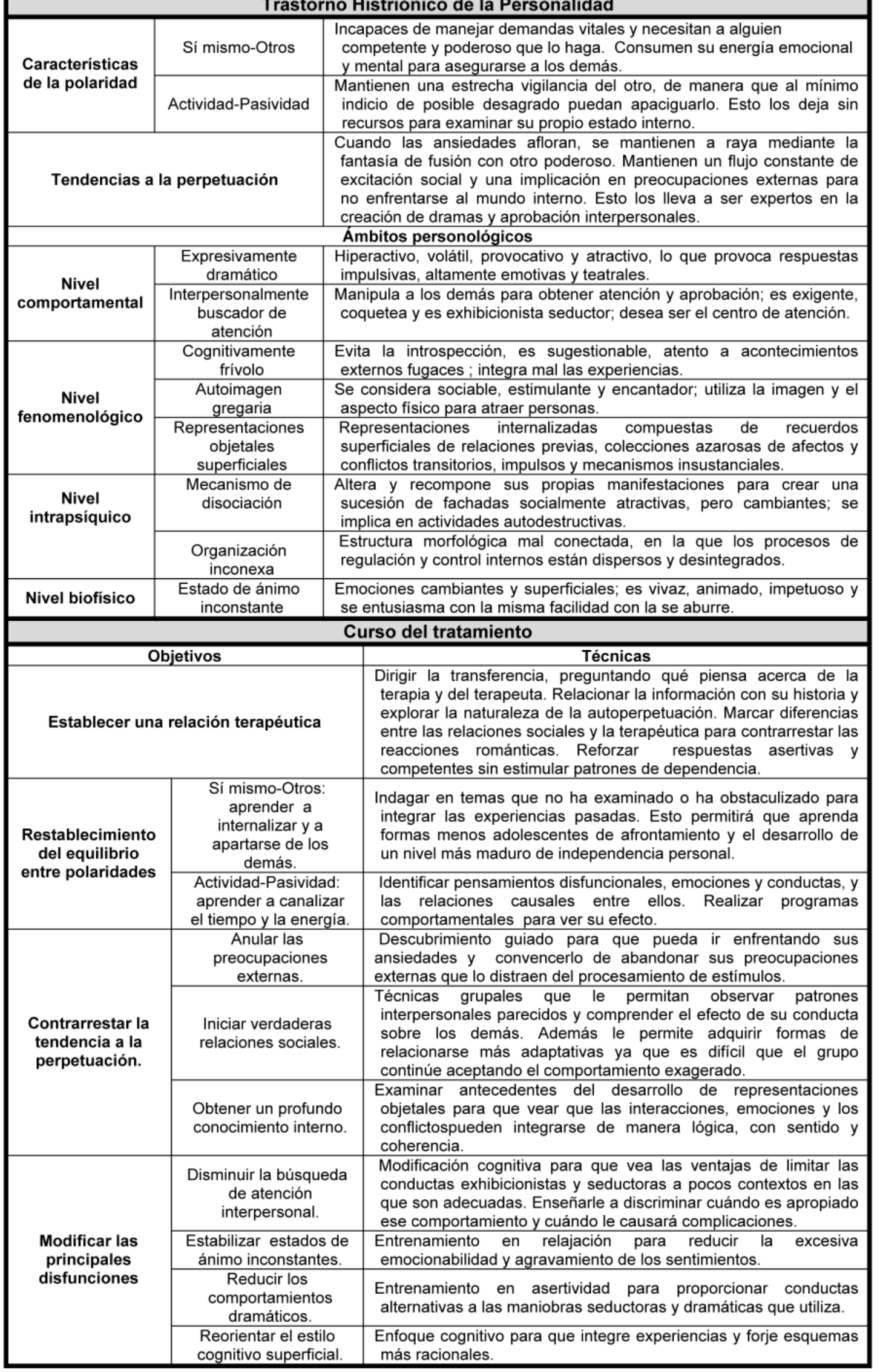




\section{Trastorno Narcisista de la Personalidad}

\begin{tabular}{|c|c|c|c|}
\hline \multicolumn{4}{|c|}{ Trastorno Narcisista de la Personalidad } \\
\hline \multirow{2}{*}{$\begin{array}{l}\text { Características de } \\
\text { la polaridad }\end{array}$} & Si mismo-Otros & \multicolumn{2}{|c|}{$\begin{array}{l}\text { Confian más en sí mismos como fuente de recompensa. Se consideran de } \\
\text { manera especial y fantasean sobre el gran reconocimiento que recibirán cuando } \\
\text { llegue su gran día. }\end{array}$} \\
\hline & Actividad-Pasividad & \multicolumn{2}{|c|}{$\begin{array}{l}\text { El sentido de superioridad suele producir una carencia general de } \\
\text { comportamientos orientados a objetivos. Creen que merecen que las cosas } \\
\text { vayan bien como producto de su intrínseca excepcionalidad. }\end{array}$} \\
\hline \multicolumn{2}{|c|}{ Tendencias a la perpetuación } & \multicolumn{2}{|c|}{$\begin{array}{l}\text { El ciclo de perpetración de los problemas empieza con experiencias tempranas de } \\
\text { elogio no contingente. Su grandioso sentido de autoimportancia los lleva } \\
\text { concluir que no hay razones para esforzarse y adquirir habilidades } \\
\text { competencias cuando 'es claro que' poseen valiosos talentos y aptitudes. Creer } \\
\text { que sus dones son razones suficientes para conseguir sus objetivos y ganarse e } \\
\text { respeto ajeno. }\end{array}$} \\
\hline \multicolumn{4}{|c|}{ Ámbitos personológicos } \\
\hline \multirow{2}{*}{$\begin{array}{l}\text { Nivel } \\
\text { comportamental }\end{array}$} & $\begin{array}{l}\text { Expresivamente } \\
\text { arrogante }\end{array}$ & \multicolumn{2}{|c|}{$\begin{array}{l}\text { Conducta arrogante y altanera, se siente por encima de las normas y las califica } \\
\text { de superficiales o inaplicables a sí mismo. Falta de atención por la integridad } \\
\text { personal y desinterés en los derechos de los demás. }\end{array}$} \\
\hline & $\begin{array}{l}\text { Interpersonalmente } \\
\text { explotador }\end{array}$ & \multicolumn{2}{|c|}{$\begin{array}{l}\text { Carece de empatía, cree merecer y espera favores especiales sin asumir } \\
\text { responsabilidades; se toma excesiva confianza y utiliza a los otros para } \\
\text { satisfacer sus deseos. }\end{array}$} \\
\hline \multirow{3}{*}{$\begin{array}{l}\text { Nivel } \\
\text { fenomenológico }\end{array}$} & $\begin{array}{l}\text { Cognitivamente } \\
\text { expansivo }\end{array}$ & \multicolumn{2}{|c|}{$\begin{array}{l}\text { Posee una imaginación desenfrenada y autoglorificantes fantasias de éxito, } \\
\text { belleza o amor; se ajusta mínimamente a la realidad. }\end{array}$} \\
\hline & $\begin{array}{l}\text { Autoimagen } \\
\text { admirable }\end{array}$ & \multicolumn{2}{|c|}{$\begin{array}{l}\text { Cree que es una persona de mérito, especial y única, que merece gran } \\
\text { admiración, se comporta de forma grandiosa y con gran confianza; tiene un } \\
\text { elevado concepto de sí mismo a pesar de ser visto por los demás como } \\
\text { egocéntrico, desconsiderado y arrogante. }\end{array}$} \\
\hline & $\begin{array}{l}\text { Representaciones } \\
\text { objetales artificiales }\end{array}$ & \multicolumn{2}{|c|}{$\begin{array}{l}\text { Representaciones internalizadas compuestas por recuerdos ilusorios y } \\
\text { cambiantes sobre relaciones pasadas; los impulsos y conflictos inaceptables son } \\
\text { rápidamente remodelados en cuanto surge la necesidad. }\end{array}$} \\
\hline \multirow[t]{2}{*}{ Nivel intrapsiquico } & $\begin{array}{l}\text { Mecanismo de } \\
\text { racionalización }\end{array}$ & \multirow{2}{*}{\multicolumn{2}{|c|}{$\begin{array}{l}\text { Se engaña a sí mismo y elabora razones plausibles para justificar st } \\
\text { egocentrismo y su comportamiento socialmente desconsiderado. } \\
\text { Las estructuras morfológicas tienden a ser débiles. Regulación marginal de los } \\
\text { impulsos, mínima canalización de las necesidades y creación de un mundo } \\
\text { interno en el que se descartan los conflictos: para justificar errores y reafirma } \\
\text { autoestima. }\end{array}$}} \\
\hline & $\begin{array}{l}\text { Organización } \\
\text { espúrea }\end{array}$ & & \\
\hline Nivel biofísico & $\begin{array}{l}\text { Estado de ánimo } \\
\text { despreocupado }\end{array}$ & \multicolumn{2}{|c|}{$\begin{array}{l}\text { Indiferencia, imperturbabilidad y fingida tranquilidad; parece friamente no } \\
\text { impresionable, excepto cuando se ve amenazada su confianza narcisista -lo que } \\
\text { le provoca ira, vergüenza o sentimiento de vacío-. }\end{array}$} \\
\hline \multicolumn{4}{|c|}{ Curso del tratamiento } \\
\hline \multicolumn{3}{|c|}{ Objetivos } & Técnicas \\
\hline \multicolumn{3}{|c|}{ Establecer una relación terapéutica } & $\begin{array}{l}\text { Brindar confianza y respeto. Cuidar las declaraciones que se hagan } \\
\text { para no promover tendencias narcisistas. Brindar interpretaciones } \\
\text { honestas en un tono de aceptación. }\end{array}$ \\
\hline \multirow{2}{*}{$\begin{array}{l}\text { Restablecimiento del } \\
\text { equilibrio entre } \\
\text { polaridades }\end{array}$} & \multicolumn{2}{|c|}{$\begin{array}{l}\text { Actividad-Pasividad: Estimular } \\
\text { la modificación activa. }\end{array}$} & $\begin{array}{l}\text { Técnica de resolución de problemas e interpersonales para mejorar las } \\
\text { interacciones y ayudar a ver el beneficio de no necesitar ser infalible y } \\
\text { considerar su parte de responsabilidad en las dificultades que se } \\
\text { presenten. }\end{array}$ \\
\hline & \multicolumn{2}{|c|}{$\begin{array}{l}\text { Si mismo-Otros: incrementar } \\
\text { el centrarse en los otros. }\end{array}$} & $\begin{array}{l}\text { Manifestar su déficit de empatía, resaltando los sentimientos de los } \\
\text { demás y señalando las situaciones de desconsideración y } \\
\text { explotación. Imitación e inversiones de papeles para imaginar cómo } \\
\text { se sienten los demás y desarrollar creencias nuevas. }\end{array}$ \\
\hline \multirow{4}{*}{$\begin{array}{l}\text { Modificar las } \\
\text { principales } \\
\text { disfunciones. }\end{array}$} & \multicolumn{2}{|c|}{$\begin{array}{l}\text { Moderar la autoimagen } \\
\text { admirable. }\end{array}$} & $\begin{array}{l}\text { Brindar una actitud terapéutica de que los errores son inevitables y } \\
\text { humanos para que evalúen su autovalia de forma realista. Utilizar la } \\
\text { autorrevelación para facilitar la introspección sobre el impacto } \\
\text { negativo de su conducta en los demás. }\end{array}$ \\
\hline & \multicolumn{2}{|c|}{$\begin{array}{l}\text { Desmantelar la explotación } \\
\text { interpersonal. }\end{array}$} & $\begin{array}{l}\text { Imitación y modelado que ayuden a extinguir el comportamiento } \\
\text { interpersonal explotador y produzcan situaciones interpersonales más } \\
\text { genuinas. }\end{array}$ \\
\hline & \multicolumn{2}{|c|}{$\begin{array}{l}\text { Controlar el comportamiento } \\
\text { arrogante. }\end{array}$} & $\begin{array}{l}\text { Inhibición comportamental y desensibilización sistemática para } \\
\text { extinguir la conducta arrogante y reemplazarla. }\end{array}$ \\
\hline & \multicolumn{2}{|c|}{$\begin{array}{l}\text { Disminuir las cogniciones } \\
\text { expansivas. }\end{array}$} & $\begin{array}{l}\text { Registro pensamientos y creencias desadaptativas para someterlos a } \\
\text { prueba y adquirir nuevas creencias funcionales. }\end{array}$ \\
\hline \multirow[t]{2}{*}{$\begin{array}{l}\text { Contrarrestar la } \\
\text { tendencia a la } \\
\text { perpetuación. }\end{array}$} & \multicolumn{2}{|c|}{$\begin{array}{l}\text { Anular las ilusiones } \\
\text { insustanciales, adquiriendo } \\
\text { disciplina y autocontrol. }\end{array}$} & $\begin{array}{l}\text { Brindar valoraciones realistas de su 'sí mismo' para que vea la } \\
\text { perfección como insostenible y utilice la autodisciplina para conseguir } \\
\text { objetivos y controlar el impulso de escaparse hacia ilusiones } \\
\text { improductivas. }\end{array}$ \\
\hline & \multicolumn{2}{|c|}{$\begin{array}{c}\text { Reducir las } \\
\text { desconsideraciones sociales. }\end{array}$} & $\begin{array}{l}\text { Comprensión empática para sensibilizarlo de los sentimientos de los } \\
\text { demás y motivarlo a adoptar conductas cooperativas. }\end{array}$ \\
\hline
\end{tabular}




\section{Trastorno Antisocial de la Personalidad}

\begin{tabular}{|c|c|c|c|}
\hline \multirow{2}{*}{$\begin{array}{l}\text { Caracteristicas } \\
\text { de la polaridad }\end{array}$} & Sí mismo-Otros & \multicolumn{2}{|c|}{$\begin{array}{l}\text { Se vuelven a sí mismos, cuidándose contra los perjuicios, asegurándose } \\
\text { la obtención de gratificaciones. Los demás son vistos como objetos. }\end{array}$} \\
\hline & $\begin{array}{l}\text { Actividad- } \\
\text { Pasividad }\end{array}$ & \multicolumn{2}{|c|}{$\begin{array}{l}\text { Buscan compensar privaciones pasadas y hacen lo que sea necesario } \\
\text { para obtenerlas.. }\end{array}$} \\
\hline \multicolumn{2}{|c|}{ Tendencias a la perpetuación } & \multicolumn{2}{|c|}{$\begin{array}{l}\text { Aprendieron a anticipar y reaccionar a un entorno indiferente y poco } \\
\text { fiable con una autonomía defensiva, suspicaz y hostil. En su esfuerzo } \\
\text { por no pasar por alto ningún signo de amenaza, malinterpretan } \\
\text { acontecimientos causales como pruebas de los impulsos desleales de } \\
\text { los demás. Ignoran los signos objetivos de benevolencia por parte de } \\
\text { los demás y los malinterpretan de manera suspicaz. }\end{array}$} \\
\hline \multicolumn{4}{|c|}{ Ámbitos personológicos } \\
\hline \multirow{2}{*}{$\begin{array}{l}\text { Nivel } \\
\text { comportamental }\end{array}$} & $\begin{array}{l}\text { Expresivamente } \\
\text { impulsivo }\end{array}$ & \multicolumn{2}{|c|}{$\begin{array}{l}\text { Impetuoso e incontrolable, actúa espontánea y precipitadamente; } \\
\text { imprudente, incauto, incapaz de planear sus actos o considerar otras } \\
\text { alternativas sin prever consecuencias. }\end{array}$} \\
\hline & $\begin{array}{l}\text { Interpersonalmente } \\
\text { irresponsable }\end{array}$ & \multicolumn{2}{|c|}{$\begin{array}{l}\text { Persona de poco fiar, es incapaz o se niega a hacerse cargo de sus } \\
\text { responsabilidades; se inmiscuye en la vida de los demás y viola sus } \\
\text { derechos; transgrede normas sociales. }\end{array}$} \\
\hline \multirow{3}{*}{$\begin{array}{c}\text { Nivel } \\
\text { fenomenológico }\end{array}$} & $\begin{array}{l}\text { Cognitivamente } \\
\text { desviado }\end{array}$ & \multicolumn{2}{|c|}{$\begin{array}{l}\text { Construye los acontecimientos y las relaciones según creencias y } \\
\text { valores morales que socialmente son poco ortodoxos; no acepta las } \\
\text { normas sociales y menosprecia los valores convencionales. }\end{array}$} \\
\hline & $\begin{array}{c}\text { Autoimagen } \\
\text { autónoma }\end{array}$ & \multicolumn{2}{|c|}{$\begin{array}{l}\text { Se ve a si mismo como si las restricciones sociales y las limitaciones de } \\
\text { las lealtades personales no le afectasen; valora la imagen y el sentido } \\
\text { de libertad, y desconfia de personas, lugares o rutinas. }\end{array}$} \\
\hline & $\begin{array}{l}\text { Representaciones } \\
\text { objetales } \\
\text { degradadas }\end{array}$ & \multicolumn{2}{|c|}{$\begin{array}{l}\text { Las representaciones internalizadas se componen de relaciones } \\
\text { interpersonales degradadas y corruptas que reflejan actitudes e } \\
\text { impulsos negativos que transgreden los ideales y costumbres } \\
\text { culturales, devalúan los sentimientos personales y codician beneficios } \\
\text { materiales. }\end{array}$} \\
\hline $\begin{array}{l}\text { Nivel } \\
\text { intrapsíquico }\end{array}$ & $\begin{array}{l}\text { Mecanismo de } \\
\text { impulsividad- } \\
\text { actuación }\end{array}$ & \multicolumn{2}{|c|}{$\begin{array}{l}\text { Rara vez limita las tensiones internas que pueden incrementarse } \\
\text { posponiendo la expresión de pensamientos ofensivos y acciones } \\
\text { malevolentes. Los impulsos socialmente reprobables se descargan sin } \\
\text { culpa. }\end{array}$} \\
\hline & $\begin{array}{l}\text { Organización } \\
\text { indisciplinada }\end{array}$ & \multicolumn{2}{|c|}{$\begin{array}{l}\text { La estructura morfológica interna que contiene los impulsos es escasa } \\
\text { al igual que el control de las energias y actitudes refractarias, lo que } \\
\text { produce una fácil transgresión de los controles, bajos umbrales para la } \\
\text { descarga hostil o erótica, poca sublimación, gran autoexpresión } \\
\text { intolerancia a la frustración. }\end{array}$} \\
\hline Nivel biofísico & $\begin{array}{l}\text { Estado de ánimo } \\
\text { insensible }\end{array}$ & \multicolumn{2}{|c|}{$\begin{array}{l}\text { Duro, irritable y agresivo, déficit de caridad social y compasión; falta de } \\
\text { civismo y desinterés en su seguridad y la de los demás. }\end{array}$} \\
\hline \multicolumn{4}{|c|}{ Curso del tratamiento } \\
\hline \multicolumn{3}{|c|}{ Objetivos } & Técnicas \\
\hline Establecer una & la relación terapéuti & & $\begin{array}{l}\text { Comentar la vulnerabilidad de la terapia debido a sus } \\
\text { manipulaciones. Reducirr la posibilidad de que se sienta } \\
\text { desafiado y adopte una actitud oposicionista. Poseer una } \\
\text { objetividad fiable pero no infalible, un estilo interpersonal } \\
\text { relajado, un sentido claro de los limites personales, un gran } \\
\text { sentido del humor y seguridad de sí mismo. }\end{array}$ \\
\hline \multirow{2}{*}{$\begin{array}{l}\text { Restablecimiento } \\
\text { del equilibrio entre } \\
\text { polaridades }\end{array}$} & \multicolumn{2}{|c|}{$\begin{array}{l}\text { Sí mismo-Otros: centrar } \\
\text { la atención en las } \\
\text { necesidades de los otros. }\end{array}$} & $\begin{array}{l}\text { Utilizar programa de terapia salvaje que proporciona } \\
\text { oportunidades para la interdependencia, la necesidad de } \\
\text { cooperación y la deferencia. }\end{array}$ \\
\hline & \multicolumn{2}{|c|}{$\begin{array}{l}\text { Actividad-Pasividad: } \\
\text { reducir las actuaciones } \\
\text { impulsivas. }\end{array}$} & $\begin{array}{l}\text { Crecimiento cognitivo para ayudarlo pasar de las operaciones } \\
\text { concretas y las conductas impulsivas al pensamiento } \\
\text { abstracto que posibilite la amabilidad interpersonal. }\end{array}$ \\
\hline \multirow{3}{*}{$\begin{array}{l}\text { Contrarrestar la } \\
\text { tendencia a la } \\
\text { perpetuación. }\end{array}$} & \multicolumn{2}{|c|}{$\begin{array}{l}\text { Reducir la tendencia } \\
\text { hacia la provocación. }\end{array}$} & Técnicas cognitivas que alteren creencias de vulnerabilidad. \\
\hline & \multicolumn{2}{|c|}{$\begin{array}{l}\text { Ver el afecto y la } \\
\text { cooperación como algo } \\
\text { positivo. }\end{array}$} & $\begin{array}{l}\text { Terapia de grupo para aprender técnicas de resolución de } \\
\text { problemas, ayudando a los demás en situaciones parecidas, y } \\
\text { los ejemplos de otros miembros pueden servir de modelo. }\end{array}$ \\
\hline & \multicolumn{2}{|c|}{$\begin{array}{l}\text { Cambiar las expectativas } \\
\text { de degradación }\end{array}$} & $\begin{array}{l}\text { Técnicas interpersonales y terapia familiar para alterar la } \\
\text { creencia de que los demás van a abusar de él. }\end{array}$ \\
\hline \multirow{3}{*}{$\begin{array}{l}\text { Modificar las } \\
\text { principales } \\
\text { disfunciones }\end{array}$} & \multicolumn{2}{|c|}{$\begin{array}{l}\text { Compensar el descuido y } \\
\text { el comportamiento poco } \\
\text { previsor. }\end{array}$} & $\begin{array}{l}\text { Examinar las posibilidades y consecuencias antes de elaborar } \\
\text { una conclusión sobre cuál es la conducta más apropiada. }\end{array}$ \\
\hline & \multicolumn{2}{|c|}{$\begin{array}{l}\text { Motivar el } \\
\text { comportamiento } \\
\text { interpersonal } \\
\text { responsable. }\end{array}$} & $\begin{array}{l}\text { Enseñarle a considerar los efectos de sus actos y ver las } \\
\text { ventajas de abandonar las conductas impulsivas y actuar de } \\
\text { un modo prosocial y concordante con los deseos de los otros. }\end{array}$ \\
\hline & \multicolumn{2}{|c|}{$\begin{array}{l}\text { Alterar las cogniciones } \\
\text { desviadas. }\end{array}$} & $\begin{array}{l}\text { Reestructuración cognitiva. No se apunta a un cambio moral } \\
\text { ya que es poco probable. }\end{array}$ \\
\hline
\end{tabular}




\begin{tabular}{|c|c|c|c|}
\hline \multicolumn{4}{|c|}{ Trastorno Sádico de la Personalidad } \\
\hline \multirow{2}{*}{$\begin{array}{l}\text { Características de } \\
\text { la polaridad }\end{array}$} & Placer-Dolor & \multicolumn{2}{|r|}{$\begin{array}{l}\text { La principal forma de relacionarse con los demás es infligiendo dolor. } \\
\text { La humillación y victimización de los otros les permite descargar su } \\
\text { ira y su dolor psíquico. Se involucran en conductas que les permiten } \\
\text { controlar y expresar dominio sobre los demás. }\end{array}$} \\
\hline & Sí mismo-Otros & \multicolumn{2}{|r|}{$\begin{array}{l}\text { Se ven a si mismos como personas fuertes y competitivas y } \\
\text { consideran a los otros como meros objetos impersonales sin valor, } \\
\text { que no merecen respeto alguno. }\end{array}$} \\
\hline \multicolumn{2}{|c|}{ Tendencias a la perpetuación } & \multicolumn{2}{|c|}{$\begin{array}{l}\text { Aprendieron a atender estímulos de su entorno que apoyan sus } \\
\text { creencias distorsionadas. La mayoría de sus experiencias actuales } \\
\text { se tiñen de maldad y los motivos benevolentes de los otros se } \\
\text { malinterpretan. También aprendieron a ser precavidos y desconfiar } \\
\text { de los demás. Evitan expresar sentimientos y responder con } \\
\text { empatia para protegerse de la humillación y el abuso que anticipan. }\end{array}$} \\
\hline \multicolumn{4}{|c|}{ Ámbitos personológicos } \\
\hline \multirow{2}{*}{$\begin{array}{l}\text { Nivel } \\
\text { comportamental }\end{array}$} & $\begin{array}{l}\text { Expresivamente } \\
\text { precipitado }\end{array}$ & \multicolumn{2}{|r|}{$\begin{array}{l}\text { Reaccionan con explosiones emocionales bruscas, de naturaleza } \\
\text { inesperada e injustificada; reacciona de modo imprudente, le atraen } \\
\text { los desafios, el riesgo y el peligro, y parece insensible al dolor y al } \\
\text { castigo }\end{array}$} \\
\hline & $\begin{array}{l}\text { Interpersonalmente } \\
\text { áspero }\end{array}$ & \multicolumn{2}{|r|}{$\begin{array}{l}\text { Manifiesta satisfacción al intimidar, coaccionar y humillar a los } \\
\text { demás; se expresa verbalmente de forma abusiva, hace } \\
\text { comentarios socialmente humillantes y tiene un comportamiento } \\
\text { físico rudo. }\end{array}$} \\
\hline \multirow{3}{*}{$\begin{array}{c}\text { Nivel } \\
\text { fenomenológico }\end{array}$} & $\begin{array}{c}\text { Cognitivamente } \\
\text { dogmático }\end{array}$ & \multicolumn{2}{|r|}{ Rígido y cerrado, autoritario, socialmente intolerante y prejuicioso. } \\
\hline & $\begin{array}{l}\text { Autoimagen } \\
\text { combativa }\end{array}$ & \multicolumn{2}{|r|}{$\begin{array}{l}\text { Se enorgullece de verse a sí mismo como una persona competitiva, } \\
\text { enérgica y obstinada; valora de sí mismo el tener una imagen } \\
\text { belicosa, dominante y orientada al poder. }\end{array}$} \\
\hline & $\begin{array}{l}\text { Representaciones } \\
\text { objetales } \\
\text { perniciosas }\end{array}$ & \multicolumn{2}{|r|}{$\begin{array}{l}\text { Las representaciones internalizadas del pasado se distinguen por } \\
\text { relaciones que generaron fuertes energias agresivas y actitudes } \\
\text { malvadas, como falta de recuerdos sentimentales, afectos tiernos, } \\
\text { conflictos internos y sentimientos de culpa o vergüenza. }\end{array}$} \\
\hline & $\begin{array}{l}\text { Mecanismo de } \\
\text { aislamiento }\end{array}$ & \multirow{2}{*}{\multicolumn{2}{|c|}{$\begin{array}{l}\text { No parece tener conciencia del impacto de sus actos destructivos, ve } \\
\text { los objetos de los que abusa como algo impersonal, sin ningún valor. } \\
\text { Su estructura morfológica es coherente y compuesta por controles, } \\
\text { defensas y canales de expresión adecuados; sin embargo se } \\
\text { amenazada por poderosas energías de naturaleza agresiva y sexual } \\
\text { que sobrepasan los controles, produciendo explosiones bruscas. }\end{array}$}} \\
\hline $\begin{array}{l}\text { Nivel } \\
\text { intrapsiquico }\end{array}$ & $\begin{array}{l}\text { Organización } \\
\text { eruptiva }\end{array}$ & & \\
\hline Nivel biofísico & $\begin{array}{l}\text { Estado de ánimo } \\
\text { hostil }\end{array}$ & \multicolumn{2}{|c|}{$\begin{array}{l}\text { Temperamento excitable e irritable que aflora rápidamente y se } \\
\text { transforma en discusiones y; desea hacer daño y perseguir a los } \\
\text { demás. }\end{array}$} \\
\hline \multicolumn{4}{|c|}{ Curso del tratamiento } \\
\hline \multicolumn{3}{|c|}{ Objetivos } & Téc \\
\hline \multirow{2}{*}{$\begin{array}{l}\text { Establecer una } \\
\text { relación } \\
\text { terapéutica }\end{array}$} & \multicolumn{2}{|c|}{$\begin{array}{l}\text { Brindar sentimientos que } \\
\text { permitan establecer una } \\
\text { alianza. }\end{array}$} & $\begin{array}{l}\text { Brindarle una sensación de confianza, mirando los problemas } \\
\text { a través de sus ojos. }\end{array}$ \\
\hline & \multicolumn{2}{|c|}{$\begin{array}{l}\text { Establecer límites claros en } \\
\text { la relación. }\end{array}$} & $\begin{array}{l}\text { Evitar entrar en una lucha de poderes. Mantener un equilibrio } \\
\text { entre la firmeza profesional y la autoridad, mezclado con } \\
\text { tolerancia hacia los rasgos menos atractivos del paciente. }\end{array}$ \\
\hline \multirow{2}{*}{$\begin{array}{l}\text { Restablecimiento } \\
\text { del equilibrio } \\
\text { entre polaridades }\end{array}$} & \multicolumn{2}{|c|}{$\begin{array}{l}\text { Placer-Dolor: Invertir la } \\
\text { discordancia existente en } \\
\text { la polaridad. }\end{array}$} & $\begin{array}{l}\text { Proporcionar experiencias y situaciones que promuevan la } \\
\text { colaboración. Ayudar a reconocer las recompensas en las } \\
\text { relaciones interpersonales, evitando elementos destructivos. }\end{array}$ \\
\hline & \multicolumn{2}{|c|}{$\begin{array}{l}\text { Si mismo-Otros: reducir la } \\
\text { tendencia activa a } \\
\text { centrarse en sí mismo. }\end{array}$} & $\begin{array}{l}\text { Aumentar su capacidad de empatizar con los demás y } \\
\text { animarlo a implicarse en actos que preserven la vida en vez } \\
\text { de destruirla. }\end{array}$ \\
\hline \multirow{2}{*}{$\begin{array}{l}\text { Contrarrestar la } \\
\text { tendencia a la } \\
\text { perpetuación }\end{array}$} & \multicolumn{2}{|c|}{$\begin{array}{l}\text { Controlar los } \\
\text { comportamientos } \\
\text { desadaptativos. }\end{array}$} & $\begin{array}{l}\text { Técnicas cognitivas que aumenten las percepciones } \\
\text { adecuadas y reduzcan distorsiones cognitivas. Reevaluar las } \\
\text { consecuencias de su comportamiento agresivo y la manera } \\
\text { en que le impacta negativamente en su vida. }\end{array}$ \\
\hline & \multicolumn{2}{|c|}{$\begin{array}{l}\text { Modificar la imagen de } \\
\text { extrema dureza que } \\
\text { presenta el paciente. }\end{array}$} & $\begin{array}{l}\text { Implicarlo en comportamientos prosociales para que obtenga } \\
\text { recompensas adicionales por estas conductas más afiliativas. } \\
\text { Ayudar al paciente a manifestar su lado más sensible y } \\
\text { emocional para implicarse en actividades sin atacar a los } \\
\text { demás. }\end{array}$ \\
\hline \multirow{3}{*}{$\begin{array}{l}\text { Modificación de } \\
\text { las disfunciones } \\
\text { de ámbito }\end{array}$} & \multicolumn{2}{|c|}{$\begin{array}{l}\text { Moderar el estado de } \\
\quad \text { ánimo hostil. }\end{array}$} & $\begin{array}{l}\text { Técnicas de autocontrol para que aprenda a controlar su ira. } \\
\text { Desensibilización sistemática mediante una jerarquia de } \\
\text { situaciones que provocan ira. Entrenamiento en habilidades } \\
\text { sociales para lograr mayor asertividad. }\end{array}$ \\
\hline & \multicolumn{2}{|c|}{$\begin{array}{l}\text { Reducir el comportamiento } \\
\text { interpersonal áspero. }\end{array}$} & $\begin{array}{l}\text { Enseñarle estilos de interacción alternativos para elevar su } \\
\text { autoeficacia y sublimar su agresividad. }\end{array}$ \\
\hline & \multicolumn{2}{|c|}{$\begin{array}{l}\text { Controlar los } \\
\text { comportamientos } \\
\text { impulsivos. }\end{array}$} & $\begin{array}{l}\text { Técnicas de autocontrol para tener mayor control cuando los } \\
\text { impulsos pueden sobrepasarlo. }\end{array}$ \\
\hline
\end{tabular}




\begin{tabular}{|c|c|c|}
\hline \multicolumn{3}{|c|}{ Trastorno Compulsivo de la Personalidad } \\
\hline \multirow{2}{*}{$\begin{array}{l}\text { Características } \\
\text { de la polaridad }\end{array}$} & Sí mismo-Otros & $\begin{array}{l}\text { Actúan creyendo que sus deseos están equivocados y que expresarlos } \\
\text { conlleva la intimidación y el castigo. Reprimen la hostilidad por los } \\
\text { deseos que pueden entrar en conflicto con los de otros poderosos. }\end{array}$ \\
\hline & $\begin{array}{l}\text { Actividad- } \\
\text { Pasividad }\end{array}$ & $\begin{array}{l}\text { Manifiestan su ambivalencia de manera pasiva. Muchas de sus } \\
\text { producciones son respuesta a las demandas y expectativas de otros, } \\
\text { reales o imaginadas. Rara vez tienen iniciativas para cambiar sus } \\
\text { circunstancias debido a su excesivo temor a cometer un error. }\end{array}$ \\
\hline $\begin{array}{l}\text { Tendencias a la } \\
\text { perpetuación }\end{array}$ & \multirow{2}{*}{\multicolumn{2}{|c|}{$\begin{array}{l}\text { La autocrítica previene cualquier desviación de las reglas establecidas. Al hacerse } \\
\text { reprimendas internas, demuestran sus buenas intenciones y obvian la desaprobación de } \\
\text { fuentes externas. Evitan situaciones nuevas o ambiguas volviéndose intensamente rígidos. } \\
\text { Los procesos de pensamiento se limitan al ámbito de lo probado y lo aceptable para que no } \\
\text { sentir culpa. Se vuelven extraordinariamente sensibles a las normas, reglas, leyes y } \\
\text { convenciones, ya que estas le ayudan a controlar los impulsos inaceptables, guiar el } \\
\text { pensamiento, dictar su comportamiento y asegurar que nunca se les reprochará nada. } \\
\text { Ámbitos personológicos }\end{array}$}} \\
\hline & & \\
\hline \multirow{2}{*}{$\begin{array}{l}\text { Nivel } \\
\text { Comportamental }\end{array}$} & $\begin{array}{l}\text { Expresivamente } \\
\text { disciplinado }\end{array}$ & $\begin{array}{l}\text { Mantienen una vida regulada, muy estructurada y estrictamente } \\
\text { organizada; el perfeccionismo interfiere al tomar decisiones y finalizar } \\
\text { tareas. }\end{array}$ \\
\hline & $\begin{array}{l}\text { Interpersonalmente } \\
\text { respetuoso }\end{array}$ & $\begin{array}{l}\text { Respetan de modo inusual los cánones sociales; son escrupulosos y } \\
\text { tercos en temas de moral y ética; prefieren relaciones educadas, } \\
\text { formales y correctas. }\end{array}$ \\
\hline \multirow{3}{*}{$\begin{array}{l}\text { Nivel } \\
\text { Fenomenológico }\end{array}$} & $\begin{array}{l}\text { Cognitivamente } \\
\text { constreñido }\end{array}$ & $\begin{array}{l}\text { Construyen el mundo en términos de reglas, normas, programaciones } \\
\text { de tiempo y jerarquías; rígidos, obstinados e indecisos y suelen } \\
\text { alterarse frente a ideas y hábitos nuevos. }\end{array}$ \\
\hline & $\begin{array}{l}\text { Autoimagen } \\
\text { escrupulosa }\end{array}$ & $\begin{array}{l}\text { Se consideran entregados al trabajo, dignos de confianza, meticulosos } \\
\text { y eficientes, excluyen el ocio; temen el error y valoran la disciplina } \\
\text { perfección, prudencia y lealtad. }\end{array}$ \\
\hline & $\begin{array}{l}\text { Representaciones } \\
\text { objetales ocultas }\end{array}$ & $\begin{array}{l}\text { Sólo permiten la expresión comportamental o el conocimiento conciente } \\
\text { de representaciones internalizadas, siempre que estén aprobadas } \\
\text { socialmente; sus acciones y recuerdos están muy regulados, alejan } \\
\text { impulsos prohibidos y niegan conflictos personales y sociales. }\end{array}$ \\
\hline $\begin{array}{c}\text { Nivel } \\
\text { Intransín }\end{array}$ & $\begin{array}{l}\text { Mecanismo de } \\
\text { formación reactiva }\end{array}$ & $\begin{array}{l}\text { Repetidos pensamientos positivos y comportamientos socialmente } \\
\text { aceptables; sensatos y maduros al afrontar situaciones que generan } \\
\text { ira o consternación bajo un control estricto. }\end{array}$ \\
\hline & zación & $\begin{array}{l}\text { Las estructuras morfológicas están organizadas en un sistema donde } \\
\text { impulsos, memoria y cognición están separados, con poca interacción. }\end{array}$ \\
\hline Nivel Biofísico & $\begin{array}{l}\text { Estado de ánimo } \\
\text { solemne }\end{array}$ & $\begin{array}{l}\text { Están tensos, sin alegría y sombríos; reprimen los sentimientos cálidos } \\
\text { y mantienen casi todas las emociones bajo un control riguroso. }\end{array}$ \\
\hline \multicolumn{3}{|c|}{ Curso del tratamiento } \\
\hline \multicolumn{2}{|c|}{ Objetivos } & \\
\hline \multicolumn{2}{|c|}{ Establecer una relación terapéutica } & $\begin{array}{l}\text { Comunicación espontánea al inicio. Exponer de manera lógica } \\
\text { algunas de sus conductas y causas para fomentar su confianza. }\end{array}$ \\
\hline \multirow[t]{2}{*}{$\begin{array}{l}\text { Restablecimiento } \\
\text { del equilibrio } \\
\text { entre } \\
\text { polaridades }\end{array}$} & $\begin{array}{l}\text { Sí mismo- Otros: } \\
\text { Establecer una identidad } \\
\text { que diferencie sus } \\
\text { propios sentimientos y } \\
\text { deseos de lo que } \\
\text { percibe que se espera } \\
\text { de él. }\end{array}$ & $\begin{array}{l}\text { Enseñar el modelo cognitivo y establecer objetivos relacionados } \\
\text { con sus problemas. Registro de pensamientos que interfieren con } \\
\text { los objetivos para ponerlos a prueba y refutarlos. Elaborar la ira } \\
\text { reprimida y el temor a la desaprobación. Equilibrar sus esfuerzos } \\
\text { para asegurar recompensas entre ambas alternativas. }\end{array}$ \\
\hline & $\begin{array}{l}\text { Actividad - Pasividad: } \\
\text { modificar la reacción } \\
\text { (pasiva) al entorno. }\end{array}$ & $\begin{array}{l}\text { Reconocer y considerar como válidas sus expectativas y la de los } \\
\text { demás. Establecer un estilo más activo de afrontamiento y } \\
\text { buscar objetivos propios. }\end{array}$ \\
\hline \multirow{3}{*}{$\begin{array}{l}\text { Contrarrestar la } \\
\text { tendencia a la } \\
\text { perpetuación }\end{array}$} & $\begin{array}{l}\text { Aflojar la intensa rigidez } \\
\text { y preocupación por las } \\
\text { reglas. }\end{array}$ & $\begin{array}{l}\text { Desensibilización sistemática de los estímulos que provocan } \\
\text { ansiedad. Explorar diferentes maneras de abordar los estímulos } \\
\text { de su entorno y beneficiarse de un aprendizaje adaptativo. }\end{array}$ \\
\hline & $\begin{array}{l}\text { Reducir la preocupación } \\
\text { por las reglas. }\end{array}$ & $\begin{array}{l}\text { Continúo de independencia/dependencia, para que vea que los } \\
\text { valores y las relaciones en blanco y negro son fenómenos } \\
\text { multidimensionales. Experimentar comportamientos más } \\
\text { espontáneos. }\end{array}$ \\
\hline & $\begin{array}{l}\text { Moderar la culpa y la } \\
\text { autocritica. }\end{array}$ & $\begin{array}{l}\text { Reconocer emociones reprimidas y mostrar empatía y compasión. } \\
\text { Establecer normas más realistas para disipar la ansiedad y ver el } \\
\text { perfeccionismo y el control total como metas irreales. }\end{array}$ \\
\hline \multirow{3}{*}{$\begin{array}{l}\text { Modificación de } \\
\text { las disfunciones } \\
\text { de ámbito }\end{array}$} & $\begin{array}{l}\text { Moderar el estilo } \\
\text { cognitivo restringido. }\end{array}$ & $\begin{array}{l}\text { Enfoque cognitivo que confronte supuestos disfuncionales. } \\
\text { Promover un estilo cognitivo más fluido y creativo. }\end{array}$ \\
\hline & $\begin{array}{c}\text { Ajustar los } \\
\text { comportamientos } \\
\text { perfeccionistas. }\end{array}$ & $\begin{array}{l}\text { Regular el catastrofismo ante la posibilidad de cometer errores. } \\
\text { Experimentar conductas alternativas ante las situaciones. } \\
\text { Realizar actividades orientadas a las relaciones y otras } \\
\text { gratificaciones. }\end{array}$ \\
\hline & $\begin{array}{l}\text { Probar interacciones } \\
\text { espontáneas y } \\
\text { gratificantes. }\end{array}$ & $\begin{array}{l}\text { Utilizar enfoques de pareja y sexual como auxiliares de la terapia } \\
\text { individual. }\end{array}$ \\
\hline
\end{tabular}




\section{Trastorno Negativista de la Personalidad}

\begin{tabular}{|c|c|c|c|}
\hline \multicolumn{4}{|c|}{ 10 Negativista de la Personalidad } \\
\hline \multirow{2}{*}{$\begin{array}{l}\text { Características de } \\
\text { la polaridad }\end{array}$} & Sí mismo-Otros & \multicolumn{2}{|r|}{$\begin{array}{l}\text { Oscilan entre someterse y la gratificarsus necesidades. Intentan obtener cuidados } \\
\text { de los demás sin evaluar sus propias capacidades. }\end{array}$} \\
\hline & Actividad-Pasividad & \multicolumn{2}{|r|}{$\begin{array}{l}\text { Modo activo de adaptación en el que se muestra cambiante e hiperreactivo. Para } \\
\text { evitar el malestar, ponen marcha conductas que no sólo molestan a los demás, } \\
\text { sino que también les perjudican a ellos mismos. }\end{array}$} \\
\hline \multicolumn{2}{|c|}{ Tendencias a la perpetuación } & \multirow{2}{*}{\multicolumn{2}{|c|}{$\begin{array}{l}\text { Las inconsistencias a las que fueron sometidos durante su infancia reforzaron la } \\
\text { creencia de que las decepciones son inevitables. Al realizar este tipo de } \\
\text { anticipaciones, se retiran prematuramente de experiencias potencialmente } \\
\text { gratificantes, se descentran y varian sus objetivos, lo que sólo sirve para repetir el } \\
\text { mismo ciclo disfuncional. } \\
\text { Ámbitos personológicos }\end{array}$}} \\
\hline & & \\
\hline \multirow{2}{*}{$\begin{array}{l}\text { Nivel } \\
\text { Comportamental }\end{array}$} & $\begin{array}{l}\text { Expresivamente } \\
\text { resentido }\end{array}$ & \multicolumn{2}{|r|}{$\begin{array}{l}\text { Se resiste a satisfacer las expectativas de los demás; posponedor, ineficaz y } \\
\text { obstinado, conductas de oposición y fastidio; se gratifica al desmoralizar y } \\
\text { socavar el bienestar y las aspiraciones ajenos. }\end{array}$} \\
\hline & $\begin{array}{l}\text { Interpersonalmente } \\
\text { no cooperador }\end{array}$ & \multicolumn{2}{|r|}{$\begin{array}{l}\text { Asume papeles conflictivos y variables en las relaciones; conjuga envidia y rabia } \\
\text { con los más afortunados que él; obstructivo e intolerante. }\end{array}$} \\
\hline \multirow{3}{*}{$\begin{array}{c}\text { Nivel } \\
\text { Fenomenológico }\end{array}$} & $\begin{array}{l}\text { Cognitivamente } \\
\text { escéptico }\end{array}$ & \multicolumn{2}{|r|}{$\begin{array}{l}\text { Es cínico, dubitativo y desconfiado, evalúa posibilidades futuras con pesimismo, } \\
\text { ira y ansia; se queja de la vida y hace comentarios dañosos sobre quienes tienen } \\
\text { mejor fortuna que él. }\end{array}$} \\
\hline & $\begin{array}{l}\text { Autoimagen } \\
\text { descontenta }\end{array}$ & \multicolumn{2}{|r|}{$\begin{array}{l}\text { Se ve como alguien incomprendido, sin suerte, despreciado y devaluado por otros; } \\
\text { reconoce sentirse amargado, descontento y desilusionado. }\end{array}$} \\
\hline & $\begin{array}{l}\text { Representaciones } \\
\text { objetales vacilantes }\end{array}$ & \multicolumn{2}{|r|}{$\begin{array}{l}\text { Las representaciones internalizadas del pasado comprenden relaciones } \\
\text { desequilibradas que producen sentimientos contradictorios, tendencias } \\
\text { conflictivas y recuerdos incompatibles impulsados por la intención de devaluar las } \\
\text { consecuciones y el bienestar de los demás, sin parecerlo. }\end{array}$} \\
\hline \multirow{2}{*}{$\begin{array}{c}\text { Nivel } \\
\text { Intrapsíquico }\end{array}$} & $\begin{array}{l}\text { Mecanismo de } \\
\text { desplazamiento }\end{array}$ & \multicolumn{2}{|r|}{$\begin{array}{l}\text { Descarga su ira y otras emociones negativas de forma precipitada } \\
\text { desplazándolas desde su verdadero instigador hacia otras situaciones o } \\
\text { personas; desahoga su desaprobación de forma pasiva o sustitutiva. }\end{array}$} \\
\hline & $\begin{array}{l}\text { Organización } \\
\text { divergente }\end{array}$ & \multicolumn{2}{|r|}{$\begin{array}{l}\text { Las estructuras morfológicas está tan divididas que las estrategias defensivas y de } \\
\text { afrontamiento se dirigen hacia objetivos incompatibles, no resuelve los principales } \\
\text { conflictos y hace imposible la cohesión. }\end{array}$} \\
\hline Nivel Biofísico & $\begin{array}{l}\text { Estado de ánimo } \\
\quad \text { irritable }\end{array}$ & \multicolumn{2}{|r|}{$\begin{array}{l}\text { Alterna entre susceptibilidad, irritabilidad, malhumor y aislamiento melancólico; } \\
\text { petulante e impaciente, desprecia las figuras de autoridad, por quienes se siente } \\
\text { molesto o frustrado. }\end{array}$} \\
\hline \multicolumn{4}{|c|}{ Curso del tratamiento } \\
\hline \multicolumn{3}{|c|}{ Objetivos } & Técnicas \\
\hline \multirow{2}{*}{$\begin{array}{l}\text { Establecer una } \\
\text { relación terapéutica } \\
\text { colaborativa }\end{array}$} & \multicolumn{2}{|c|}{$\begin{array}{l}\text { Comprometerlo con la } \\
\text { terapia brindándole cierto } \\
\text { control. }\end{array}$} & $\begin{array}{l}\text { Proponerle tareas afiliativas, reforzando la autonomía que desea. No } \\
\text { desafiar directamente la pertinencia de sus creencias disfuncionales. }\end{array}$ \\
\hline & \multicolumn{2}{|c|}{$\begin{array}{l}\text { Reducir la ambivalencia } \\
\text { manejando la } \\
\text { confrontación. }\end{array}$} & $\begin{array}{l}\text { Establecer contratos comportamentales concisos y a corto plazo para } \\
\text { facilitar el cumplimiento de prescripciones. Establecer reglas estrictas, } \\
\text { sesiones estructuradas y justificar cada intervención. }\end{array}$ \\
\hline \multirow[t]{2}{*}{$\begin{array}{l}\text { Restablecimiento del } \\
\text { equilibrio entre } \\
\text { polaridades }\end{array}$} & \multicolumn{2}{|c|}{$\begin{array}{l}\text { Disminuir el conflicto de la } \\
\text { polaridad Sí mismo- } \\
\text { Otros. }\end{array}$} & $\begin{array}{l}\text { Adoptar mecanismos de afrontamiento que le permitan moverse desde la } \\
\text { consecución sin culpa de sus deseos a la orientación hacia los demás sin } \\
\text { resentimiento. }\end{array}$ \\
\hline & \multicolumn{2}{|c|}{$\begin{array}{l}\text { Atenuar el desequilibrio } \\
\text { de la polaridad Actividad } \\
\text { - Pasividad. }\end{array}$} & $\begin{array}{l}\text { Adoptar una posición más pasiva en las situaciones ambiguas para explorar } \\
\text { distintas opciones y obtener mayor evidencia y evitar la reacción impulsiva } \\
\text { y caprichosa. }\end{array}$ \\
\hline \multirow{3}{*}{$\begin{array}{l}\text { Contrarrestar la } \\
\text { tendencia a la } \\
\text { perpetuación }\end{array}$} & \multicolumn{2}{|c|}{$\begin{array}{l}\text { Reducir la previsión de las } \\
\text { decepciones. }\end{array}$} & $\begin{array}{l}\text { Técnica de autocontrol para que adquiera control en sus impulsos. } \\
\text { Estimularlo a comprometerse con un determinado plan de acción y seguirlo } \\
\text { para no retirarse rápido de experiencias gratificantes. }\end{array}$ \\
\hline & \multicolumn{2}{|c|}{$\begin{array}{l}\text { Moderar los } \\
\text { comportamientos } \\
\text { impredecibles. }\end{array}$} & $\begin{array}{l}\text { Entrenamiento en asertividad para que aprenda a expresar su descontento } \\
\text { y sus emociones adecuadamente, lo que dará lugar a relaciones más } \\
\text { maduras y evitará los comportamientos cambiantes y oposicionistas. }\end{array}$ \\
\hline & \multicolumn{2}{|c|}{$\begin{array}{l}\text { Prevenir la formación de } \\
\text { desilusión. }\end{array}$} & $\begin{array}{l}\text { Utilizar la relación diádica como modelo estable de relación interpersonal a } \\
\text { seguir y como punto de partida para que aprenda nuevas formas de } \\
\text { relación y evite la desilusión. }\end{array}$ \\
\hline \multirow{4}{*}{$\begin{array}{l}\text { Modificar las } \\
\text { disfunciones de } \\
\text { ámbito }\end{array}$} & \multicolumn{2}{|c|}{$\begin{array}{l}\text { Fortalecer una } \\
\text { autoimagen consistente. }\end{array}$} & $\begin{array}{l}\text { Registro de pensamientos erróneos y emociones. Establecer hipótesis y } \\
\text { someterlas a prueba para obtener información más precisa sobre la } \\
\text { probabilidad de ocurrencia. }\end{array}$ \\
\hline & \multicolumn{2}{|c|}{$\begin{array}{l}\text { Regular emociones } \\
\text { variables y volátiles. }\end{array}$} & $\begin{array}{l}\text { Entrenamiento en control de impulsos y asertividad para que el paciente } \\
\text { aprenda a controlar su ira y sus afectos negativos. }\end{array}$ \\
\hline & $\begin{array}{r}\text { Alterar el escepticis } \\
\text { estilo cognitiv }\end{array}$ & del & $\begin{array}{l}\begin{array}{l}\text { Registro de pensamientos erróneos para ponerlos a prueba y } \\
\text { reemplazarlos por otros más adaptativos. }\end{array} \\
\end{array}$ \\
\hline & $\begin{array}{r}\text { Modificar conduct } \\
\text { cooperadora }\end{array}$ & & $\begin{array}{l}\text { Regular conductas oposicionistas y aumentar la tolerancia a los demás, } \\
\text { para que sus conductas sociales sean más consideradas. }\end{array}$ \\
\hline
\end{tabular}




\section{Trastorno Masoquista de la Personalidad}

\begin{tabular}{|c|c|c|}
\hline \multirow{2}{*}{$\begin{array}{l}\text { Características de } \\
\text { las polaridades }\end{array}$} & Placer-Dolor & $\begin{array}{l}\text { Creen que no merecen ningún placer ni diversión. No sólo encuentran en el } \\
\text { sufrimiento una forma de expirar su culpa, sino que es lo único que pueden } \\
\text { permitirse ante la posibilidad de un vacío interior. }\end{array}$ \\
\hline & Actividad-Pasividad & $\begin{array}{l}\text { Conducta autoderrotista y predecible que hace declinar en la participación } \\
\text { de actividades placenteras y negar experiencias alegres. }\end{array}$ \\
\hline $\begin{array}{l}\text { Tendencia a la } \\
\text { perpetuación }\end{array}$ & \multicolumn{2}{|c|}{$\begin{array}{l}\text { Perpetúan las situaciones displacenteras. Interpretan los acontecimientos como molestos y } \\
\text { problemáticos por temor a que el optimismo traiga consecuencias angustiosas. Aprendieron a } \\
\text { sentirse importantes cuando los demás se muestran hostiles con ellos y que esta crueldad } \\
\text { disminuye cuando ellos sufren, por eso concluyen que su valía aumenta acorde a su infelicidad. } \\
\text { Encuentran injustificado el intentar sentirse mejor y su sufrimiento y desesperanza sirven para } \\
\text { proporcionarles una identidad y un papel social tangibles. }\end{array}$} \\
\hline \multicolumn{3}{|c|}{ Ámbitos personológicos } \\
\hline \multirow[b]{2}{*}{$\begin{array}{c}\text { Nivel } \\
\text { Comportamental }\end{array}$} & $\begin{array}{l}\text { Expresivamente } \\
\text { abstinente }\end{array}$ & \multirow{2}{*}{$\begin{array}{l}\text { Se muestra sencillo y cumplidor; reticente a buscar experiencias } \\
\text { gratificantes; se sitúa en segundo plano y actúa en forma discreta. } \\
\text { Se distancia de los que lo apoyan y se relaciona con quien puede ser servil; } \\
\text { deja que los otros lo exploten, traten mal o se aprovechen; acepta culpas y } \\
\text { críticas injustas para ganarse el favor de los demás. }\end{array}$} \\
\hline & $\begin{array}{l}\text { Interpersonalmente } \\
\text { deferente }\end{array}$ & \\
\hline \multirow{3}{*}{$\begin{array}{c}\text { Nivel } \\
\text { Fenomenológico }\end{array}$} & $\begin{array}{l}\text { Congnitivamente } \\
\text { inseguro }\end{array}$ & $\begin{array}{l}\text { Reticente a interpretar positivamente las cosas por temor a que se } \\
\text { conviertan en problemas o acaben siendo autodenigrantes; se habitúa a } \\
\text { expresar repetidamente actitudes y anticipaciones pesimistas. }\end{array}$ \\
\hline & $\begin{array}{l}\text { Autoimagen } \\
\text { desmerecedora }\end{array}$ & $\begin{array}{l}\text { Cree que merece ser avergonzado y despreciado. Por no poder cumplir las } \\
\text { expectativas de los otros. }\end{array}$ \\
\hline & $\begin{array}{l}\text { Representaciones } \\
\text { objetales } \\
\text { desacreditadas }\end{array}$ & $\begin{array}{l}\text { Compuestas de relaciones que fracasaron y logros personales } \\
\text { menospreciados, sentimientos positivos e impulsos eróticos transformados } \\
\text { en sus opuestos, conflictos internos intencionalmente agravados, y } \\
\text { mecanismos para reducir la disforia que aumentan el malestar. }\end{array}$ \\
\hline \multirow{2}{*}{$\begin{array}{c}\text { Nivel } \\
\text { Intrapsíquico }\end{array}$} & $\begin{array}{l}\text { Mecanismo de } \\
\text { exageración }\end{array}$ & $\begin{array}{l}\text { Recuerda las injusticias pasadas y anticipa decepciones futuras; obstaculiza } \\
\text { los objetivos personales y sabotea las cosas buenas que le ocurren para } \\
\text { mantener o potenciar el nivel habitual de sufrimiento. }\end{array}$ \\
\hline & $\begin{array}{l}\text { Organización } \\
\text { invertida }\end{array}$ & $\begin{array}{l}\text { Destrucción del afecto, transposición de los canales de gratificación de las } \\
\text { necesidades y de los que producen frustración, implicación en actividades } \\
\text { cuyas consecuencias son antiéticas o autodestructivas. }\end{array}$ \\
\hline Nivel Biofísico & $\begin{array}{l}\text { Estado de ánimo } \\
\text { disfórico }\end{array}$ & $\begin{array}{l}\text { Experimenta una mezcla de emociones; manifiesta intencionadamente una } \\
\text { apariencia que induce en los demás a la culpa y el malestar. }\end{array}$ \\
\hline \multicolumn{3}{|r|}{ Curso del tratamiento } \\
\hline \multicolumn{2}{|c|}{ Objetivos } & Técnicas \\
\hline \multicolumn{2}{|c|}{ Establecer una relación terapéutica } & $\begin{array}{l}\text { Entender su tendencia a generar reacciones negativas en los demás } \\
\text { como un autocastigo. Ayudarlo a tomar conciencia de su resentimiento } \\
\text { y expresarlo más directamente. Ofrecer calidez y empatía que brinde } \\
\text { un modelo a internalizar para la autoevaluación y que permita superar } \\
\text { su tendencia hacia la autofrustración. }\end{array}$ \\
\hline \multirow{2}{*}{$\begin{array}{l}\text { Restablecimiento } \\
\text { del equilibrio } \\
\text { entre polaridades }\end{array}$} & $\begin{array}{l}\text { Placer-Dolor: } \\
\text { Modificar conductas de } \\
\text { autosabotaje y } \\
\text { perpetuación del abuso. }\end{array}$ & $\begin{array}{l}\text { Clarificación e internalización de la diferencia entre los } \\
\text { comportamientos afectuosos y los abusivos. } \\
\text { Reorientación cognitiva para que alcance una autoimagen más } \\
\text { positiva y adaptativa. }\end{array}$ \\
\hline & $\begin{array}{l}\text { Actividad-Pasividad: } \\
\text { Fortalecer el foco activo y } \\
\text { eliminar la pasividad } \\
\text { derrotista. }\end{array}$ & $\begin{array}{l}\text { Entrenamiento en asertividad y habilidades sociales para relacionarse } \\
\text { con los demás de forma constructivas. Dedicar un tiempo cada día a } \\
\text { implicarse en actividades placenteras y recompensarse por } \\
\text { interacciones apropiadas que haya hecho. }\end{array}$ \\
\hline \multirow{3}{*}{$\begin{array}{l}\text { Modificar las } \\
\text { principales } \\
\text { disfunciones }\end{array}$} & $\begin{array}{l}\text { Moderar el estado de } \\
\text { ánimo disfórico. }\end{array}$ & $\begin{array}{l}\text { Identificar creencias disfuncionales y ponerlas a prueba para que vea } \\
\text { que su ánimo viene de la valoración de sí mismo y e mundo. }\end{array}$ \\
\hline & $\begin{array}{l}\text { Ayudar a adoptar un } \\
\text { concepto de sí mismo } \\
\text { menos severo. }\end{array}$ & $\begin{array}{l}\text { Discutir experiencias pasadas que crearon su autoimagen y el } \\
\text { mantenimiento de hábitos cognitivos disfuncionales. Reorientación } \\
\text { cognitiva para ver que su timidez perpetúa sus dificultades. }\end{array}$ \\
\hline & $\begin{array}{l}\text { Modificar la deferencia } \\
\text { interpersonal. }\end{array}$ & $\begin{array}{l}\text { Entrenamiento en habilidades sociales y asertividad para obtener } \\
\text { nuevas formas de interacción. Terapia de grupo para brindarle } \\
\text { modelos asertivos. }\end{array}$ \\
\hline \multirow{3}{*}{$\begin{array}{l}\text { Contrarrestar la } \\
\text { tendencia a la } \\
\text { perpetuación }\end{array}$} & $\begin{array}{c}\text { Contrarrestar la } \\
\text { disposición del paciente a } \\
\text { que abusen de él. }\end{array}$ & $\begin{array}{l}\text { Técnicas cognitivas para comprender una gama más amplia de } \\
\text { interacciones, y concebir posibles experiencias de relación sin } \\
\text { victimización. Entrenamiento en asertividad y habilidades sociales } \\
\text { para relacionarse de forma más equitativa y constructiva, fortaleciendo } \\
\text { los límites personales que previenen el abuso. }\end{array}$ \\
\hline & $\begin{array}{c}\text { Detener la implicación en } \\
\text { experiencias que lo } \\
\text { devalúan. }\end{array}$ & $\begin{array}{l}\text { Brindar comprensión de sus procesos desadaptativos para animar a } \\
\text { adoptar nuevas actitudes y estilos de interacción. }\end{array}$ \\
\hline & $\begin{array}{l}\text { Prevenir anulación de } \\
\text { sucesos positivos. }\end{array}$ & $\begin{array}{l}\text { Identificar sucesos y actividades positivas que favorecen su } \\
\text { autoestima. Ayudarlo a esforzarse por conseguir recompensas. }\end{array}$ \\
\hline
\end{tabular}


Trastorno Esquizotípico de la personalidad

\begin{tabular}{|c|c|c|c|}
\hline \multicolumn{4}{|c|}{ Trastorno Esquizotípico de la personalidad } \\
\hline \multirow[t]{2}{*}{$\begin{array}{l}\text { Características } \\
\text { de la polaridad }\end{array}$} & Placer-Dolor & \multicolumn{2}{|c|}{$\begin{array}{l}\text { La variante aislado-activo o insípido no están motivados por el dolor o el } \\
\text { placer: la capacidad para los sentimientos notablemente reducida. La variante } \\
\text { aislado-activo o timorato es muy sensible a las experiencias dolorosas } \\
\text { generadas intrapsíquicamente y las producidas por el entorno, haciendo que } \\
\text { se sientan autoalienados y se aíslen. }\end{array}$} \\
\hline & Actividad-Pasividad & \multicolumn{2}{|r|}{$\begin{array}{l}\text { El subtipo timorato presenta fuerte temor al rechazo y al insulto por parte del } \\
\text { entorno lo que hace que se sientan autoalienados y se aíslen. El subtipo } \\
\text { insípido al no tener motivación para los sentimientos quedan aislados, sin } \\
\text { estrategias de intercambio social y que sean adaptativas. }\end{array}$} \\
\hline \multicolumn{2}{|c|}{ Tendencias a la perpetuación } & \multicolumn{2}{|c|}{$\begin{array}{l}\text { El aislamiento social y la dependencia no sólo perpetúan su estilo de } \\
\text { personalidad sino que realmente intensifican los déficit. Muchos contribuyen a } \\
\text { su deterioro mediante la evitación de interacciones sociales que podrían } \\
\text { ofrecerles la estimulación y el feedback más funcionales. }\end{array}$} \\
\hline \multirow{2}{*}{$\begin{array}{l}\text { Nivel } \\
\text { comportamental }\end{array}$} & $\begin{array}{l}\text { Expresivamente } \\
\text { excéntrico }\end{array}$ & \multirow{2}{*}{\multicolumn{2}{|c|}{$\begin{array}{l}\text { Manierismos peculiares y socialmente inadecuados; los otros los perciben } \\
\text { como atípicos, de comportamiento raro, reservado, curioso o extraño. } \\
\text { Privacidad y aislamiento, pocos intentos de contacto y obligaciones } \\
\text { personales; adoptan papeles laborales periféricos y actividades marginales. }\end{array}$}} \\
\hline & $\begin{array}{l}\text { Interpersonalmente } \\
\text { reservado }\end{array}$ & & \\
\hline \multirow{3}{*}{$\begin{array}{c}\text { Nivel } \\
\text { fenomenológico }\end{array}$} & $\begin{array}{r}\text { Cognitivamente } \\
\text { desorganizado }\end{array}$ & \multicolumn{2}{|c|}{$\begin{array}{l}\text { Disfuncional capacidad para leer pensamientos o sentimientos ajenos; } \\
\text { mezclan comunicaciones sociales con irrelevancias personales; lenguaje } \\
\text { circunstancial, ideas de referencia y digresiones metafóricas; se pierden en } \\
\text { ensoñaciones con pensamiento mágico ocasional, ilusiones corporales, } \\
\text { suspicacias, creencias raras y confusión entre fantasía y realidad. }\end{array}$} \\
\hline & $\begin{array}{c}\text { Autoimagen } \\
\text { enajenada }\end{array}$ & \multicolumn{2}{|r|}{$\begin{array}{l}\text { Perplejidad e ilusiones sociales, despersonalización, desrealización y } \\
\text { disociación; se ve desamparado, pensamientosde vacio vital. }\end{array}$} \\
\hline & $\begin{array}{l}\text { Representaciones } \\
\text { objetales caóticas }\end{array}$ & \multicolumn{2}{|c|}{$\begin{array}{l}\text { Representaciones internalizadas que consisten en una mezcla de elementos } \\
\text { de relaciones y afectos de la infancia, impulsos y motivaciones aleatorios, y } \\
\text { canales de regulación descoordinados. }\end{array}$} \\
\hline $\begin{array}{l}\text { Nivel } \\
\text { intrapsíquico }\end{array}$ & $\begin{array}{l}\text { Mecanismo de } \\
\text { anulación }\end{array}$ & \multicolumn{2}{|c|}{$\begin{array}{l}\text { Manierismos extraños y pensamientos idiosincrásicos como retracción o } \\
\text { inversión de los actos o ideas previos que generaron ansiedad, conflicto o } \\
\text { culpa; los rituales o comportamientos mágicos sirven para arrepentirse o } \\
\text { anular los pensamientos 'perversos'. }\end{array}$} \\
\hline & $\begin{array}{l}\text { Organización } \\
\text { fragmentada }\end{array}$ & \multicolumn{2}{|c|}{$\begin{array}{l}\text { Límites del Yo permeables; operaciones defensivas y de afrontamiento } \\
\text { ordenadas al azar en un conjunto de estructuras morfológicas aisladas, que } \\
\text { llevan a acciones vagas donde se descargan los pensamientos y afectos } \\
\text { primitivos, con pocas sublimaciones e importantes desintegraciones } \\
\text { posteriores a un nivel estructural psicótico. }\end{array}$} \\
\hline Nivel biofísico & $\begin{array}{l}\text { Estado de ánimo } \\
\text { aturdido o } \\
\text { insensible }\end{array}$ & \multicolumn{2}{|c|}{$\begin{array}{l}\text { Excesivamente perspicaces y se aturden. Sobre todo en los encuentros } \\
\text { sociales; agitados y en estado de alerta ansiosa; desconfianza, suspicacia, } \\
\text { monotonia, apatia, pereza, falta de alegría y aspecto insípido. }\end{array}$} \\
\hline \multicolumn{4}{|c|}{ Curso del tratamiento } \\
\hline \multicolumn{3}{|c|}{ Objetivos } & Técnicas \\
\hline \multicolumn{3}{|c|}{5} & $\begin{array}{l}\text { Distinguir los subtipos del trastorno para conseguir al máximo los } \\
\text { objetivos y las estrategias terapéuticos. Respetar las sensibilidades } \\
\text { particulares que presenta. Indagar la experiencia de terapia para } \\
\text { asegurarse de que su percepción refleja la realidad. Ofrecerse como } \\
\text { un 'yo auxiliar' de comprobación de la realidad. } \\
\text { Realizar intervenciones y sesiones bien estructuradas. }\end{array}$ \\
\hline \multirow[b]{2}{*}{$\begin{array}{l}\text { Restablecimiento } \\
\text { del equilibrio entre } \\
\text { polaridades }\end{array}$} & \multicolumn{2}{|c|}{$\begin{array}{l}\text { Placer-Dolor: Aumentar la } \\
\text { sensibilidad al placer. }\end{array}$} & $\begin{array}{l}\text { Mejorar sentimiento de autovalia estimulándoloa reconocer sus } \\
\text { atributos positivos y guiarlo a explorar actividades placenteras. }\end{array}$ \\
\hline & \multicolumn{2}{|c|}{$\begin{array}{l}\text { Actividad-Pasividad: } \\
\text { equilibrar los polos según } \\
\text { los subtipos del trastorno. }\end{array}$} & $\begin{array}{l}\text { Entrenamiento en habilidades sociales y el modelado para que el } \\
\text { subtipo pasivo sea más activo y el subtipo activo canalice la energía } \\
\text { hacia objetivos gratificantes y sea más pasivo en cuanto a evitar las } \\
\text { posibles amenazas, casi ilusorias. }\end{array}$ \\
\hline \multirow{3}{*}{$\begin{array}{l}\text { Modificar las } \\
\text { principales } \\
\text { disfunciones }\end{array}$} & \multicolumn{2}{|c|}{$\begin{array}{l}\text { Prevenir el aislamiento } \\
\text { social. }\end{array}$} & $\begin{array}{l}\text { Entrenamiento de las habilidades sociales, reorientación cognitiva y } \\
\text { control del entorno para desarrollar relaciones sociales. }\end{array}$ \\
\hline & \multicolumn{2}{|c|}{$\begin{array}{l}\text { Anular la dependencia } \\
\text { excesiva. }\end{array}$} & $\begin{array}{l}\text { Enseñar habilidades sociales básicas para que adquieran cierta } \\
\text { independencia. Estimularlos a que practiquen por sí solos tanto } \\
\text { como sea posible. }\end{array}$ \\
\hline & \multicolumn{2}{|c|}{$\begin{array}{l}\text { Reducir las } \\
\text { preocupaciones de la } \\
\text { fantasia. }\end{array}$} & $\begin{array}{l}\text { Enseñarle a reconocer cuando está distorsionando la realidad a } \\
\text { través de la fantasía. }\end{array}$ \\
\hline \multirow{3}{*}{$\begin{array}{l}\text { Contrarrestar la } \\
\text { tendencia a la } \\
\text { perpetuación }\end{array}$} & \multicolumn{2}{|c|}{$\begin{array}{l}\text { Corregir los } \\
\text { comportamientos } \\
\text { excéntricos. }\end{array}$} & $\begin{array}{l}\text { Modelado, entrenamiento en habilidades sociales y el simple } \\
\text { complejo para tratar estos comportamientos. }\end{array}$ \\
\hline & \multicolumn{2}{|c|}{$\begin{array}{l}\text { Invertir el estilo cognitivo } \\
\text { autista. }\end{array}$} & $\begin{array}{l}\text { Enseñar habilidades cognitivas para alterar patrones desadaptativos } \\
\text { de pensamiento, contrarrestando ideas y predicciones. }\end{array}$ \\
\hline & \multicolumn{2}{|c|}{$\begin{array}{l}\text { Reconstruir la autoimagen } \\
\text { enajenada. }\end{array}$} & $\begin{array}{l}\text { Mejorar sentimiento de autovalía y estimular a reconocer sus } \\
\text { atributos positivos y explorar actividades sociales gratificantes. }\end{array}$ \\
\hline
\end{tabular}


Trastorno Límite de la personalidad

Características de la polaridad

\begin{tabular}{|c|c|}
\hline Placer-Dolor & Oscilan entre la motivación a través del dolor y el placer. \\
\hline Actividad-Pasividad & $\begin{array}{l}\text { Oscilan entre tomar una actitud activa o pasiva en relación a la manipulación } \\
\text { de su entorno. }\end{array}$ \\
\hline Si mismo-Otros & $\begin{array}{l}\text { Oscilan en volverse hacia los demás o hacia sí mismos en busca de } \\
\text { gratificación. }\end{array}$ \\
\hline
\end{tabular}

Tendencias a la perpetuación

Suelen adoptar estrategias de afrontamiento opuestas cuando se dan cuenta de que sus patrones comportamentales más habituales no producen las consecuencias deseadas.

\section{Ámbitos personológicos}

\begin{tabular}{|c|c|c|}
\hline \multirow[t]{2}{*}{$\begin{array}{c}\text { Nivel } \\
\text { comportamental }\end{array}$} & $\begin{array}{l}\text { Expresivamente } \\
\text { irregular }\end{array}$ & $\begin{array}{l}\text { Niveles de energía inusitados con arranques de impulsividad inesperados y } \\
\text { súbitos; cambios repentinos y endógenos de sus impulsos y sus controles } \\
\text { inhibitorios; esto pone en peligro la activación y el equilibrio emocional, y } \\
\text { provoca conductas recurrentes de automutilación o suicidio. }\end{array}$ \\
\hline & $\begin{array}{l}\text { Interpersonalmente } \\
\text { paradójico }\end{array}$ & $\begin{array}{l}\text { Aunque necesita atención y afecto, es contrariamente manipulador y voluble, } \\
\text { suscitando rechazo más que apoyo; reacciona frenéticamente al temor al } \\
\text { abandono y la soledad, pero de forma autolesiva. }\end{array}$ \\
\hline \multirow{3}{*}{$\begin{array}{c}\text { Nivel } \\
\text { fenomenológico }\end{array}$} & $\begin{array}{l}\text { Cognitivamente } \\
\text { caprichoso }\end{array}$ & $\begin{array}{l}\text { Sus percepciones o pensamientos sobre lo que ocurre cambian rápidamente, } \\
\text { igual que las emociones contrarias y los pensamientos conflictivos sobre si } \\
\text { mismo y los demás, pasando del amor a la ira y a la culpa; en efecto, } \\
\text { provoca en los otros reacciones vacilantes y contradictorias. }\end{array}$ \\
\hline & $\begin{array}{c}\text { Autoimagen } \\
\text { insegura }\end{array}$ & $\begin{array}{l}\text { Experimenta confusiones propias de un sentido de identidad inmaduro, } \\
\text { nebuloso o cambiante, que suelen acompañarse de sentimientos de vacío; } \\
\text { busca redimir sus acciones con comportamientos autopunitivos. }\end{array}$ \\
\hline & $\begin{array}{l}\text { Representaciones } \\
\text { objetales } \\
\text { incompatibles }\end{array}$ & $\begin{array}{l}\text { Las representaciones internalizadas se crearon forma rudimentaria y se } \\
\text { componen de aprendizajes repetidamente abortados que dan lugar a } \\
\text { recuerdos conflictivos, actitudes discordantes, necesidades contradictorias, } \\
\text { emociones contrarias, impulsos descontrolados, etc. }\end{array}$ \\
\hline \multirow[t]{2}{*}{$\begin{array}{c}\text { Nivel } \\
\text { intrapsíquico }\end{array}$} & $\begin{array}{l}\text { Mecanismo de } \\
\text { regresión }\end{array}$ & $\begin{array}{l}\text { En situaciones de estrés retrocede hacia niveles de tolerancia muy primitivos } \\
\text { de la ansiedad, control de los impulsos y adaptación social; comportamientos } \\
\text { inmaduros o infantiles ya desde la adolescencia. }\end{array}$ \\
\hline & $\begin{array}{l}\text { Organización } \\
\text { dividida }\end{array}$ & $\begin{array}{l}\text { Las estructuras internas están divididas y tienen una configuración conflictiva } \\
\text { por la falta de consistencia y congruencia; los niveles de conciencia suelen } \\
\text { variar, moviendo las percepciones, los recuerdos y los afectos contrarios, } \\
\text { provocando periódicamente episodios psicóticos. }\end{array}$ \\
\hline Nivel b & $\begin{array}{l}\text { Estado de ánimo } \\
\text { lábil }\end{array}$ & $\begin{array}{l}\text { No consigue adaptar su estado de ánimo inestable a la rea } \\
\text { experimenta cambios acusados desde la normalidad a la } \\
\text { excitación, del abatimiento y apatía a la ira intensa y ansiedad o }\end{array}$ \\
\hline
\end{tabular}
Curso del tratamiento

Objetivos

\section{Técnicas}

Intervenciones de apoyo para establecer una alianza de trabajo sólida capaz de alterar la idea del paciente sobre los peligros inherentes a la relación. Ayudarlo a establecer objetivos comportamentales que les proporcionen éxito inicial en el tratamiento.

\begin{tabular}{|c|c|c|}
\hline $\begin{array}{l}\text { Restablecimiento } \\
\text { del equilibrio entre } \\
\text { polaridades }\end{array}$ & $\begin{array}{l}\text { Reducir los conflictos entre } \\
\text { dolor-placer, actividad- } \\
\text { pasividad y sí mismo- } \\
\text { otros. }\end{array}$ & $\begin{array}{l}\text { Informar de manera empática las inevitables consecuencias } \\
\text { negativas de adoptar comportamientos extremos. } \\
\text { Enseñar estrategias de afrontamiento más adaptativas y moderadas. }\end{array}$ \\
\hline \multirow{3}{*}{$\begin{array}{c}\text { Contrarrestar la } \\
\text { tendencia a la } \\
\text { perpetuación }\end{array}$} & $\begin{array}{l}\text { Reducir la emocionalidad } \\
\text { caprichosa. }\end{array}$ & $\begin{array}{l}\text { Animar al paciente a expresar sentimientos negativos de forma } \\
\text { moderada. }\end{array}$ \\
\hline & $\begin{array}{l}\text { Moderar las actitudes } \\
\text { incoherentes. }\end{array}$ & $\begin{array}{l}\text { Análisis de sueños, la asociación libre, las imitaciones y las } \\
\text { exposiciones. Ayudarlo a comprender la conexión entre sus } \\
\text { síntomas presentes y su historia previa para que tome conciencia de } \\
\text { sus actitudes incoherentes desadaptativas. }\end{array}$ \\
\hline & $\begin{array}{l}\text { Adaptar los } \\
\text { comportamientos } \\
\text { imprevisibles. }\end{array}$ & $\begin{array}{l}\text { Ayudarlo a tolerar la ansiedad que causa el hecho de adoptar } \\
\text { comportamientos contradictorios e imprevisibles. Evaluar si la } \\
\text { amenaza que percibe es real o imaginada para poder elegir una } \\
\text { respuesta más saludable. Examinar ventajas y desventajas de } \\
\text { intentar nuevos comportamientos. }\end{array}$ \\
\hline \multirow{3}{*}{$\begin{array}{l}\text { Modificar las } \\
\text { principales } \\
\text { disfunciones }\end{array}$} & $\begin{array}{l}\text { Estabilizar el } \\
\text { comportamiento } \\
\text { interpersonal paradójico. }\end{array}$ & $\begin{array}{l}\text { Evaluar y modificar el pensamiento dicotómico, causa de su conducta } \\
\text { paradójica. Enseñarle los puntos medios entre las conductas para } \\
\text { que tome conciencia de que el mundo no se estructura en blanco y } \\
\text { negro. }\end{array}$ \\
\hline & $\begin{array}{l}\text { Reconstituir la autoimagen } \\
\text { inestable. }\end{array}$ & $\begin{array}{l}\text { Examinar los primeros recuerdos para que tome conciencia de las } \\
\text { emociones contrapuestas, las necesidades contradictorias y las } \\
\text { representaciones equivocadas que se tiene de los demás e ir } \\
\text { estabilizando la estructura de la personalidad. }\end{array}$ \\
\hline & $\begin{array}{l}\text { Estabilizar estados de } \\
\text { ánimo lábiles. }\end{array}$ & $\begin{array}{l}\text { Intervención psicofarmacológica para estabilizar el temperamento } \\
\text { que presenta el paciente. }\end{array}$ \\
\hline
\end{tabular}




\section{Trastorno Paranoide de la Personalidad}

\begin{tabular}{|c|c|c|c|}
\hline \multirow{2}{*}{$\begin{array}{l}\text { Características } \\
\text { de la polaridad }\end{array}$} & Placer-Dolor: & \multicolumn{2}{|r|}{$\begin{array}{l}\text { Altamente sensibles al dolor psiquico, anticipando rechazo y humillación. Evitan } \\
\text { situaciones aversivas o que proporcionan un refuerzo negativo. }\end{array}$} \\
\hline & Si mismo-Otros & \multicolumn{2}{|r|}{$\begin{array}{l}\text { Cautelosos de lo que los demás pueden hacer para dañarlos, han aprendido a } \\
\text { aislarse y centrarse en si mismos. }\end{array}$} \\
\hline \multicolumn{2}{|c|}{ Tendencias a la perpetuación } & \multicolumn{2}{|r|}{$\begin{array}{l}\text { El carácter suspicaz y la desconfianza extrema hacia los demás constituyen el } \\
\text { punto central de los problemas que presentan. Vigilan constantemente ante los } \\
\text { indicios de rechazo, acaban siempre por descubrirlos. Las acusaciones y } \\
\text { provocaciones, combinadas con la proyección de su propia inseguridad en los } \\
\text { demás generan la hostilidad ajena. }\end{array}$} \\
\hline \multicolumn{4}{|r|}{ Ámbitos personológicos } \\
\hline \multirow[b]{2}{*}{$\begin{array}{l}\text { Nivel } \\
\text { comportamental }\end{array}$} & $\begin{array}{l}\text { Expresivamente } \\
\text { defensivo }\end{array}$ & \multirow{2}{*}{\multicolumn{2}{|c|}{$\begin{array}{l}\text { Vigilante, alerta para anticipar y detener el menosprecio, las intenciones maliciosas } \\
\text { y los engaños; se resiste a las fuentes de control externas. } \\
\text { Guarda rencor y no olvida los agravios del pasado; actitud pendenciera, reacia y } \\
\text { hostil hacia los conocidos recientes; comprobación de lealtad y preocupación } \\
\text { inquisidora de intenciones ocultas. }\end{array}$}} \\
\hline & $\begin{array}{l}\text { Interpersonalmente } \\
\text { provocativo }\end{array}$ & & \\
\hline \multirow{3}{*}{$\begin{array}{l}\text { Nivel } \\
\text { fenomenológico }\end{array}$} & $\begin{array}{l}\text { Cognitivamente } \\
\text { suspicaz }\end{array}$ & \multicolumn{2}{|r|}{$\begin{array}{l}\text { Escéptico, cínico y desconfiado hacia las intenciones de los demás; busca } \\
\text { significados ocultos en temas neutros y exagera dificultades como si se trataran de } \\
\text { segundas intenciones o traiciones, sobre todo en cuanto a la fidelidad y } \\
\text { confiabilidad en el cónyuge o en un amigo intimo. }\end{array}$} \\
\hline & Autoimagen inviolable & \multicolumn{2}{|r|}{$\begin{array}{l}\text { Ideas de autorreferencia, se siente excesivamente importante, considerando } \\
\text { acciones neutras como despectivas y provocadoras; reacios a confiar en los } \\
\text { demás y se aisla, aunque teme perder la identidad, el status y el poder de } \\
\text { autodeterminación. }\end{array}$} \\
\hline & $\begin{array}{l}\text { Representaciones } \\
\text { objetales inalterables }\end{array}$ & \multicolumn{2}{|r|}{$\begin{array}{l}\text { Internaliza representaciones de relaciones tempranas significativas que se } \\
\text { configuran en creencias y actitudes profundas; se guian por convicciones } \\
\text { inflexibles que constituyen una jerarquia fija de presupuestos, temores y } \\
\text { conjeturas. }\end{array}$} \\
\hline \multirow[t]{2}{*}{$\begin{array}{c}\text { Nivel } \\
\text { intrapsiquico }\end{array}$} & $\begin{array}{l}\text { Mecanismo de } \\
\text { proyección }\end{array}$ & \multicolumn{2}{|r|}{$\begin{array}{l}\text { Repudia rasgos y motivos personales indeseables y los atribuye a los demás; ciego } \\
\text { a sus propias fallas, hiperalerta e hipercrítico con las caracteristicas similares de } \\
\text { los demás. }\end{array}$} \\
\hline & $\begin{array}{l}\text { Organización } \\
\text { inflexible }\end{array}$ & \multicolumn{2}{|r|}{$\begin{array}{l}\text { La inflexibilidad del sistema de estructuras morfológicas que lo sustentan, la rigidez } \\
\text { de los canales de afrontamiento, la mediación de conflictos y la necesidad de } \\
\text { gratificación generan una estructura demasiado excitable, en tensión y pocc } \\
\text { acomodable para cambiar. }\end{array}$} \\
\hline Nivel biofísico & $\begin{array}{l}\text { Estado de ánimo } \\
\text { irascible }\end{array}$ & \multicolumn{2}{|r|}{$\begin{array}{l}\text { Proceder frí, taciturno, grosero y sin sentido del humor; aparenta no tener } \\
\text { emociones ni objetivos, pero es inquieto, envidioso, celoso, rápido de ofender y } \\
\text { reacciona con cólera. }\end{array}$} \\
\hline \multicolumn{4}{|r|}{ Curso del tratamiento } \\
\hline \multicolumn{3}{|c|}{ Objetivos } & Técnicas \\
\hline \multicolumn{3}{|c|}{ Establecer una relación terapéutica } & $\begin{array}{l}\text { Suscitar confianza mediante una serie de pasos lentos y progresivos y } \\
\text { mostrar un respeto tranquilo, formal y verdadero. }\end{array}$ \\
\hline \multirow{2}{*}{$\begin{array}{l}\text { Restablecimiento } \\
\text { del equilibrio entre } \\
\text { polaridades }\end{array}$} & \multicolumn{2}{|c|}{$\begin{array}{l}\text { Placer-Dolor: reducir el } \\
\text { dolor. }\end{array}$} & $\begin{array}{l}\text { Aceptar, sin confirmar, las creencias inusuales y permitirle que explore sus } \\
\text { pensamientos y sentimientos a un ritmo tolerable. } \\
\text { Mostrarle que puede compartir sus ansiedades con otras personas sin sufrir } \\
\text { la humillación ni el maltrato a los que está acostumbrado. }\end{array}$ \\
\hline & \multicolumn{2}{|c|}{$\begin{array}{l}\text { Sí mismo-Otros: } \\
\text { incrementar el polo de } \\
\text { los demás. }\end{array}$} & $\begin{array}{l}\text { Estimularlo a explorar los beneficios de estar solo frente a mantener } \\
\text { relaciones intimas. }\end{array}$ \\
\hline \multirow{3}{*}{$\begin{array}{l}\text { Contrarrestar la } \\
\text { tendencia a la } \\
\text { perpetuación. }\end{array}$} & \multicolumn{2}{|c|}{$\begin{array}{l}\text { Detener las } \\
\text { provocaciones de } \\
\text { rechazo. }\end{array}$} & $\begin{array}{l}\text { Entrenamiento en habilidades sociales que ayude a superar la falta de } \\
\text { atención hacia los demás y mejore su capacidad de empatía. } \\
\text { Pedirle al paciente que anticipe el efecto de sus acciones sobre los demás y } \\
\text { que imagine lo que sentiria si estuviera en su lugar. }\end{array}$ \\
\hline & \multicolumn{2}{|c|}{$\begin{array}{l}\text { Modificar las mini-ideas } \\
\text { delirantes rígidas. }\end{array}$} & $\begin{array}{l}\text { Introducir un elemento de duda en su pensamiento en cuanto a la validez de } \\
\text { sus creencias. Intervención farmacológica si empeora el contacto con la } \\
\text { realidad y hay la posibilidad de un brote psicótico. }\end{array}$ \\
\hline & \multicolumn{2}{|c|}{$\begin{array}{l}\text { Anular el retraimiento } \\
\text { autoprotector. }\end{array}$} & $\begin{array}{l}\text { Técnicas cognitivas para centrarse en la percepción irreal de su entorno y } \\
\text { que conlleva a un retraimiento protector. Desarrollar hipótesis alternativas } \\
\text { para poner en duda sus creencias. Estimularlo a que explore las } \\
\text { características potencialmente positivas de los otros en las relaciones } \\
\text { interpersonales. }\end{array}$ \\
\hline \multirow{3}{*}{$\begin{array}{l}\text { Modificar las } \\
\text { principales } \\
\text { disfunciones }\end{array}$} & \multicolumn{2}{|c|}{$\begin{array}{l}\text { Alterar la autoimagen } \\
\text { inviolable. }\end{array}$} & $\begin{array}{l}\text { Registro de pensamientos y creencias que constituyen su autoimagen para } \\
\text { someterlos a prueba y adoptar nuevas creencias. }\end{array}$ \\
\hline & \multicolumn{2}{|c|}{$\begin{array}{l}\text { Moderar el estado de } \\
\text { ánimo irascible. }\end{array}$} & $\begin{array}{l}\text { Entrenamiento en asertividad para enseñarle a expresar sus pensamientos } \\
\text { de manera constructiva y sin la intensidad de la afectividad negativa. Análisis } \\
\text { funcional para identificar y eliminar los elementos del ambiente que lo irritan. }\end{array}$ \\
\hline & \multicolumn{2}{|c|}{$\begin{array}{l}\text { Reorientar la suspicacia } \\
\text { cognitiva. }\end{array}$} & $\begin{array}{l}\text { Monitorear experiencias interpersonales con las cogniciones y emociones las } \\
\text { acompañan. Explorar explicaciones alternativas. }\end{array}$ \\
\hline
\end{tabular}

